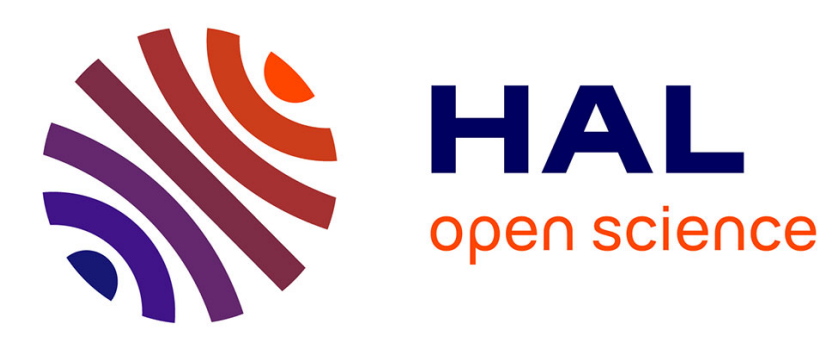

\title{
Modelling of gas clathrate hydrate equilibria using the electrolyte non-random two-liquid (eNRTL) model
}

\author{
Matthias Kwaterski, Jean-Michel Herri
}

\section{To cite this version:}

Matthias Kwaterski, Jean-Michel Herri. Modelling of gas clathrate hydrate equilibria using the electrolyte non-random two-liquid (eNRTL) model. Fluid Phase Equilibria, 2014, 371, pp.22-40. 10.1016/j.fluid.2014.02.032 . hal-00978703

\section{HAL Id: hal-00978703 \\ https://hal.science/hal-00978703}

Submitted on 14 Apr 2014

HAL is a multi-disciplinary open access archive for the deposit and dissemination of scientific research documents, whether they are published or not. The documents may come from teaching and research institutions in France or abroad, or from public or private research centers.
L'archive ouverte pluridisciplinaire HAL, est destinée au dépôt et à la diffusion de documents scientifiques de niveau recherche, publiés ou non, émanant des établissements d'enseignement et de recherche français ou étrangers, des laboratoires publics ou privés. 


\title{
Modelling of Gas Clathrate Hydrate Equilibria using the Electrolyte Non-Random Two-Liquid (eNRTL) Model
}

\author{
Matthias Kwaterski ${ }^{1, *}$ and Jean-Michel Herri ${ }^{1, \dagger}$ \\ ${ }^{1}$ Centre SPIN, Département Propice, UMR CNRS 5307 LGF, École Nationale Supérieure des \\ Mines de Saint-Etienne, France
}

\section{Abstract}

Calculations on solid (S)-liquid $\left(\mathrm{L}_{\mathrm{w}}\right)$-gas $(\mathrm{G})$-phase equilibria of selected ternary \{water + salt + gas $\}$ and quaternary $\left\{\right.$ water + salt $_{1}+$ salt $_{2}+$ gas $\}$ systems (salt $=\mathrm{NaCl}, \mathrm{KCl}, \mathrm{CaCl}_{2}$; gas $\left.=\mathrm{CH}_{4}, \mathrm{CO}_{2}\right)$ comprising a gas clathrate hydrate phase $(\mathrm{S} \equiv \mathrm{H})$ have been performed. The thermodynamic description of the liquid phase non-idealities observed in these systems has been provided by means of the semi-empirical electrolyte NRTL (eNRTL) excess Gibbs energy model. Multicomponent expressions for individual as well as mean ionic activity coefficients as defined by both, a previous and the most recent version of the eNRTL model, have been implemented in a computer programme written in the Java programming language. Basic model parameters are provided by means of a data bank set up in the xml file format. The correctness of the programme implementation of the eNRTL expressions has been verified by comparing the results of selected example calculations with corresponding results given in the original literature sources. The programme code of the model implementation has been incorporated into a previously developed in-house programme enabling to perform equilibrium calculations on non-electrolyte aqueous systems involving gas hydrate phases. In the $\mathrm{H}-\mathrm{L}_{\mathrm{w}}-\mathrm{G}$ calculations, fugacities in the gas phase were calculated by means of the SoaveRedlich-Kwong (SRK) equation of state (EOS), whereas a Henry's law approach in combination with the eNRTL model has been applied to characterise the liquid phase. The van der Waals and Platteeuw model has been used to describe the gas clathrate hydrate phase. A satisfying predictive description of the experimental $p-T-\mathrm{H}-\mathrm{L}_{\mathrm{w}}-\mathrm{G}$ phase equilibrium data is achieved with average absolute relative deviations (AARD) between experimental and calculated pressures ranging from $1 \%$ to $15 \%$.

Keywords: Modelling, gas hydrate, eNRTL model, electrolytes, phase equilibrium, $\mathrm{CO}_{2}, \mathrm{CH}_{4}$

\footnotetext{
* Corresponding author: Phone: +33 (0) 4774200 62, Fax: +33 (0) 4774996 92, e-mail: kwaterski@emse.fr

† Phone: +33 (0) 4774202 92, Fax +33 (0) 4774996 92, e-mail: herri@emse.fr
} 



\section{IntroductionFormelabschnitt 1}

Gas clathrate hydrates are mixed solid crystalline phases which are built up by a network of hydrogen bonded water molecules comprising cage-like structural units, each of which can encapsulate a single appropriately sized guest molecule. The guest species, generally molecules of low molecular weight gases and organic compounds [1], stabilise the solid solvent, the thermodynamically metastable host lattice, by interacting with the water molecules of the cavities through van der Waals forces [2]. Gas clathrate hydrates are thermodynamically stable in regions of ambient or lower temperatures (near the normal freezing point of water) and elevated pressures (typically more than $0.6 \mathrm{MPa}$ ) [3,4] and crystallise in the two cubic structures I (sI) and II (sII), and the hexagonal structure $\mathrm{H}(\mathrm{sH})$. Besides having the potential for numerous applications in the oil and gas industry and the energy sector (e.g. in gas storage and separation, air-conditioning systems and water desalination and treatment [5]), gas hydrates can also cause problems in the oil and gas industry (e.g. pipeline blockages by hydrates in drilling applications or gas pipelines) [6]. Species being capable of forming hydrogen bonds with the water molecules like methanol or ethylene glycol as well as water-soluble polymers or electrolytes are known for acting as thermodynamic inhibitors with respect to the formation of gas hydrates [3]. These additives can prevent the formation of hydrate plugs by altering the state of the liquid phase [3] and thereby changing the phase transition conditions [7].

Due to the electrostatic forces acting between ions the thermodynamic description of electrolyte solutions is significantly more difficult than the treatment of non-electrolyte systems [8,9]. To model electrolyte solutions, an electrolyte equation of state (EOS), especially useful at high pressures, an excess Gibbs energy model [8] or a combination of the two strategies is usually employed. Several electrolyte EOS, like e.g. the Fürst-Renon EOS $[10,11]$, the electrolyte modification [8] of the Trebble-Bishnoi EOS [12,13], or the statistical associating fluid theory with variable range for electrolytes (SAFT-VRE) EOS [14] have been developed. Besides, numerous semi-empirical excess Gibbs energy models have been proposed [15], as e.g. the model of Bromley [16], the ion-interaction model of Pitzer [17,18], the model of Cruz and Renon [19], the eNRTL-model of Chen et al. [15,20-23], the LIQUAC- model of Li et al. [24] and the MSA-model of Papaiconomou et al. [25].

To model the Hydrate $(\mathrm{H})$-Liquid $\left(\mathrm{L}_{\mathrm{w}}\right)$-Gas $(\mathrm{G})$-phase boundary in systems containing electrolytes, an equation of state and/or activity coefficient approach for the fluid phases is combined with the hydrate model of van der Waals and Platteeuw (vdW-P) [26]. Englezos and Bishnoi [27] e.g. presented an approach to predict the thermodynamic gas hydrate formation conditions in aqueous systems containing light hydrocarbon gases and single or mixed electrolytes using Pitzer's [17] and Meissner's [28] activity coefficient models. Clarke and Bishnoi [8] have developed an electrolyte EOS for mixed salt and mixed solvent systems to describe the Liquid-Vapour- (L-V-) equilibrium in these mixtures. The EOS was also used to model the $\mathrm{H}-\mathrm{L}-\mathrm{V}$-equilibrium obtained in systems containing additionally one or more of the gases $\mathrm{CH}_{4}, \mathrm{CO}_{2}, \mathrm{H}_{2} \mathrm{~S}$ and/or $\mathrm{C}_{3} \mathrm{H}_{8}$ [8]. Hsieh et al. [7] presented an approach for modelling the change in hydrate forming conditions in mixtures containing electrolytes and molecular inhibitors. They combined the vdW-P model with the Peng-Robinson-Stryjek-Vera EOS [29], using the first order modified Huron-Vidal (MHV1) mixing rule [30] with two activity coefficient models, the UNIQUAC [31] and the COSMO-SAC [32,33] model.

Prior to initiating the current modelling work, incipient gas hydrate forming conditions in non-electrolyte aqueous systems were modelled in our research group. The calculations were 
performed with our in-house programme named "GasHyDyn" which was created and described earlier [34] using the object oriented programming language Java. The programme has been based on the algorithm proposed by Sloan [35] and its code is available from the second author on request. The need for extending this in-house programme to enable the treatment of electrolyte systems originated from the attempt to model the thermodynamics of so-called (gas-)semiclathrate hydrates of tri- $n$-butylammonium bromide (TBAB), the results of which will be dealt with in a forthcoming article [36]. Since TBAB dissociates into ions in aqueous solution, an electrolyte model was required to describe the liquid phase non-idealities in this system with sufficient accuracy. Bèlvèze et al. [37] showed that the eNRTL-model $[20,21]$ does an excellent job in describing experimental data on the mean molal activity coefficient of TBAB, $\gamma_{b, \mathrm{TBAB}, \pm}^{*}$, in aqueous solution at $298.15 \mathrm{~K}$ [38] over a wide range of TBAB concentration (maximum overall molality $\bar{b}_{\mathrm{TBAB}, \max }=27 \mathrm{~mol} \mathrm{~kg}^{-1}$, residual standard deviation of $\sigma=0.038$ with respect to calculated and measured results on $\ln \gamma_{b, \mathrm{TBAB}, \pm}^{*}$ ). Moreover, only two parameters are required for the isothermal description of single electrolyte solutions with this model [20,21] (e.g. the famous Pitzer model [17] needs three). Therefore we decided to use the eNRTL-model to describe the isobaric $\mathrm{H}-\mathrm{L}_{\mathrm{w}}$ equilibrium in the system $\left\{\mathrm{H}_{2} \mathrm{O}+\mathrm{TBAB}\right\}$ and $\mathrm{H}-\mathrm{L}_{\mathrm{w}}-\mathrm{G}$-equilibria in the corresponding gas semi-clathrate hydrate systems. In this preliminary study the aim is to test the suitability of the model to describe systems with conventional gas hydrate phases in the presence of electrolytes. Therefore, a Java implementation of both the previous [21] and the updated version of the single-solvent multicomponent eNRTL-model [23] was created initially. After having thoroughly tested the correctness of the eNRTL-code, the programme was incorporated into our previously existing in-house programme for modelling $\mathrm{H}-\mathrm{L}_{\mathrm{w}}$-G-phase equilibria. Subsequently, by means of the new programme, incipient gas hydrate formation conditions were modelled in systems with sodium chloride $(\mathrm{NaCl})$ and potassium chloride $(\mathrm{KCl})$ or calcium chloride $\left(\mathrm{CaCl}_{2}\right)$ and the gases methane $\left(\mathrm{CH}_{4}\right)$ or carbon dioxide $\left(\mathrm{CO}_{2}\right)$.

\section{Modelling approach Formelabschnitt (nächster)}

\subsection{Hydrate-liquid-gas equilibrium}

Thermodynamic equilibrium between the gas hydrate phase $(\mathrm{H})$ and the aqueous liquid phase $\left(\mathrm{L}_{\mathrm{w}}\right)$ under incipient hydrate formation conditions, when being in simultaneous equilibrium with a gas phase $(\mathrm{G})$, can be expressed by

$$
\Delta_{\beta}^{\mathrm{H}} \mu_{\mathrm{w}}=\Delta_{\beta}^{\mathrm{L}_{\mathrm{w}}} \mu_{\mathrm{w}}
$$

where $\Delta_{\beta}^{\mathrm{H}} \mu_{\mathrm{w}} \equiv \mu_{\mathrm{w}}^{\mathrm{H}}-\mu_{\mathrm{w}}^{\mathrm{o}, \beta}$ denotes the difference in the chemical potential of water in the gas hydrate phase and the pure (index $\circ$ ) solid solvent phase, i.e. the empty metastable hydrate lattice (index $\beta$ ). Similarly, $\Delta_{\beta}^{\mathrm{L}_{\mathrm{w}}} \mu_{\mathrm{w}} \equiv \mu_{\mathrm{w}}^{\mathrm{L}_{\mathrm{w}}}-\mu_{\mathrm{w}}^{\circ, \beta}$ designates the chemical potential difference of water in the liquid and the empty hydrate phase. It should be pointed out that the way for expressing the equilibrium condition in eq. (1) differs from the way it is usually found in the literature, firstly because minuend and subtrahend are reversed as it was also done by Ballard and Sloan [39] (i.e., $\mu_{\mathrm{w}}^{\pi}-\mu_{\mathrm{w}}^{\mathrm{o}, \beta}$ instead of $\mu_{\mathrm{w}}^{\mathrm{o}, \beta}-\mu_{\mathrm{w}}^{\pi}$ with $\pi=\mathrm{H}, \mathrm{L}_{\mathrm{w}}$ ), and secondly, because the nomenclature is adopted from the notation as recommended by the IUPAC Commission I.2. [40]. Since the presence of water in the gas phase was neglected in a good approximation, the condition involving the chemical potential of water in this phase was not considered. 


\subsection{The thermodynamic description of the hydrate phase}

The clathrate hydrate phase is described by means of the ideal solid solution theory of van der Waals and Platteuuw [26]. In this statistical thermodynamic model, the chemical potential difference $\Delta_{\beta}^{\mathrm{H}} \mu_{\mathrm{w}}$, expressed on a molar basis, is given by

$$
\frac{\Delta_{\beta}^{\mathrm{H}} \mu_{\mathrm{w}}}{R T}=\sum_{i \in S_{\text {cav }}} v_{i} \ln \left(1-\sum_{j \in S_{\mathrm{g}}} \theta_{j i}^{\mathrm{H}}\right)
$$

In eq. (2), $R$ denotes the universal gas constant [41], $S_{\text {cav }}=\left\{1, \ldots, N_{\text {cav }}\right\}$ the set of indices of the $N_{\text {cav }}$ different types of cavities, and $S_{\mathrm{g}}=\left\{1, \ldots, N_{\mathrm{g}}\right\}$ the set of indices identifying the $N_{\mathrm{g}}$ different types of guest species. $v_{i}$ is the number of type $i$ cavities per water molecule, and $\theta_{j i}^{\mathrm{H}}$ the fractional occupancy of guest $j$ in cavity $i$ in the hydrate phase. $\theta_{j i}^{\mathrm{H}}$ can be expressed in terms of the Langmuir constant $C_{j i}$ of guest $j$ in cavity $i$, and the fugacity $f_{j}$ of $j$ as

$$
\theta_{j i}^{\mathrm{H}}=\frac{C_{j i} f_{j}}{1+\sum_{j^{\prime} \in S_{\mathrm{g}}} C_{j^{\prime} i} f_{j^{\prime}}} \quad\left(\text { for all } j \in S_{\mathrm{g}} \text { and } i \in S_{\text {cav }}\right. \text { ) }
$$

The expression in eq. (3) resembles the well known relation describing the two dimensional adsorption according to the Langmuir model. At $\mathrm{H}-\mathrm{L}_{\mathrm{w}}-\mathrm{G}$-equilibrium, the isofugacity criterion, implicitly incorporated into eq. (2) [27] does hold. The latter states the equality of the fugacities $f_{j}$ throughout the co-existing phases, i.e. $f_{j}^{\mathrm{H}}=f_{j}^{\mathrm{L}_{\mathrm{w}}}=f_{j}^{\mathrm{G}}\left(\equiv f_{j}\right)$. Hence, any of the $f_{j}$ 's in one of the three phases may be employed for calculating $f_{j}$. For practical reasons, the gas phase fugacities $f_{j}^{\mathrm{G}}$, obtained from the SRK-EOS [42], were used for this purpose.

The Langmuir constants were calculated from an expression proposed by Parrish and Prausnitz [43] describing the cell potential energy of guest $j$ within the spherically assumed cavity $i$ of water molecules. The latter in turn is based on the Kihara core potential [44] which accounts for the single interactions between the guest and each of the water molecules constituting the cavity [1]. In that way, $C_{j i}$ is given in terms of the Kihara parameters $\sigma_{j \mathrm{w}}$, $\varepsilon_{j \mathrm{w}}$ and $a_{j}$, the core distance at which attraction and repulsion of a guest host-pair balance each other, the corresponding characteristic energy, and the core radius of the guest molecule, respectively, and the lattice specific quantities $z_{i}$ and $R_{i}$, the coordination number and the radius of the cavity $i$, respectively [1]. The relations $C_{j i}=f\left(a_{j}, \sigma_{j \mathrm{w}}, \varepsilon_{j \mathrm{w}}, z_{i}, R_{i}\right)$ in which the water molecules are assigned a zero core radius (i.e., $a_{\mathrm{w}}=0 \Rightarrow 2 a_{j \mathrm{w}}=a_{j}$ ) [45] are compiled in appendix A.1. The values for $a_{j}, \sigma_{j \mathrm{w}}$ and $\varepsilon_{j \mathrm{w}}$ used in this study are listed in Table 6 along with literature data on $\sigma_{j \mathrm{w}}$ and $\varepsilon_{j \mathrm{w}}$. The values for $z_{i}$ and $R_{i}$ were taken from [35].

\subsection{Dependence of the liquid phase chemical potential difference on the state variables}

The model description for $\Delta_{\beta}^{\mathrm{L}_{\mathrm{w}}} \mu_{\mathrm{w}}$ as function of temperature $T$, pressure $p$ and the vector of independent mole fractions $\vec{x}^{\mathrm{L}_{\mathrm{w}}}$, was provided by the following equation

$$
\begin{aligned}
\frac{\Delta_{\beta}^{\mathrm{L}_{\mathrm{w}}} \mu_{\mathrm{w}}\left(T, p, \vec{x}^{\mathrm{L}_{\mathrm{w}}}\right)}{R T}= & \frac{\Delta_{\beta}^{\mathrm{L}_{\mathrm{w}}} \mu_{\mathrm{w}}^{\circ}\left(T_{0}, p_{0}\right)}{R T_{0}}+\frac{b T_{0}+\Delta_{\beta}^{\mathrm{L}_{\mathrm{w}}} C_{p, \mathrm{~m}, \mathrm{w}}^{\circ}\left(T_{0}, p_{0}\right)}{R} \ln \left(\frac{T_{0}}{T}\right)+\frac{b}{2 R}\left(T-T_{0}\right) \\
& +\frac{1}{R}\left(\frac{\Delta_{\beta}^{\mathrm{L}_{\mathrm{w}}} H_{\mathrm{m}, \mathrm{w}}^{\circ}\left(T_{0}, p_{0}\right)}{T_{0}}-\Delta_{\beta}^{\mathrm{L}_{\mathrm{w}}} C_{p, \mathrm{~m}, \mathrm{w}}^{\circ}\left(T_{0}, p_{0}\right)-\frac{b}{2} T_{0}\right)\left(\frac{T_{0}}{T}-1\right) \\
& +\frac{\Delta_{\beta}^{\mathrm{L}_{\mathrm{w}}} V_{\mathrm{m}, \mathrm{w}}^{\circ}\left(T_{0}, p_{0}\right)}{R T}\left(p-p_{0}\right)-\ln \gamma_{x, \mathrm{w}}^{\mathrm{L}_{\mathrm{w}}}\left(T, p, \vec{x}^{\mathrm{L}_{\mathrm{w}}}\right)-\ln x_{\mathrm{w}}^{\mathrm{L}_{\mathrm{w}}}
\end{aligned}
$$


where $x_{\mathrm{w}}^{\mathrm{L}_{\mathrm{w}}}$ and $\gamma_{x, \mathrm{w}}^{\mathrm{L}_{\mathrm{w}}}$ denotes the mole fraction and the activity coefficient of water in the liquid phase, respectively. $\Delta_{\beta}^{\mathrm{L}_{\mathrm{w}}} \mu_{\mathrm{w}}^{\circ}\left(T_{0}, p_{0}\right), \quad \Delta_{\beta}^{\mathrm{L}_{\mathrm{w}}} H_{\mathrm{m}, \mathrm{w}}^{\circ}\left(T_{0}, p_{0}\right), \quad \Delta_{\beta}^{\mathrm{L}_{\mathrm{w}}} C_{p, \mathrm{~m}, \mathrm{w}}^{\circ}\left(T_{0}, p_{0}\right) \quad$ and $\Delta_{\beta}^{\mathrm{L}_{\mathrm{w}}} V_{\mathrm{m}, \mathrm{w}}^{\circ}\left(T_{0}, p_{0}\right)$ are the difference in chemical potential, molar enthalpy, isobaric molar heat capacity and molar volume between water in the pure liquid and the pure metastable hydrate phase under reference conditions for temperature and pressure of $T_{0}=273.15 \mathrm{~K}$ and $p_{0}=0 \mathrm{MPa}$ [34], respectively. Along with the empirical constant $b$, these quantities are regarded as parameters determined by using various experimental and calculation techniques [35]. Eq. (4) is derived from an empirical expression for $\Delta_{\beta}^{\mathrm{L}_{\mathrm{w}}} C_{p, \mathrm{~m}, \mathrm{w}}^{\circ}$, which was e.g. also used by Holder et al. [46], via classical thermodynamic relationships (Appendix A.2).

The reference parameters describing the phase change $\beta \rightarrow \mathrm{L}_{\mathrm{w}}$ were taken from different literature sources [35,47-49] as compiled in Table 1. Since the data available for $\Delta_{\beta}^{\mathrm{L}_{\mathrm{w}}} \mu_{\mathrm{w}}^{\circ}\left(T_{0}, p_{0}\right)$ show strong variations among different laboratories [34], this parameter needs to be selected with precaution when being used in calculations of $C_{j i}$ along with a given set of Kihara parameters [34]. A great variation is also detected among the values published for $\Delta_{\beta}^{\mathrm{L}_{\mathrm{w}}} H_{\mathrm{m}, \mathrm{w}}^{\circ}\left(T_{0}, p_{0}\right)$. In contrast, literature data on $\Delta_{\beta}^{\mathrm{L}_{\mathrm{w}}} C_{p, \mathrm{~m}, \mathrm{w}}^{\circ}\left(T_{0}, p_{0}\right), b$ and $\Delta_{\beta}^{\mathrm{L}_{\mathrm{w}}} V_{\mathrm{m}, \mathrm{w}}^{\circ}\left(T_{0}, p_{0}\right)$ are less numerous. Based on the conclusions drawn in [34], the data of Handa and Tse [49] were used for $\Delta_{\beta}^{\mathrm{L}_{\mathrm{w}}} \mu_{\mathrm{w}}^{\circ}\left(T_{0}, p_{0}\right)$ and $\Delta_{\beta}^{\mathrm{L}_{\mathrm{w}}} H_{\mathrm{m}, \mathrm{w}}^{\circ}\left(T_{0}, p_{0}\right)$. The value for $\Delta_{\beta}^{\mathrm{L}_{\mathrm{w}}} V_{\mathrm{m}, \mathrm{w}}^{\circ}\left(T_{0}, p_{0}\right)$ was taken from John et al. [48], while the values for $\Delta_{\beta}^{\mathrm{L}_{\mathrm{w}}} C_{p, \mathrm{~m}, \mathrm{w}}^{\circ}\left(T_{0}, p_{0}\right)$ and $b$ were taken from Sloan [35].

Table 1 Parameters characterising the phase change between the "empty" hydrate phase $\beta$ and the pure liquid water phase $\mathrm{L}_{\mathrm{w}}$

\begin{tabular}{lcc}
\hline & $\mathrm{sI}$ & $\mathrm{sII}$ \\
\hline$\Delta_{\beta}^{\mathrm{L}_{\mathrm{w}}} \mu_{\mathrm{w}}^{\circ}\left(T_{0}, p_{0}\right) / \mathrm{J} \mathrm{mol}^{-1 \mathrm{a}}$ & $-1263^{\mathrm{c}}$ & $-883.8^{\mathrm{c}}$ \\
& $-1297^{\mathrm{d}}$ & $-937^{\mathrm{d}}$ \\
& $-1120^{\mathrm{e}}$ & $-931^{\mathrm{e}}$ \\
$\Delta_{\beta}^{\mathrm{L}_{\mathrm{w}}} H_{\mathrm{m}, \mathrm{w}}^{\circ}\left(T_{0}, p_{0}\right) / \mathrm{J} \mathrm{mol}^{-1 \mathrm{a}, \mathrm{b}}$ & $1287^{\mathrm{f}}$ & $-1068^{\mathrm{f}}$ \\
& $4622^{\mathrm{c}}$ & $4986^{\mathrm{c}}$ \\
& $4622^{\mathrm{d}}$ & $4986^{\mathrm{d}}$ \\
$\Delta_{\beta}^{\mathrm{L}_{\mathrm{w}}} C_{p, \mathrm{~m}, \mathrm{w}}^{\circ}\left(T_{0}, p_{0}\right) / \mathrm{J} \mathrm{K}^{-1} \mathrm{~mol}^{-1 \mathrm{a}}$ & $4297^{\mathrm{e}}$ & $4611^{\mathrm{e}}$ \\
$b / \mathrm{J} \mathrm{K}^{-2} \mathrm{~mol}^{-1 \mathrm{a}}$ & $5080^{\mathrm{f}}$ & $5247^{\mathrm{f}}$ \\
$\Delta_{\beta}^{\mathrm{L}_{\mathrm{w}}} V_{\mathrm{m}, \mathrm{w}}^{\circ}\left(T_{0}, p_{0}\right) / \mathrm{cm}^{3} \mathrm{~mol}^{-1 \mathrm{a}}$ & $38.12^{\mathrm{c}}$ & $38.12^{\mathrm{c}}$ \\
\hline
\end{tabular}

\footnotetext{
${ }^{a}$ The numerical values for the parameters compiled here are the negative values of the values given in the original sources due to the inversely defined differences as outlined in the text.

${ }^{\mathrm{b}}$ Since the original data are given as $\Delta_{\mathrm{I}}^{\beta} H_{\mathrm{m}, \mathrm{w}}^{\circ}\left(T_{0}, p_{0}\right)$, the $\Delta_{\beta}^{\mathrm{L}_{\mathrm{w}}} H_{\mathrm{m}, \mathrm{w}}^{\circ}\left(T_{0}, p_{0}\right)$-values presented here are derived by adding the molar enthalpy of fusion $\Delta_{\text {fus }} H_{\mathrm{m}, \mathrm{w}}^{\circ}\left(T_{0}, p_{0}\right)=\Delta_{\mathrm{I}}^{\mathrm{L}_{\mathrm{w}}} H_{\mathrm{m}, \mathrm{w}}^{\circ}\left(T_{0}, p_{0}\right)=6011 \mathrm{~J} \mathrm{~mol}^{-1}$ [48] to $-\Delta_{\mathrm{I}}^{\beta} H_{\mathrm{m}, \mathrm{w}}^{\circ}\left(T_{0}, p_{0}\right)$. ${ }^{c} 2^{\text {nd }}$ ed. of the monograph of Sloan [35].

${ }^{\mathrm{d}}$ Dharmawardhana [47].

${ }^{\mathrm{e}} \mathrm{John}$ et al. [48]. Since the authors present $\Delta_{\mathrm{I}}^{\beta} V_{\mathrm{m}, \mathrm{w}}^{\circ}\left(T_{0}, p_{0}\right)$, the value the molar volume of fusion of ice, $\Delta_{\text {fus }} V_{\mathrm{m}, \mathrm{w}}^{\circ}\left(T_{0}, p_{0}\right)=\Delta_{\mathrm{I}}^{\mathrm{L}_{\mathrm{W}}} V_{\mathrm{m}, \mathrm{w}}^{\circ}\left(T_{0}, p_{0}\right)=-1.6 \mathrm{~cm}^{3} \mathrm{~mol}^{-1}$, as determined from X-ray diffraction data of von Stackelberg and Müller [50], has been added to $-\Delta_{\mathrm{I}}^{\mathrm{L}_{\mathrm{w}}} V_{\mathrm{m}, \mathrm{w}}^{\circ}\left(T_{0}, p_{0}\right)$ for obtaining $\Delta_{\beta}^{\mathrm{L}_{\mathrm{w}}} V_{\mathrm{m}, \mathrm{w}}^{\circ}\left(T_{0}, p_{0}\right)$.

${ }^{\mathrm{f}}$ Handa and Tse [49].
} 


\subsection{The solubility of the gases in the aqueous liquid phase}

The solubility of gas $j\left(j=\mathrm{CH}_{4}, \mathrm{CO}_{2}\right)$ in the liquid phase, expressed in terms of the mole fraction $x_{j}^{\mathrm{L}_{\mathrm{w}}}$, is estimated via a Henry's law approach. Hereby, the assumption was made that the activity coefficient of $j, \gamma_{x, j}^{*, \mathrm{~L}_{\mathrm{w}}}$, i.e. the so-called salting-in or salting-out effect [9], can be neglected. Setting $\gamma_{x, j}^{*, \mathrm{~L}_{\mathrm{w}}}=1$ and assuming that the partial molar volume $V_{\mathrm{m}, j}^{\infty, \mathrm{L}_{\mathrm{w}}}$ of $j$ at infinite dilution is independent of pressure, the phase equilibrium condition reads [35]

$$
f_{j}^{\mathrm{G}}=f_{j}^{\mathrm{L}_{\mathrm{w}}}=x_{j}^{\mathrm{L}_{\mathrm{w}}} k_{\mathrm{H}, j, \mathrm{w}}\left(T, p_{\mathrm{w}}^{\sigma}\right) \exp \left(\frac{p V_{\mathrm{m}, j}^{\infty, \mathrm{L}_{\mathrm{w}}}}{R T}\right)
$$

where $f_{j}^{\mathrm{G}}$ is the fugacity of $j$ in the gas phase which is calculated by means of the SoaveRedlich-Kwong EOS [42] and $k_{\mathrm{H}, j, \mathrm{w}}\left(T, p_{\mathrm{w}}^{\sigma}\right)$ denotes Henry's constant at the saturation pressure $p_{\mathrm{w}}^{\sigma}$ of the pure solvent, i.e., at infinite dilution of $j$. The lower integration limit in the Poynting correction has been approximately set to $p=0 \mathrm{MPa}$, as it was done by Sloan [35]. Like in our previous work [34], an average value of $V_{\mathrm{m}, j}^{\infty, \mathrm{L}_{\mathrm{w}}}=32 \mathrm{~cm}^{3} \mathrm{~mol}^{-1}$ [51] was used for both gases. Henry's constant at $T$ and $p_{\mathrm{w}}^{\sigma}$ was calculated from the empirical relation [35]

$$
\frac{k_{\mathrm{H}, j, \mathrm{w}}\left(T, p_{\mathrm{w}}^{\sigma}\right)}{1.01325 \times 10^{5} \mathrm{~Pa}}=\exp \left(-\frac{4.185 \mathrm{~J}}{R \times \mathrm{K} \mathrm{mol}}\left(a_{0}+a_{1} \frac{\mathrm{K}}{T}+a_{2} \ln \left(\frac{T}{\mathrm{~K}}\right)+a_{3} \frac{T}{\mathrm{~K}}\right)\right)
$$

The numerical values of the constants $a_{0}, a_{1}, a_{2}$ and $a_{3}$ are listed in Table 2 .

Table 2 Parameters appearing in the correlation (eq. (6)) for Henry's law constant

\begin{tabular}{ccccc}
\hline & $a_{0}$ & $a_{1}$ & $a_{2}$ & $a_{3}$ \\
\hline $\mathrm{CH}_{4}{ }^{\mathrm{a}}$ & -365.183 & 18106.7 & 49.7554 & -0.000285 \\
$\mathrm{CO}_{2}{ }^{\mathrm{a}}$ & -317.658 & 17371.2 & 43.0607 & -0.002191 \\
\hline
\end{tabular}

${ }^{a} 2^{\text {nd }}$ ed. of the monograph of Sloan [35].

\subsection{The eNRTL-model}

For the case of a single solvent, aqueous multicomponent electrolyte system considered here, the eNRTL model $[15,20]$ describes its molar excess Gibbs energy by referring to the basic microscopic characteristics of electrolyte solutions. The model accounts for the long ranging inter-ionic forces (subscript LR) and the short range forces (subscript SR) acting between the various species by splitting up the molar excess Gibbs energy $G_{\mathrm{m}}^{\mathrm{E} *}$ into the sum of the two corresponding contributions $G_{\mathrm{m}, \mathrm{LR}}^{\mathrm{E} *}$ and $G_{\mathrm{m}, \mathrm{SR}}^{\mathrm{E} *}[20]$, respectively, according to

$$
G_{\mathrm{m}}^{\mathrm{E} *}=G_{\mathrm{m}, \mathrm{LR}}^{\mathrm{E} *}+G_{\mathrm{m}, \mathrm{SR}}^{\mathrm{E} *},
$$

where $G_{\mathrm{m}, \mathrm{LR}}^{\mathrm{E} *}$ stands for the long-range and $G_{\mathrm{m}, \mathrm{SR}}^{\mathrm{E} *}$ for the short-range contribution to $G_{\mathrm{m}}^{\mathrm{E} *}$. The asterisk denotes the unsymmetric reference state (see further below). From an expression for $G_{\mathrm{m}}^{\mathrm{E}}$ or $G_{\mathrm{m}}^{\mathrm{E} *}$, expressions for the symmetrically referenced activity coefficients $\gamma_{x, j}$ and the unsymmetrically referenced activity coefficients $\gamma_{x, j}^{*}$ can be derived in the usual way via the thermodynamic relationships given in Appendix A.3. It follows from eq. (7) that for all species $j \in S_{m} \cup S_{\mathrm{C}} \cup S_{\mathrm{A}}$ (see explanations below) $\ln \gamma_{x, j}$ (as well as $\ln \gamma_{x, j}^{*}$ ) is given by

$$
\ln \gamma_{x, j}=\ln \gamma_{x, j, \mathrm{LR}}+\ln \gamma_{x, j, \mathrm{SR}},
$$


where $\gamma_{x, j, \mathrm{LR}}$ and $\gamma_{x, j, \mathrm{SR}}$ are the respective contributions to $\gamma_{x, j}$. The presentation of the model in the following sub-sections is mainly based on the modification published by Bollas et al. [] of the multicomponent version of the eNRTL-model of Chen and Evans [

\subsubsection{The description of the composition of the system}

In the most general case the system is a multicomponent electrolyte solution consisting of $N_{m}+1$ molecular components $m_{0}, m_{1}, \ldots, m_{N_{m}}, N_{\mathrm{C}}$ cationic species $\mathrm{C}_{1}, \ldots, \mathrm{C}_{N_{\mathrm{C}}}$ and $N_{\mathrm{A}}$ anionic species $\mathrm{A}_{1}, \ldots, \mathrm{A}_{N_{A}}$, respectively. Whereas $m_{0}$ stands for the molecular solvent (here water, i.e. $\left.m_{0} \equiv \mathrm{W}\right), m_{1}, \ldots, m_{N_{m}}$ designates the set of possible additional molecular solute species, respectively. The corresponding sets of species are denoted by $S_{m}, S_{\mathrm{C}}$ and $S_{\mathrm{A}}$, i.e.

$$
\left.\begin{array}{rl}
S_{m} & =\left\{m_{0}, m_{1}, \ldots, m_{N_{m}}\right\} \\
S_{\mathrm{C}} & =\left\{\mathrm{C}_{1}, \ldots, \mathrm{C}_{N_{\mathrm{C}}}\right\} \\
S_{\mathrm{A}} & =\left\{\mathrm{A}_{1}, \ldots, \mathrm{A}_{N_{\mathrm{A}}}\right\}
\end{array}\right\}
$$

The systems treated here contain strong electrolytes $\mathrm{C}_{v_{\mathrm{C}, \mathrm{CA}}} \mathrm{A}_{v_{\mathrm{A}, \mathrm{CA}}}$ (abbreviated as CA) which dissociate completely into $v_{\mathrm{C}, \mathrm{CA}}$ cations $\mathrm{C}^{z_{\mathrm{C}}{ }^{+}}$and $v_{\mathrm{A}, \mathrm{CA}}$ anions $\mathrm{A}^{\left|z_{\mathrm{A}}\right|-}$

$$
\mathrm{C}_{v_{\mathrm{C}, \mathrm{CA}}} \mathrm{A}_{v_{\mathrm{A}, \mathrm{CA}}} \rightarrow v_{\mathrm{C}, \mathrm{CA}} \mathrm{C}^{z_{\mathrm{C}}^{+}}+v_{\mathrm{A}, \mathrm{CA}} \mathrm{A}^{\left|z_{\mathrm{A}}\right|-}
$$

The composition of the system might either be characterised by means of the mole fraction $x_{j}$ of species $j$, calculated from the complete set of mole numbers $n_{j}$ of species according to

$$
x_{j}=\frac{n_{j}}{\sum_{j^{\prime} \in S_{m} \cup S_{\mathrm{C}} \cup S_{\mathrm{A}}} n_{j^{\prime}}} \quad \text { for all } j \in S_{m} \cup S_{\mathrm{C}} \cup S_{\mathrm{A}} \text { ), }
$$

or in terms of the amounts of the chemical components regardless of what happens to their particles when being dissolved. These quantities are called here "overall" or "apparent" quantities. For example, the overall molality $\bar{b}_{k}$ of component $k$ is defined as

$$
\bar{b}_{k}=\frac{\bar{n}_{k}}{\bar{m}_{\mathrm{w}}}=\frac{\bar{n}_{k}}{\bar{n}_{\mathrm{w}} M_{\mathrm{w}}} \quad\left(\text { for all } k \in\left\{S_{m} \cup S_{\mathrm{CA}}\right\} \backslash\{\mathrm{w}\}\right)
$$

where $\bar{n}_{k}$ is the overall mole number of component $k$, and $\bar{m}_{\mathrm{w}}$ and $M_{\mathrm{w}}$ are the overall mass and the molar mass of water, respectively. $S_{\mathrm{CA}}$ designates the set of salts used for preparing the respective solution, which in combination with the condition of complete dissociation determines unambiguously the mixture composition in terms its species.

\subsubsection{The long-range interaction contribution}

In the framework of the eNRTL model the long-range contribution to $G_{\mathrm{m}}^{\mathrm{E} *}, G_{\mathrm{m}, \mathrm{LR}}^{\mathrm{E} *}=G_{\mathrm{m}, \mathrm{PDH}}^{\mathrm{E} *}$, is modelled by a Debye-Hückel term as modified by Pitzer (indicated by subscript PDH), in which the solvent is treated as a dielectric continuum [17,18]. The set of independent variables for representing $G_{\mathrm{m}, \mathrm{PDH}}^{\mathrm{E} *}$ consists of temperature, molar volume, the chemical potential of the solvent and the mole numbers of all solute species, corresponding to the socalled McMillan-Meyer-framework [52]. Therefore the Pitzer-Debye-Hückel equation is based on an unsymmetric reference state whereby $G_{\mathrm{m}, \mathrm{PDH}}^{\mathrm{E} *}$ vanishes when the mole fraction of the solvent species $x_{\mathrm{w}}$ approaches unity. 


$$
\lim _{x_{\mathrm{w}} \rightarrow 1} G_{\mathrm{m}, \mathrm{PDH}}^{\mathrm{E} *}=0,
$$

$x_{\mathrm{w}} \rightarrow 1$ is equivalent to the condition $\sum_{j \neq \mathrm{w}} x_{j} \rightarrow 0$, explaining the term "unsymmetric". $G_{\mathrm{m}, \mathrm{PDH}}^{\mathrm{E} *}$ vanishes if the pure component state is approached for the solvent, but the state of infinite dilution is approached for the solute species.

Since $G_{\mathrm{m}, \mathrm{PDH}}^{\mathrm{E} *}$ accounts for the long-range Coulomb forces between the charged species only, its composition dependence can be represented entirely by means of the ionic strength. The ionic strength, expressed with respect to the mole fraction concentration scale, $I_{x}$, is defined through the relation

$$
I_{x}=\frac{1}{2} \sum_{j \in S_{\mathrm{C}} \cup S_{\mathrm{A}}} z_{j}^{2} x_{j}
$$

where $z_{j}$ is the positive or negative charge number of ion $j$. With $I_{x}$, the defining equation for $G_{\mathrm{m}, \mathrm{PDH}}^{\mathrm{E} *}[18]$ reads

$$
\frac{G_{\mathrm{m}, \mathrm{LR}}^{\mathrm{E} *}}{R T}=\frac{G_{\mathrm{m}, \mathrm{PDH}}^{\mathrm{E} *}}{R T}=-4 A_{\phi} M_{\mathrm{w}}^{-1 / 2} \frac{I_{x}}{\rho} \ln \left(1+\rho I_{x}^{1 / 2}\right)
$$

In eq. (15), $T$ denotes the absolute temperature, $M_{\mathrm{w}}$ the molar mass of the solvent water and $\rho$ the closest approach parameter, respectively. $A_{\phi}$ is the so-called Debye-Hückel-parameter which for aqueous electrolyte systems can be expressed by

$$
A_{\phi}=\frac{1}{3} \frac{\left(2 N_{\mathrm{Av}} \rho_{\mathrm{w}}^{\circ}\right)^{1 / 2}}{8 \pi}\left(\frac{e^{2}}{\varepsilon_{0} \varepsilon_{\mathrm{r}, \mathrm{w}}^{\circ} k_{\mathrm{B}} T}\right)^{3 / 2},
$$

where $N_{\mathrm{Av}}, k_{\mathrm{B}}, e$, and $\varepsilon_{0}$ stands for the Avogadro constant, the Boltzmann constant, the elementary charge and the permittivity of free space, respectively [41]. $\varepsilon_{\mathrm{r}, \mathrm{w}}^{\circ}$ is the relative permittivity and $\rho_{\mathrm{w}}^{\circ}$ the density of water, respectively. Since the numerical value for each of the quantities in eq. (15) and (16) depends on the respective unit employed, the numerical factor 1000 given in the original publications (e.g. [17,18,53]) has been omitted in both eq. (15) and eq. (16). $A_{\phi}$ is based on molality as the underlying composition scale and has the dimension $\operatorname{mass}^{1 / 2} \times(\text { amount of substance })^{-1 / 2}$. Numerical values of the Debye-Hückel parameter are usually given in $\mathrm{kg}^{1 / 2} \mathrm{~mol}^{-1 / 2}$ and at $298.15 \mathrm{~K}_{\phi}=0.391 \mathrm{~kg}^{1 / 2} \mathrm{~mol}^{-1 / 2}$. In case of water being the solvent, $A_{\phi}$ is provided as an empirical function of temperature by Chen et al. [20], which was also used here. It should be remarked that the expression given in [20] has to be multiplied by $\mathrm{kg}^{1 / 2} \mathrm{~mol}^{-1 / 2}$ to give the correct results. The closest approach parameter $\rho$ has been set to a value of 14.9 in accordance with the work of Chen and co-workers [20,21].

The general expression for the long range interaction contribution to the activity coefficient $\gamma_{x, j, \mathrm{LR}}^{*}$, valid for all types of species, ionic as well as molecular solute and solvent species, i.e., $j \in S_{m} \cup S_{\mathrm{C}} \cup S_{\mathrm{A}}$, is derived from eq. (15) by using eq. (A.8) in appendix A.3.

$$
\ln \gamma_{x, j, \mathrm{LR}}^{*}=-A_{\phi} M_{\mathrm{w}}{ }^{-1 / 2}\left(\left(\frac{2 z_{j}^{2}}{\rho}\right) \ln \left(1+\rho I_{x}^{1 / 2}\right)+\frac{z_{j}^{2} I_{x}^{1 / 2}-2 I_{x}^{3 / 2}}{1+\rho I_{x}^{1 / 2}}\right)
$$

\subsubsection{The short-range interaction contribution}

A modified version of the Non-Random-Two-Liquid model of Renon and Prausnitz [54] (indicated by subscript mod-NRTL) which is based on the local composition concept (index 
LC) is used to describe the short range contribution $G_{\mathrm{m}, \mathrm{SR}}^{\mathrm{E} *}=G_{\mathrm{m}, \mathrm{mod}-\mathrm{NRTL}}^{\mathrm{E} *}=G_{\mathrm{m}, \mathrm{LC}}^{\mathrm{E} *}$ to $G_{\mathrm{m}}^{\mathrm{E} *}$. In contrast to the Pitzer-Debye-Hückel model, the modified NRTL model is based on a symmetric reference state, i.e., it provides an expression for $G_{\mathrm{m}, \mathrm{SR}}^{\mathrm{E}}$, the symmetrically referenced molar excess Gibbs energy rather than for $G_{\mathrm{m}, \mathrm{SR}}^{\mathrm{E} *}$. In other words, the model uses the pure liquid solvent, the hypothetically pure liquid molecular and the hypothetically pure liquid homogeneously mixed electrolyte solutes, respectively, as reference states.

$$
\left.\begin{array}{ll}
\lim _{\bar{x}_{\mathrm{w}} \rightarrow 1} G_{\mathrm{m}, \mathrm{SR}}^{\mathrm{E}}=0 & \\
\lim _{\bar{x}_{m} \rightarrow 1} G_{\mathrm{m}, \mathrm{SR}}^{\mathrm{E}}=0 \quad\left(\text { for all } m \in S_{m} \backslash\{\mathrm{w}\}\right) \\
\lim _{\bar{x}_{\mathrm{CA}} \rightarrow 1} G_{\mathrm{m}, \mathrm{SR}}^{\mathrm{E}}=0 \quad\left(\text { for all } \mathrm{CA} \in S_{\mathrm{CA}}\right)
\end{array}\right\}
$$

where $\bar{x}_{\mathrm{w}}, \bar{x}_{m}$ and $\bar{x}_{\mathrm{CA}}$ denote the overall mole fractions of the solvent, the molecular and the electrolyte solute components, respectively.

The reference value used for defining the short range contribution to the excess molar Gibbs energy is the residual molar Gibbs energy of the pure molecular component/species for each $m \in S_{m}$. The hypothetically homogeneously mixed completely dissociated liquid electrolyte mixture [21] is used as reference state for the residual molar Gibbs energy of ionic species $\mathrm{C} \in S_{\mathrm{C}}$ and $\mathrm{A} \in S_{\mathrm{A}}$ respectively.

$$
\begin{aligned}
& \left.G_{\mathrm{m}, m \text {-cell }}^{\mathrm{R} \mathrm{ref}}=G_{\mathrm{m}, m \text {-cell }}^{\mathrm{R} \circ}=g_{m m} \quad \text { (for all } m \in S_{m}\right) \\
& G_{\mathrm{m}, \mathrm{C} \text {-cell }}^{\mathrm{R} \text { ref }}=z_{\mathrm{C}} \sum_{\mathrm{A} \in S_{\mathrm{A}}} Y_{\mathrm{A}} g_{\mathrm{AC}} \quad\left(\text { for all } \mathrm{C} \in S_{\mathrm{C}}\right. \text { ) } \\
& G_{\mathrm{m}, \mathrm{A} \text {-cell }}^{\mathrm{R} \text { ref }}=\left|z_{\mathrm{A}}\right| \sum_{\mathrm{C} \in S_{\mathrm{C}}} Y_{\mathrm{C}} g_{\mathrm{CA}} \quad\left(\text { for all } \mathrm{A} \in S_{\mathrm{A}}\right)
\end{aligned}
$$

In eqs. (19)-(21), $g_{m m}, g_{\mathrm{AC}}$ and $g_{\mathrm{CA}}$ denote the energies of interaction between $m-m$, A-C and C-A species, respectively. With regard to the individual ionic activity coefficients, the symmetrical reference frame implies that the activity coefficients approach unity only if for a given $\mathrm{C} \in S_{\mathrm{C}}$ (or $\mathrm{A} \in S_{\mathrm{A}}$ ) all other ions vanish except for another single counter ion $\mathrm{A} \in S_{\mathrm{A}}$ (or $\mathrm{C} \in S_{\mathrm{C}}$ ). This corresponds to the state of the pure, hypothetically homogeneously mixed liquid pure electrolyte component CA. In eqs. (20) and (21), $Y_{\mathrm{A}}$ and $Y_{\mathrm{C}}$ are the so-called ionic charge fractions defined according to [15]

$$
\begin{gathered}
Y_{\mathrm{C}}=\frac{X_{\mathrm{C}}}{\sum_{\mathrm{C}^{\prime} \in S_{\mathrm{C}}} X_{\mathrm{C}^{\prime}}} \quad\left(\text { for all } \mathrm{C} \in S_{\mathrm{C}}\right) \\
Y_{\mathrm{A}}=\frac{X_{\mathrm{A}}}{\sum_{\mathrm{A}^{\prime} \in S_{\mathrm{A}}} X_{\mathrm{A}^{\prime}}} \quad\left(\text { for all } \mathrm{A} \in S_{\mathrm{A}}\right)
\end{gathered}
$$

In eqs. (22) and (23), $X_{j}$ is the effective mole fraction of species $j$ which is defined by [21]

$$
X_{j}=x_{j} c_{j} \quad \text { with } c_{j}=\left\{\begin{array}{c}
1 \text { for } j \in S_{m} \\
\left|z_{j}\right| \text { for } j \in S_{\mathrm{C}} \cup S_{\mathrm{A}}
\end{array}\right.
$$

The symmetric reference frame leads to the following expression for $G_{\mathrm{m}, \mathrm{SR}}^{\mathrm{E}}$ 


$$
\begin{aligned}
\frac{G_{\mathrm{m}, \mathrm{SR}}^{\mathrm{E}}}{R T}= & \sum_{m \in S_{m}} X_{m} \frac{\sum_{j \in S_{m} \cup S_{\mathrm{C}} \cup S_{\mathrm{A}}} X_{j} G_{j m} \tau_{j m}}{\sum_{j^{\prime} \in S_{m} \cup S_{\mathrm{C}} \cup S_{\mathrm{A}}} X_{j^{\prime}} G_{j^{\prime} m}}+\sum_{\mathrm{C} \in S_{\mathrm{C}}} X_{\mathrm{C}} \sum_{\mathrm{A} \in S_{\mathrm{A}}} Y_{\mathrm{A}} \frac{\sum_{j \in S_{m} \cup S_{\mathrm{A}}} X_{j} G_{j \mathrm{C}, \mathrm{AC}} \tau_{j \mathrm{C}, \mathrm{AC}}}{\sum_{j^{\prime} \in S_{m} \cup S_{\mathrm{A}}} X_{j^{\prime}} G_{j^{\prime} \mathrm{C}, \mathrm{AC}}} \\
& +\sum_{\mathrm{A} \in S_{\mathrm{A}}} X_{\mathrm{A}} \sum_{\mathrm{C} \in S_{\mathrm{C}}} Y_{\mathrm{C}} \frac{\sum_{j \in S_{m} \cup S_{\mathrm{C}}} X_{j} G_{j \mathrm{~A}, \mathrm{CA}} \tau_{j \mathrm{~A}, \mathrm{CA}}}{\sum_{j^{\prime} \in S_{m} \cup S_{\mathrm{C}}} X_{j^{\prime}} G_{j^{\prime} \mathrm{A}, \mathrm{CA}}}
\end{aligned}
$$

where $G_{j m}, G_{j \mathrm{C}, \mathrm{AC}}$ and $G_{j \mathrm{~A}, \mathrm{CA}}$ are the Boltzmann kind factors and $\tau_{j m}, \tau_{j \mathrm{C}, \mathrm{AC}}$ and $\tau_{j \mathrm{~A}, \mathrm{CA}}$ the corresponding dimensionless interaction energy parameters [15,21]. The quantities $G_{j m}$ for $j=m^{\prime}, \mathrm{C}$ and A, respectively, are calculated for any $m \in S_{m}$ according to [15,21]

$$
\begin{gathered}
G_{m^{\prime} m}=\exp \left(-\alpha_{m^{\prime} m} \tau_{m^{\prime} m}\right) \quad\left(\text { for all } m^{\prime} \in S_{m}, m \in S_{m}\right) \\
G_{\mathrm{C} m}=\sum_{\mathrm{A} \in S_{\mathrm{A}}} Y_{\mathrm{A}} G_{\mathrm{CA}, m} \quad\left(\text { for all } \mathrm{C} \in S_{\mathrm{C}}, m \in S_{m}\right) \\
\left.G_{\mathrm{A} m}=\sum_{\mathrm{C} \in S_{\mathrm{C}}} Y_{\mathrm{C}} G_{\mathrm{CA}, m} \quad \text { (for all } \mathrm{A} \in S_{\mathrm{A}}, m \in S_{m}\right)
\end{gathered}
$$

$G_{\mathrm{CA}, m}$ in turn is given by [55]

$$
G_{\mathrm{CA}, m}=\exp \left(-\alpha_{\mathrm{CA}, m} \tau_{\mathrm{CA}, m}\right) \quad\left(\text { for all } m \in S_{m}, \mathrm{C} \in S_{\mathrm{C}}, \mathrm{A} \in S_{\mathrm{A}}\right),
$$

where $\alpha_{\mathrm{CA}, m}$ and $\tau_{\mathrm{CA}, m}$ are basic model parameters. The Boltzmann kind factors $G_{j \mathrm{C}, \mathrm{AC}}$ for $j=m, \mathrm{~A}^{\prime}$, and $G_{j \mathrm{~A}, \mathrm{CA}}$ for $j=m, \mathrm{C}^{\prime}$, are defined similarly to eq. (26) and eq. (29) [55] by

$$
\begin{gathered}
G_{j \mathrm{C}, \mathrm{AC}}=\exp \left(-\alpha_{j \mathrm{C}, \mathrm{AC}} \tau_{j \mathrm{C}, \mathrm{AC}}\right) \quad\left(\text { for all } j \in S_{m} \cup S_{\mathrm{A}}, \mathrm{C} \in S_{\mathrm{C}}, \mathrm{A} \in S_{\mathrm{A}}\right) \\
G_{j \mathrm{~A}, \mathrm{CA}}=\exp \left(-\alpha_{j \mathrm{~A}, \mathrm{CA}} \tau_{j \mathrm{~A}, \mathrm{CA}}\right) \quad\left(\text { for all } j \in S_{m} \cup S_{\mathrm{C}}, \mathrm{C} \in S_{\mathrm{C}}, \mathrm{A} \in S_{\mathrm{A}}\right)
\end{gathered}
$$

In eqs. (26) and (29-31), the dimensionless quantities $\alpha_{m^{\prime} m}, \alpha_{j \mathrm{C}, \mathrm{AC}}$ and $\alpha_{j \mathrm{~A}, \mathrm{CA}}$ are the socalled nonrandomness factors.

The interaction energy parameters $\tau_{\mathrm{C} m}$ and $\tau_{\mathrm{A} m}$ are obtained from [15]

$$
\begin{gathered}
\tau_{\mathrm{C} m}=-\frac{\ln G_{\mathrm{C} m}}{\alpha_{\mathrm{C} m}} \quad\left(\text { for all } \mathrm{C} \in S_{\mathrm{C}}, m \in S_{m}\right) \\
\tau_{\mathrm{A} m}=-\frac{\ln G_{\mathrm{A} m}}{\alpha_{\mathrm{A} m}} \quad\left(\text { for all } \mathrm{A} \in S_{\mathrm{A}}, m \in S_{m}\right)
\end{gathered}
$$

where the $\alpha_{j m}$ 's are obtained from the independent nonrandomness factors $\alpha_{\mathrm{CA}, m} \equiv \alpha_{m, \mathrm{CA}}$ via the same type of mixing rule as the one being used for calculating the quantity $G_{j m}[15,21]$.

$$
\begin{array}{ll}
\alpha_{\mathrm{C} m}=\sum_{\mathrm{A} \in S_{\mathrm{A}}} Y_{\mathrm{A}} \alpha_{\mathrm{CA}, m} \quad\left(\text { for all } \mathrm{C} \in S_{\mathrm{C}}, m \in S_{m}\right) \\
\alpha_{\mathrm{A} m}=\sum_{\mathrm{C} \in S_{\mathrm{C}}} Y_{\mathrm{C}} \alpha_{\mathrm{CA}, m} \quad\left(\text { for all } \mathrm{A} \in S_{\mathrm{A}}, m \in S_{m}\right)
\end{array}
$$


Whereas $\alpha_{\mathrm{A}^{\prime} \mathrm{C}, \mathrm{AC}} \equiv \alpha_{\mathrm{AC}, \mathrm{A}^{\prime} \mathrm{C}}$ and $\alpha_{\mathrm{C}^{\prime} \mathrm{A}, \mathrm{CA}} \equiv \alpha_{\mathrm{CA}, \mathrm{C}^{\prime} \mathrm{A}}$ as well as $\tau_{\mathrm{A}^{\prime} \mathrm{C}, \mathrm{AC}}, \tau_{\mathrm{AC}, \mathrm{A}^{\prime} \mathrm{C}}, \tau_{\mathrm{C}^{\prime} \mathrm{A}, \mathrm{CA}}$ and $\tau_{\mathrm{CA}, \mathrm{C}^{\prime} \mathrm{A}}$ belong to the set of basic parameters of the model, $\tau_{m \mathrm{C}, \mathrm{AC}}$ and $\tau_{m \mathrm{~A}, \mathrm{CA}}$ are composition dependent quantities which are derived by means of the following relations $[15,23]$

$$
\begin{gathered}
\tau_{m \mathrm{C}, \mathrm{AC}}=\tau_{\mathrm{C} m}-\frac{\alpha_{\mathrm{CA}, m}}{\alpha_{m \mathrm{C}, \mathrm{AC}}}\left(\tau_{\mathrm{CA}, m}-\tau_{m, \mathrm{CA}}\right) \quad\left(\text { for all } m \in S_{m}, \mathrm{C} \in S_{\mathrm{C}}, \mathrm{A} \in S_{\mathrm{A}}\right) \\
\tau_{m \mathrm{~A}, \mathrm{CA}}=\tau_{\mathrm{A} m}-\frac{\alpha_{\mathrm{CA}, m}}{\alpha_{m \mathrm{~A}, \mathrm{CA}}}\left(\tau_{\mathrm{CA}, m}-\tau_{m, \mathrm{CA}}\right) \quad\left(\text { for all } m \in S_{m}, \mathrm{C} \in S_{\mathrm{C}}, \mathrm{A} \in S_{\mathrm{A}}\right)
\end{gathered}
$$

Like $\tau_{m^{\prime} m}$ and $\tau_{\mathrm{CA}, m}, \tau_{m, \mathrm{CA}}$ is yet another independent model parameter. In contrast, $\alpha_{m \mathrm{C}, \mathrm{AC}}$ and $\alpha_{m \mathrm{~A}, \mathrm{CA}}$ are set to $[15,23]$

$$
\begin{array}{ll}
\alpha_{m \mathrm{C}, \mathrm{AC}}=\alpha_{\mathrm{C} m} & \left(\text { for all } m \in S_{m}, \mathrm{C} \in S_{\mathrm{C}}, \mathrm{A} \in S_{\mathrm{A}}\right) \\
\alpha_{m \mathrm{~A}, \mathrm{CA}}=\alpha_{\mathrm{A} m} & \text { (for all } m \in S_{m}, \mathrm{C} \in S_{\mathrm{C}}, \mathrm{A} \in S_{\mathrm{A}} \text { ) }
\end{array}
$$

Since the solvent activity coefficient, $\gamma_{x, \mathrm{w}}^{\mathrm{L}_{\mathrm{w}}}$, is of fundamental importance in modelling the $\mathrm{H}-\mathrm{L}_{\mathrm{w}}-\mathrm{G}$-equilibria treated in this study, the expression for the short range contribution to the symmetrically referenced activity coefficient $\gamma_{x, m \text {,SR }}$ of molecular species $m$ is explicitly presented at this stage. Partial differentiation of the $G_{\mathrm{m}, \mathrm{SR}}^{\mathrm{E}}$-expression defined in eq. (25) with respect to $n_{j}$ for $j=m\left(m \in S_{m}\right)$ according to eq. (A.8) leads to the equation for $\ln \gamma_{x, m, \mathrm{SR}}$

$$
\begin{aligned}
\ln \gamma_{x, m, \mathrm{SR}}= & \frac{\sum_{j \in S_{m} \cup S_{\mathrm{C}} \cup S_{\mathrm{A}}} X_{j} G_{j m} \tau_{j m}}{\sum_{j^{\prime} \in S_{m} \cup S_{\mathrm{C}} \cup S_{\mathrm{A}}} X_{j^{\prime}} G_{j^{\prime} m}}+\sum_{m^{\prime} \in S_{m}} \frac{X_{m^{\prime}} G_{m m^{\prime}}}{\sum_{j^{\prime} \in S_{m} \cup S_{\mathrm{C}} \cup S_{\mathrm{A}}} X_{j^{\prime}} G_{j^{\prime} m^{\prime}}}\left(\tau_{m m^{\prime}}-\frac{\sum_{j \in S_{m} \cup S_{\mathrm{C}} \cup S_{\mathrm{A}}} X_{j} G_{j m^{\prime}} \tau_{j m^{\prime}}}{\sum_{j^{\prime} \in S_{m} \cup S_{\mathrm{C}} \cup S_{\mathrm{A}}} X_{j^{\prime}} G_{j^{\prime} m^{\prime}}}\right) \\
& +\sum_{\mathrm{C} \in S_{\mathrm{C}}} \sum_{\mathrm{A}^{\prime} \in S_{\mathrm{A}}} \frac{Y_{\mathrm{A}^{\prime}} X_{\mathrm{C}} G_{m \mathrm{C}, \mathrm{A}^{\prime} \mathrm{C}}}{\sum_{j^{\prime} \in S_{m} \cup S_{\mathrm{A}}} X_{j^{\prime}} G_{j^{\prime} \mathrm{C}, \mathrm{A}^{\prime} \mathrm{C}}}\left(\tau_{m \mathrm{C}, \mathrm{A}^{\prime} \mathrm{C}}-\frac{\sum_{j \in S_{m} \cup S_{\mathrm{A}}} X_{j} G_{j \mathrm{C}, \mathrm{A}^{\prime} \mathrm{C}} \tau_{j \mathrm{C}, \mathrm{A}^{\prime} \mathrm{C}}}{\sum_{j^{\prime} \in S_{m} \cup S_{\mathrm{A}}} X_{j^{\prime}} G_{j^{\prime} \mathrm{C}, \mathrm{A}^{\prime} \mathrm{C}}}\right) \\
& +\sum_{\mathrm{A} \in S_{\mathrm{A}}} \sum_{\mathrm{C}^{\prime} \in S_{\mathrm{C}}} \frac{\sum_{j^{\prime} \in S_{m} \cup S_{\mathrm{C}}} X_{j^{\prime}} G_{j^{\prime} \mathrm{A}, \mathrm{C}^{\prime} \mathrm{A}} X_{\mathrm{A}} G_{m \mathrm{~A}, \mathrm{C}^{\prime} \mathrm{A}}}{\sum_{j \mathrm{~A}, \mathrm{C}^{\prime} \mathrm{A}} \tau_{j \mathrm{~A}, \mathrm{C}^{\prime} \mathrm{A}}}
\end{aligned}
$$

Eq. (40) holds for all $m \in S_{m}$ and thus also for $m=m_{0} \equiv \mathrm{w}$. Since $\gamma_{x, \mathrm{w}, \mathrm{SR}}$ is normalised in line with the unsymmetric convention according to the pure component reference frame, no further adjustment of the value derived from eq. (38) is needed for this case. Contrary, for deriving the activity coefficients of molecular solute species $m \in S_{m} \backslash\{\mathrm{w}\}$, which in accordance with the unsymmetric convention are usually expressed within the Henry's law reference frame, normalisation of the activity coefficient to the infinite dilute state is required for obtaining $\ln \gamma_{x, m, \mathrm{SR}}^{*}$. Even though the presence of molecular solutes dissolved in the liquid phase was neglected in this work, the corresponding formula for $\ln \gamma_{x, m, \mathrm{SR}}^{\infty}$ [15], derived by means of eq. (A.3), is mentioned here for the sake of completeness.

$$
\ln \gamma_{x, m, \mathrm{SR}}^{\infty}=\tau_{\mathrm{w} m}+G_{m \mathrm{w}} \tau_{m \mathrm{w}} \quad\left(\text { for all } m \in S_{m} \backslash\{\mathrm{w}\}\right)
$$

In contrast to $\gamma_{x, \mathrm{w}, \mathrm{SR}}$, the expressions for the activity coefficients of the ionic species are not required for the exclusive modelling of the incipient gas hydrate formation conditions. Nevertheless, they are also discussed in the framework of this study for two reasons (see 
appendix A.4): Firstly since $\ln \gamma_{x, j}$ (along with $\ln \gamma_{x, j}^{*}$, the mean ionic activity coefficients $\ln \gamma_{x, \mathrm{CA}, \pm}^{*}$ and $\ln \gamma_{m, \mathrm{CA}, \pm}^{*}$, as well as the infinite dilution activity coefficients $\ln \gamma_{x, j}^{\infty}$ ) for all $j \in S_{\mathrm{C}} \cup S_{\mathrm{A}}$, as given in both eNRTL model versions [21,23] were also incorporated in the model implementation of this work. Secondly, since the most general expression for $\ln \gamma_{x, \mathrm{C}, \mathrm{SR}}$ in the refined eNRTL-model [23] does contain a typing error, while the expressions for both, $\ln \gamma_{x, \mathrm{C}, \mathrm{SR}}^{\infty}$ and $\ln \gamma_{x, \mathrm{~A}, \mathrm{SR}}^{\infty}$ presented in [23], respectively, are erroneous.

\subsubsection{On the basic model parameters and their temperature dependence}

The basic model parameters to be adjusted to binary \{water + electrolyte $\}$ systems at constant temperature are the nonrandomness factor $\alpha_{\mathrm{w}, \mathrm{CA}}$ and the dimensionless energetic interaction parameters $\tau_{\mathrm{w}, \mathrm{CA}}$ and $\tau_{\mathrm{CA}, \mathrm{w}}$. The latter are weak but well behaved functions of temperature. In practice, the nonrandomness factor is often a priori set to a fixed value. Hence, only two parameters are needed to describe an isothermal solution of a single electrolyte [21]. For the general case of a multicomponent system under isothermal conditions, containing besides the solvent additional molecular solutes as well as ionic species, combinatorial considerations lead to the number of eNRTL model parameters required for its description (Appendix A.5).

In multicomponent systems the independent model parameters are $\alpha_{m m^{\prime}}, \alpha_{m, \mathrm{CA}}, \alpha_{\mathrm{CA}, \mathrm{CA}^{\prime}}$, $\alpha_{\mathrm{AC}, \mathrm{AC}}, \tau_{m m^{\prime}}, \tau_{m^{\prime} m}, \tau_{m, \mathrm{CA}}, \tau_{\mathrm{CA}, m}, \tau_{\mathrm{AC}, \mathrm{AC}}, \tau_{\mathrm{AC}^{\prime}, \mathrm{AC}}, \tau_{\mathrm{CA}, \mathrm{CA}^{\prime}}$, and $\tau_{\mathrm{CA}^{\prime}, \mathrm{CA}} \cdot \tau_{m m^{\prime}}, \tau_{m^{\prime} m}$ (and possibly $\alpha_{m m^{\prime}}$ ) are adjusted to molecule-molecule binary systems (these values can be taken from data sources for the NRTL-model). $\tau_{\mathrm{AC}, \mathrm{AC}^{\prime}}, \tau_{\mathrm{AC}^{\prime}, \mathrm{AC}}, \tau_{\mathrm{CA}, \mathrm{CA}^{\prime}}$, and $\tau_{\mathrm{CA}^{\prime}, \mathrm{CA}}$ (and possibly $\alpha_{\mathrm{CA}, \mathrm{CA}^{\prime}}$ and $\left.\alpha_{\mathrm{AC}, \mathrm{AC}}\right)$ are adjusted to ternary $\left\{\right.$ solvent + salt $_{1}+$ salt $\left._{2}\right\}$ systems involving electrolytes having one ion in common. Actually it can be set $\tau_{\mathrm{AC}, \mathrm{AC}^{\prime}}=-\tau_{\mathrm{AC}^{\prime}, \mathrm{AC}}$ and $\tau_{\mathrm{CA}, \mathrm{CA}^{\prime}}=-\tau_{\mathrm{CA}^{\prime}, \mathrm{CA}}$ [21]. Good results are even obtained by setting these parameters to zero [21]. This is an example for demonstrating the predictive capabilities of the model.

The non-randomness parameters are usually set to default values, as it was also done in this work. Whereas $\alpha_{m m^{\prime}}=0.3$ is typically used for describing the molecule-molecule interactions (parameter was not used in these calculations since no molecule-molecule interaction was taken into account), a value of 0.2 is usually adopted for $\alpha_{m, \mathrm{CA}}, \alpha_{\mathrm{CA}, \mathrm{CA}}$ and $\alpha_{\mathrm{AC}, \mathrm{AC}^{\prime}}$ [53]. Confining to this procedure, $\alpha_{m, \mathrm{CA}}$ was set to 0.2 throughout in this study.

The parameters $\tau_{m m^{\prime}}, \tau_{m, \mathrm{CA}}, \tau_{\mathrm{CA}, m}, \tau_{\mathrm{CA}, \mathrm{C}^{\prime} \mathrm{A}}$ and $\tau_{\mathrm{AC}, \mathrm{A}^{\prime} \mathrm{C}}$, respectively, are functions of temperature. Their dependence on temperature is described by means of empirical functions. The molecule-molecule interaction parameters are described by [53]

$$
\tau_{m m^{\prime}}(T)=A_{m m^{\prime}, 0}+\frac{A_{m m^{\prime}, 1}}{T}+A_{m m^{\prime}, 2} \ln \left(\frac{T}{\mathrm{~K}}\right)+A_{m m^{\prime}, 3} T
$$

whereas the following functions are proposed for describing $\tau_{m, \mathrm{CA}}(T)$ and $\tau_{\mathrm{CA}, m}(T)$

$$
\begin{aligned}
& \tau_{m, \mathrm{CA}}(T)=B_{m, \mathrm{CA}, 0}+\frac{B_{m, \mathrm{CA}, 1}}{T}+B_{m, \mathrm{CA}, 2}\left(\frac{T-T^{\mathrm{ref}}}{T}+\ln \left(\frac{T}{T^{\mathrm{ref}}}\right)\right), \\
& \tau_{\mathrm{CA}, m}(T)=B_{\mathrm{CA}, m, 0}+\frac{B_{\mathrm{CA}, m, 1}}{T}+B_{\mathrm{CA}, m, 2}\left(\frac{T-T^{\mathrm{ref}}}{T}+\ln \left(\frac{T}{T^{\mathrm{ref}}}\right)\right),
\end{aligned}
$$

Similarly, $\tau_{\mathrm{CA}, \mathrm{C}^{\prime} \mathrm{A}}(T)$ and $\tau_{\mathrm{AC}, \mathrm{A}^{\prime} \mathrm{C}}(T)$ are modelled by 


$$
\begin{gathered}
\tau_{\mathrm{CA}, \mathrm{C}^{\prime} \mathrm{A}}(T)=B_{\mathrm{CA}, \mathrm{C}^{\prime} \mathrm{A}, 0}+\frac{B_{\mathrm{CA}, \mathrm{C}^{\prime} \mathrm{A}, 1}}{T}+B_{\mathrm{CA}, \mathrm{C}^{\prime} \mathrm{A}, 2}\left(\frac{T-T^{\mathrm{ref}}}{T}+\ln \left(\frac{T}{T}\right)\right) \\
\tau_{\mathrm{AC}, \mathrm{A}^{\prime} \mathrm{C}}(T)=B_{\mathrm{AC}, \mathrm{A}^{\prime} \mathrm{C}, 0}+\frac{B_{\mathrm{AC}, \mathrm{A}^{\prime} \mathrm{C}, 1}}{T}+B_{\mathrm{AC}, \mathrm{A}^{\prime} \mathrm{C}, 2}\left(\frac{T-T^{\mathrm{ref}}}{T}+\ln \left(\frac{T}{T^{\mathrm{ref}}}\right)\right)
\end{gathered}
$$

In the expressions for $\tau_{\mathrm{CA}, \mathrm{C}^{\prime} \mathrm{A}}(T)$ and $\tau_{\mathrm{AC}, \mathrm{A}^{\prime} \mathrm{C}}(T)$, the values for $B_{\mathrm{CA}, \mathrm{C}^{\prime} \mathrm{A}, 0}, B_{\mathrm{CA}, \mathrm{C}^{\prime} \mathrm{A}, 1}$ and $B_{\mathrm{CA}, \mathrm{C}^{\prime} \mathrm{A}, 2}$, and $B_{\mathrm{AC}, \mathrm{A}^{\prime} \mathrm{C}, 0}, B_{\mathrm{AC}, \mathrm{A}^{\prime} \mathrm{C}, 1}$ and $B_{\mathrm{AC}, \mathrm{A}^{\prime} \mathrm{C}, 2}$, respectively, are often set to zero, like it was also done in this study. $T^{\text {ref }}$ is set to $298.15 \mathrm{~K}$ [53].

\subsection{The thermodynamic description of the gas phase}

An equation of state (EOS) approach was used to describe the vapour phase throughout in the calculations while a cubic equation of state, the Soave-Redlich-Kwong (SRK) EOS [42], served for calculating the fugacities of the gaseous components in the gas phase. The presence of water in the gas phase was neglected, i.e., it was assumed that $f_{\mathrm{H}_{2} \mathrm{O}}^{\mathrm{G}}=0$. Like in our previous work [34], the values for the SRK-EOS-parameters were taken from Danesh [56].

\subsection{Details on the eNRTL model implementation and overall modelling procedure}

The modelling of the incipient hydrate forming conditions in systems comprising one of the guest components $\mathrm{CH}_{4}$ or $\mathrm{CO}_{2}$ and an aqueous solution of one or two strong electrolytes was performed by means of our updated in-house programme mentioned earlier. As the main part of this work, both the previous version of the eNRTL model by Chen and Evans [21] as well as the more recent version of the model by Bollas et al. [23] were incorporated into the previous programme designed for gas hyadrate modelling of systems without electrolytes. The newly implemented eNRTL routines (called "classes" in the object oriented Java language) provide expressions for treating multicomponent systems composed of the solvent water and any number of molecular, cationic and anionic solute species. Mixed solvent systems as included through the model extension of Mock et al. [57] were thus not taken into account. In particular, the eNRTL implementation contains functions (called "methods" in Java) for the calculation of individual ionic and molecular species' activity coefficients, mean ionic activity coefficients, both with respect to the mole fraction and molality concentration scale, and the osmotic coefficient, respectively. Expressions for the different types of activity coefficients at infinite dilution were also provided. The unsymmetric convention was adopted for normalising the activity coefficients, i.e., the Henry's law reference frame was used for the solute species, whereas the Lewis-Randall reference frame was applied in case of the solvent species. The basic eNRTL model parameters used for representing the energetic interaction parameters as function of temperature were retrieved from the Aspen Properties ${ }^{\circledR}$ data bank and provided to the programme by means of an xml-data file.

The algorithm presented by Sloan [35] was used for calculating the incipient hydrate formation conditions at $\mathrm{H}-\mathrm{L}_{\mathrm{w}}-\mathrm{G}$-phase equilibrium. Its central element is the solution of eq. (1 ) for the unknown state variables. In calculating the activity of water, the influence of the dissolved gases on the liquid phase non-idealities was neglected. The mole fraction of the gas dissolved in the liquid phase was thus estimated by means of the Henry's law approach presented in section 2.4 by assuming that $\gamma_{x, \mathrm{CH}_{4}}^{*, \mathrm{~L}_{\mathrm{w}}}=\gamma_{x, \mathrm{CO}_{2}}^{*, \mathrm{~L}_{\mathrm{w}}}=1$. In the calculation of $\gamma_{x, \mathrm{w}}^{*, \mathrm{~L}_{\mathrm{w}}}$, the influence of the dissolved gases on $\gamma_{x, \mathrm{w}}^{*, \mathrm{~L}_{\mathrm{w}}}$ was neglected by setting $\tau_{\mathrm{w}, j}=\tau_{j, \mathrm{w}}=0$ $\left(j=\mathrm{CH}_{4}, \mathrm{CO}_{2}\right.$ ). The gas-salt-interaction parameters were also set to zero. With regard to the Kihara parameters $\sigma_{j \mathrm{w}}$ and $\varepsilon_{j \mathrm{w}}\left(j=\mathrm{CH}_{4}, \mathrm{CO}_{2}\right)$ it turned out that it was sufficient to use the 
set of values obtained in our previous study [34] to achieve a good overall description of the incipient hydrate formation conditions at fixed salt concentration in the initial solutions.

\section{Modelling Results and Discussion}

\subsection{Verification of the correctness of the eNRTL model implementation}

Initially, in view of the quite lengthy multicomponent eNRTL-expressions for the activity coefficients, the correctness of the model implementation was thoroughly examined. For that purpose, calculated results of numerous selected examples were compared to corresponding experimental data. Mean molal activity coefficients, osmotic coefficients and solubilities were investigated for single and mixed aqueous electrolyte solutions.

\subsubsection{Osmotic coefficient of binary $\{$ solvent + salt $\}$ systems}

The calculations carried out for checking the correctness of the code were inspired by the systems treated in the publication of Chen and Evans [21]. In the first examples the osmotic coefficient $\phi$ was modelled at $25{ }^{\circ} \mathrm{C}$ and ambient pressure for single salt aqueous solutions of alkali metal chlorides $\mathrm{MCl}(\mathrm{M}=\mathrm{Li}, \mathrm{Na}, \mathrm{K}, \mathrm{Rb})$ and alkaline earth metal halides $\mathrm{MX}_{2}$ $(\mathrm{M}=\mathrm{Mg}, \mathrm{Ca} ; \mathrm{X}=\mathrm{Cl}, \mathrm{Br}, \mathrm{I})$, respectively, using data for the solvent-salt interaction coefficients reported in [21]. The quantity $\phi$ is derived by means of eq. (A.13) using calculated results for $\gamma_{x, \mathrm{w}}$. eNRTL-model parameters were taken from [21]

Root mean square relative deviations between the calculated results and the experimental data of Robinson and Stokes [58], defined according to

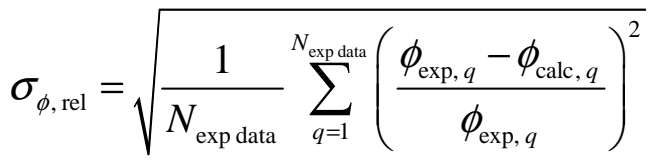

are compiled in Table 3. As can be verified in Table 3, the values of $\sigma_{\phi \text {,rel }}$ generated in this work reproduce the corresponding $\sigma_{\phi \text {,rel }}$-values of Chen and Evans [21].

Table 3 Comparison of values for the root mean square deviation $\sigma_{\phi \text {,rel }}$ between calculated and experimental results [58] on the osmotic coefficient at $25{ }^{\circ} \mathrm{C}$ and ambient pressure obtained in this study and by Chen and Evans [21], respectively, for selected alkali chloride and alkaline earth metal halide aqueous solutions

\begin{tabular}{llll}
\hline Salt & $\sigma_{\phi, \text { rel }}{ }^{\mathrm{a}}$ & $\sigma_{\phi, \text { rel }}{ }^{\mathrm{b}}$ & $\bar{b}_{\mathrm{CA}, \max }$ \\
\hline $\mathrm{LiCl}$ & 0.0227 & 0.024 & 6 \\
$\mathrm{NaCl}$ & 0.0118 & 0.012 & 6 \\
$\mathrm{KCl}$ & 0.0023 & 0.002 & 4.8 \\
$\mathrm{RbCl}$ & 0.0015 & 0.002 & 5 \\
$\mathrm{CaCl}$ & 0.0238 & 0.025 & 2.5 \\
$\mathrm{CaBr}_{2}$ & 0.1235 & 0.13 & 6 \\
$\mathrm{CaI}_{2}$ & 0.0220 & 0.024 & 2 \\
$\mathrm{MgCl}_{2}$ & 0.0838 & 0.09 & 5 \\
$\mathrm{MgBr}_{2}$ & 0.0896 & 0.09 & 5 \\
$\mathrm{MgI}_{2}$ & 0.1036 & 0.11 & 5 \\
\hline
\end{tabular}

${ }^{\mathrm{a}}$ This work. 
${ }^{\mathrm{b}}$ Results of Chen and Evans [21].

\subsubsection{Ternary $\left\{\right.$ solvent + salt $_{1}+$ salt $\left._{2}\right\}$ systems}

Calculations on solvent + salt $_{1}+$ salt $_{2}$ systems were performed in order to provide evidence for the correctness of the programme implementation for the general case of multicomponent electrolyte solutions. In each of these selected systems, the two different salts have one of their ions in common, i.e., they are either of the type $\left\{\mathrm{H}_{2} \mathrm{O}+\mathrm{C}_{1} \mathrm{~A}+\mathrm{C}_{2} \mathrm{~A}\right\}$ or $\left\{\mathrm{H}_{2} \mathrm{O}+\mathrm{CA}_{1}+\mathrm{CA}_{2}\right\}$. Osmotic coefficients $\phi$, mean molal activity coefficients $\gamma_{b, \pm, C A}^{*}$ and salt solubilities were derived and compared to results found in the literature.

At first, in an attempt to reproduce Figure 2 given in [21], $\phi$ was calculated for the system $\left\{\mathrm{H}_{2} \mathrm{O}+\mathrm{NaCl}+\mathrm{LiCl}\right\}$ at $T=298.15 \mathrm{~K}, p=0.1 \mathrm{MPa}$ and constant overall electrolyte molality of $\bar{b}_{\mathrm{NaCl}+\mathrm{LiCl}}=2 \mathrm{~mol} \mathrm{~kg}^{-1}$ as function of the relative amount of $\mathrm{LiCl}$ in the salt mixture (Figure 1). The latter was expressed in terms of the overall mole fraction of $\mathrm{LiCl}$ in the solvent-free binary sub-system $\{\mathrm{NaCl}+\mathrm{LiCl}\}$, i.e., $\bar{x}_{\mathrm{LiCl}, \mathrm{NaCl}+\mathrm{LiCl}}=\bar{b}_{\mathrm{LiCl}} /\left(\bar{b}_{\mathrm{NaCl}}+\bar{b}_{\mathrm{LiCl}}\right)$. $\phi$ was modelled for three different values of the salt-salt-interaction parameters. Chen and Evans claimed that the curves B, C, and D in Figure 2 of their article [21] would correspond to parameter values of $\tau_{\mathrm{Na}^{+} \mathrm{Cl}^{-} \mathrm{Li}^{+} \mathrm{Cl}^{-}}=-\tau_{\mathrm{Li}^{+} \mathrm{Cl}^{-} \mathrm{Na}^{+} \mathrm{Cl}^{-}}=0,1$ and 2 and $\alpha=0.2$. The curves B-D given in Figure 2 of the original publication along with the linear interpolation line A between $\phi\left(\bar{x}_{\mathrm{LiCl}, \mathrm{NaCl}+\mathrm{LiCl}}=0\right)$ and $\phi\left(\bar{x}_{\mathrm{LiCl}, \mathrm{NaCl}+\mathrm{LiCl}}=1\right)$ are reproduced from [21] by means of the programme "plotdigitizer" provided by the Physics Department of the University of South Alabama, USA [59]. They are represented as red lines in Figure 1 a) and b). Although Chen and Evans do not explicitly mention the numerical values $\tau_{\mathrm{CA}, \mathrm{w}}$ and $\tau_{\mathrm{w}, \mathrm{CA}}$ used for creating the curves of $\phi$ against $\bar{x}_{\mathrm{LiCl}, \mathrm{NaCl}+\mathrm{LiCl}}$ it can be assumed that they used the data presented in Table 1 of the same publication [21]. The latter are compiled in the rows labelled as "Figure 1 a)" in Table 4. Using these values for $\tau_{\mathrm{CA}, \mathrm{w}}$ and $\tau_{\mathrm{w}, \mathrm{CA}}$, and $0,1,2$ for the salt-salt parameters, the curves published in [21] could not be reproduced. However, when incrementing the values of the latter by one, and hence setting $\tau_{\mathrm{Na}^{+} \mathrm{Cl}^{-}, \mathrm{Li}^{+} \mathrm{Cl}^{-}}=-\tau_{\mathrm{Li}^{+} \mathrm{Cl}^{-}, \mathrm{Na}^{+} \mathrm{Cl}^{-}}=1,2,3$, the curves B-D could at least be reproduced qualitatively (see light blue curves of Figure 1 a)). Nevertheless, the values of $\phi\left(\bar{x}_{\mathrm{LiCl}, \mathrm{NaCl}+\mathrm{LiCl}}=0\right)$ between this work and [21] do still not match. Using for $\tau_{\mathrm{CA}, \mathrm{w}}$ and $\tau_{\mathrm{w}, \mathrm{CA}}$ the values provided by Chen et al. [20] and listed in the last two rows of Table 4 again together with $\tau_{\mathrm{Na}^{+} \mathrm{Cl}^{-}, \mathrm{Li}^{+} \mathrm{Cl}^{-}}=-\tau_{\mathrm{Li}^{+} \mathrm{Cl}^{-}, \mathrm{Na}^{+} \mathrm{Cl}^{-}}=1,2,3$ results in the turquoise curves in Figure $1 \mathrm{~b})$. Although the values of $\phi\left(\bar{x}_{\mathrm{LiCl}, \mathrm{NaCl}+\mathrm{LiCl}}=0\right)$ do almost coincide, a deviation can be detected for $\phi\left(\bar{x}_{\mathrm{LiCl}, \mathrm{NaCl}+\mathrm{LiCl}}=1\right)$ between this work and [21].

Since the correctness of the Java implementation has been checked independently through the same calculations performed by using the computer algebra software Mathcad ${ }^{\circledR}$ (version 14), it is believed that the results calculated in this work are correct. This conclusion is additionally supported by the fact that the change in slope of the curve D generated in this work (light blue and turquoise curve D in Figure 1 a) and b)) is smoother than it is for the corresponding curve presented by Chen and Evans (red curve D).

Table 4 Binary water-salt interaction coefficients used for generating the light blue and turquoise curves in Figure $1 \mathrm{a}$ ) an b), respectively, of $\phi$ for $\left\{\mathrm{H}_{2} \mathrm{O}+\mathrm{NaCl}+\mathrm{LiCl}\right\}$

\begin{tabular}{lcrl}
\hline & $\mathrm{CA}$ & \multicolumn{1}{c}{$\tau_{\mathrm{w}, \mathrm{CA}}$} & \multicolumn{1}{c}{$\tau_{\mathrm{CA}, \mathrm{w}}$} \\
\hline${\text { Figure } 1 \mathrm{a})^{\mathrm{a}}}$ & $\mathrm{NaCl}$ & 9.0234 & -4.5916 \\
& $\mathrm{LiCl}$ & 10.1242 & -5.1737
\end{tabular}




\begin{tabular}{|c|c|c|c|}
\hline Figure $1 \mathrm{~b})^{\mathrm{b}}$ & $\begin{array}{c}\mathrm{NaCl} \\
\mathrm{LiCl}\end{array}$ & $\begin{array}{r}8.885 \\
10.031\end{array}$ & $\begin{array}{l}-4.549 \\
-5.154\end{array}$ \\
\hline
\end{tabular}

${ }^{\mathrm{a}}$ Chen and Evans [21].

${ }^{\mathrm{b}}$ Chen et al. [20].

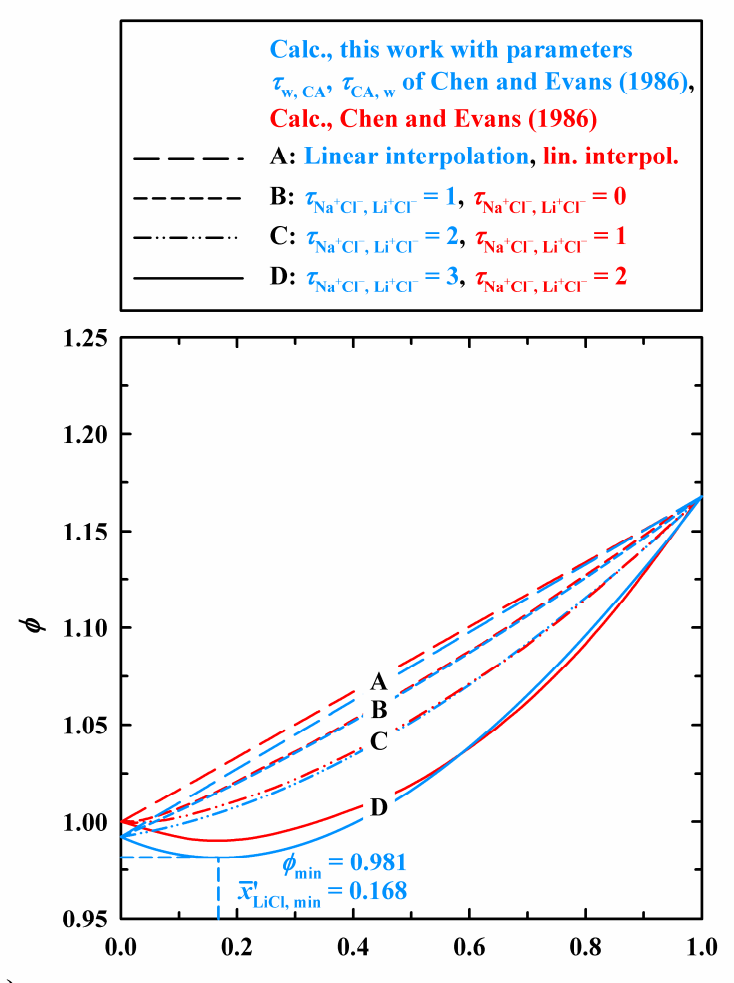

a)

$$
\bar{x}_{\mathrm{LiCl}}^{\prime}=\bar{x}_{\mathrm{LiCl}, \mathrm{NaCl} \mathrm{LiCl}}
$$
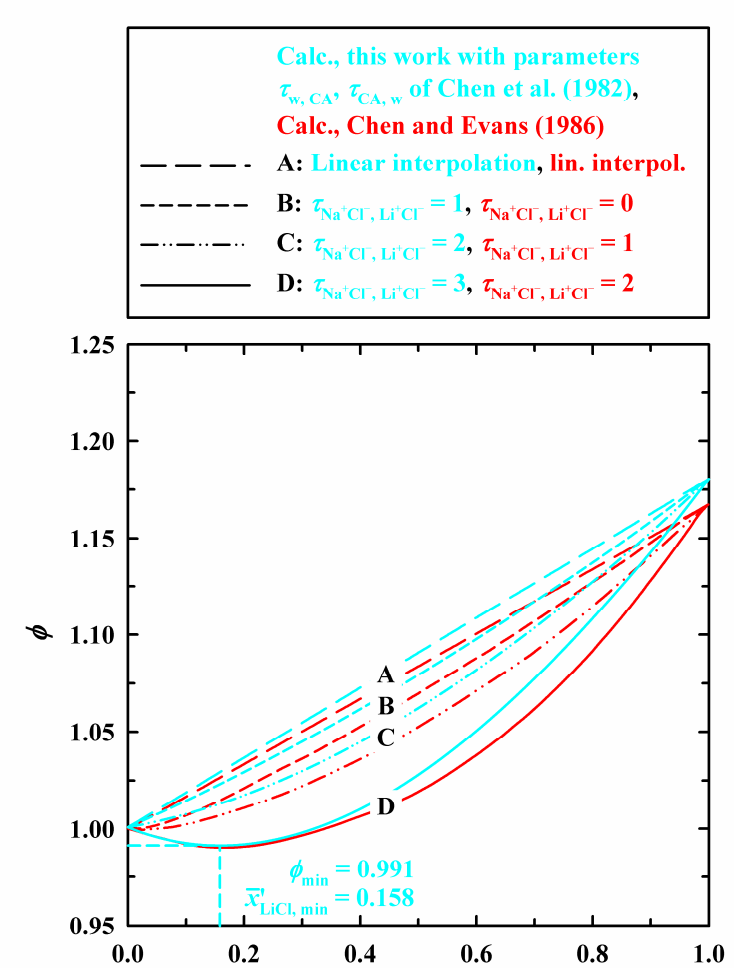

b)

$\bar{x}_{\mathrm{LiCl}}^{\prime}=\bar{x}_{\mathrm{LiCl}, \mathrm{NaCl} \mathrm{LiCl}}$

Figure 1 Osmotic coefficient of the system $\left\{\mathrm{H}_{2} \mathrm{O}+\mathrm{NaCl}+\mathrm{LiCl}\right\}$ at constant total overall molality $\bar{b}_{\mathrm{NaCl}+\mathrm{LiCl}}=2 \mathrm{~mol} \mathrm{~kg}^{-1}, T=298.15 \mathrm{~K}$ and ambient pressure as function of the salt mole fraction $\bar{x}_{\mathrm{LiCl}, \mathrm{NaCl}+\mathrm{LiCl}}=\bar{b}_{\mathrm{LiCl}} /\left(\bar{b}_{\mathrm{NaCl}}+\bar{b}_{\mathrm{LiCl}}\right)$. Light blue curves in a) and turquoise curves in $b$ ), this work with solvent-salt parameters given in [21] and [20], respectively, and salt-salt-parameters $\tau_{\mathrm{NaCl}, \mathrm{LiCl}}=-\tau_{\mathrm{LiCl}, \mathrm{NaCl}}=1,2,3$ for curves B-D, respectively. Red curves in a) and b) reproductions of the curves presented in Figure 2 of the original publication of Chen and Evans [21] with supposed values $\tau_{\mathrm{NaCl}, \mathrm{LiCl}}=-\tau_{\mathrm{LiCl}, \mathrm{NaCl}}=0,1,2$. Curves A: linear interpolation.

As a further example for verifying the correctness of our eNRTL model implementation, the mean molal activity coefficients $\gamma_{b, \mathrm{CA}, \pm}^{*}$ of $\mathrm{NaCl}$ and $\mathrm{KCl}$ in the $\left\{\mathrm{H}_{2} \mathrm{O}+\mathrm{NaCl}+\mathrm{KCl}\right\}-$ system have been modelled at $25^{\circ} \mathrm{C}$ (Figure 2) using eqs. (A.9)-(A.12) along with eqs. (A.15)-(A.18). For the expressions for $\gamma_{x, j}$ and $\gamma_{x, j}^{\infty}\left(j \in S_{\mathrm{C}} \cup S_{\mathrm{A}}\right)$ in the older model version, the reader is referred to [21] and [15], respectively. The calculations were inspired by Figure 1 presented in the article of Bollas et al. [23] in which the authors have performed calculations on $\gamma_{b, \mathrm{NaCl}, \pm}^{*}$ and $\gamma_{b, \mathrm{KCl}, \pm}^{*}$ using values for the salt-salt-interaction parameters of $\tau_{\mathrm{Na}^{+} \mathrm{Cl}^{-}, \mathrm{K}^{+} \mathrm{Cl}^{-}}=$ $-\tau_{\mathrm{K}^{+} \mathrm{Cl}^{-}, \mathrm{Na}^{+} \mathrm{Cl}^{-}}=0,0.25,0.50$ to compare the performance of the simplified [21] (Figure $2 \mathrm{a}$ )) and the refined eNRTL model version (Figure $2 \mathrm{~b}$ )), respectively [23]. The reproducibility of the curves given in [23] (reproduced from [23] as red and orange lines in Figure 2, respectively, using the freely available programme "plotdigitizer" [59]) by means of our 
programme in both model versions (blue and turquoise lines in Figure 2, respectively) serves as a further evidence that both the new [23] and the previous model equations [21] had been correctly implemented in our programme.
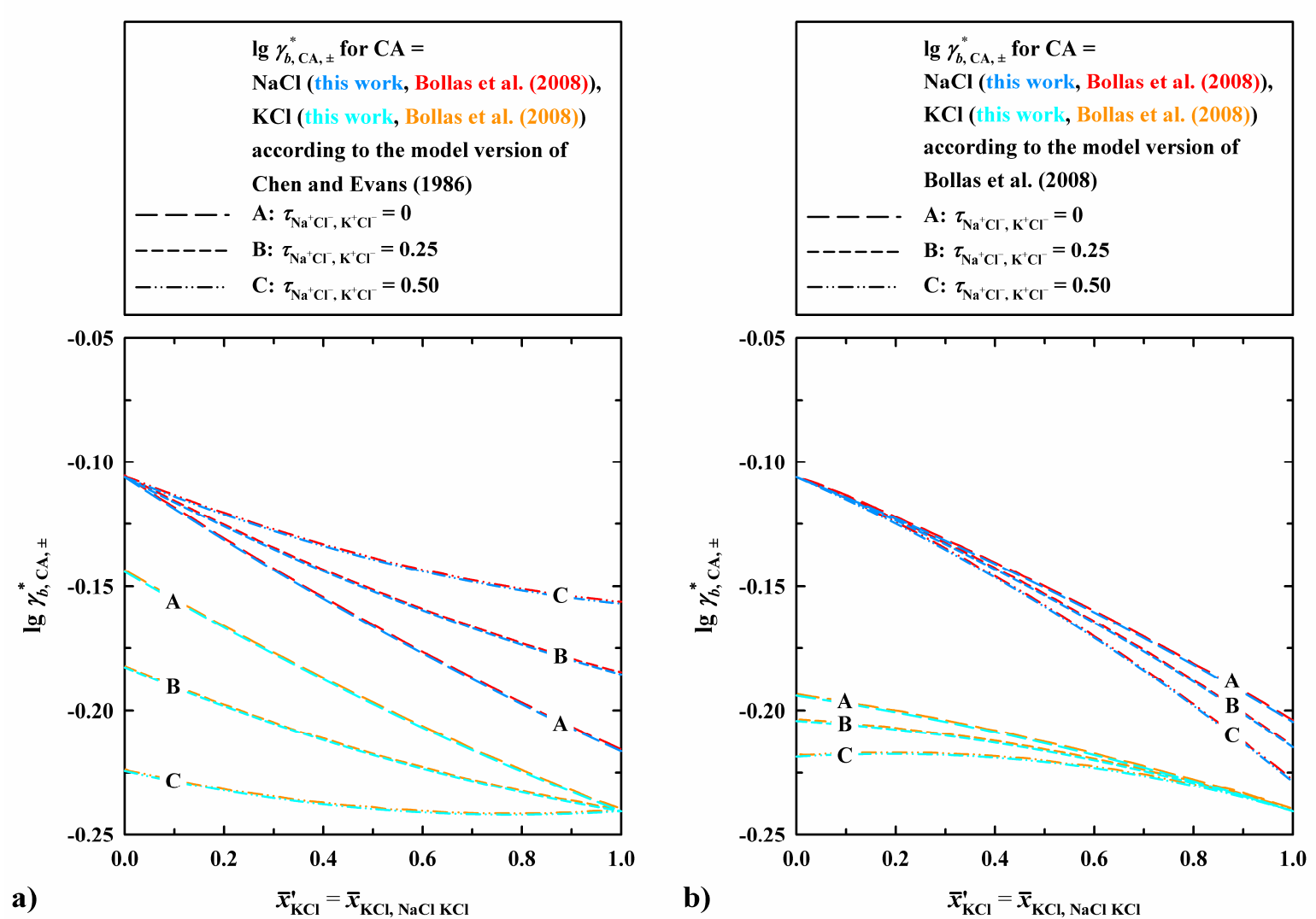

Figure 2 Prediction of the mean molal ionic activity coefficients of $\mathrm{NaCl}$ and $\mathrm{KCl}, \gamma_{b, \mathrm{NaCl}, \pm}^{*}$ and $\gamma_{b, \mathrm{KCl}, \pm}^{*}$, of the system $\left\{\mathrm{H}_{2} \mathrm{O}+\mathrm{NaCl}+\mathrm{KCl}\right\}$ at $298.15 \mathrm{~K}$ and a total overall molality $\bar{b}_{\mathrm{NaCl}+\mathrm{KCl}}=4 \mathrm{~mol} \mathrm{~kg}^{-1}$ with various salt-salt energy parameters using the equations for $\gamma_{x, \mathrm{C}}^{*}$ and $\gamma_{x, \mathrm{~A}}^{*}$ of a) Chen and Evans [21] and b) Bollas et al. [23]. Comparison between the results of the eNRTL implementation for $\gamma_{b, \mathrm{NaCl}, \pm}^{*}$ and in this work and the results on $\gamma_{b, \mathrm{NaCl}, \pm}^{*}$ and $\gamma_{b, \mathrm{KCl}, \pm}^{*}$ given in [23].

\subsection{3 $\mathrm{S}_{\mathrm{KX}}-\mathrm{L}_{\mathrm{w}}$ and $\mathrm{S}_{\mathrm{KCl}}-\mathrm{S}_{\mathrm{KI}}-\mathrm{L}_{\mathrm{w}}$ equilibria encountered in the system $\left\{\mathrm{H}_{2} \mathrm{O}+\mathrm{KI}+\mathrm{KCl}\right\}$}

As an example for equilibrium calculations performed with the eNRTL model, the solubility curve of the system $\left\{\mathrm{H}_{2} \mathrm{O}+\mathrm{KI}+\mathrm{KCl}\right\}$ at $T=298.15 \mathrm{~K}$ and $p=0.1 \mathrm{MPa}$ is shown in Figure 3 . To model the solubilties in this ternary electrolyte system, values for the solubility products of the salts, $K_{\mathrm{sp}, \mathrm{KI}}$ and $K_{\mathrm{sp}, \mathrm{KCl}}$, are needed in addition to the eNRTL model parameters. With $K_{\mathrm{sp}, \mathrm{KI}}=-4.2346$ and $K_{\mathrm{sp}, \mathrm{KCl}}=-5.9695$ [21] gained from a data regression of the solubility data of Linke [60], the salt-solvent interaction parameters $\tau_{\mathrm{K}^{+} \mathrm{I}^{-, \mathrm{w}}}=-4.1217, \tau_{\mathrm{w}, \mathrm{K}^{+} \mathrm{I}^{-}}=7.9408$, $\tau_{\mathrm{K}^{+} \mathrm{Cl}^{-}, \mathrm{w}}=-4.1341$ and $\tau_{\mathrm{w}, \mathrm{K}^{+} \mathrm{Cl}^{-}}=8.1354$ [21] and the salt-salt-parameters $\tau_{\mathrm{K}^{+} \mathrm{Cl}^{-}, \mathrm{K}^{+} \mathrm{I}^{-}}=0.109$ and $\tau_{\mathrm{K}^{+} \mathrm{I}^{-}, \mathrm{K}^{+} \mathrm{Cl}^{-}}=0.124$ [21], the solubility curves (Figure 3) were reproduced well. However, since the visibility of the respective curves in Figure 5 a) of [21] is restricted, no attempt was made to reproduce the fragments of the curve. Instead, only the experimental data compiled by Linke [60] are shown in Figure 3 for comparison. 


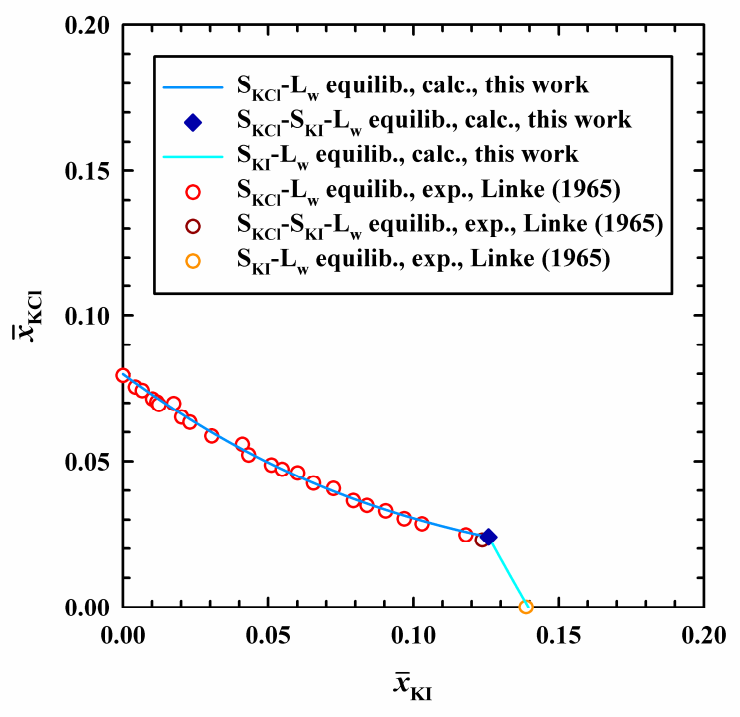

Figure 3 Salt Precipitation in the system $\left\{\mathrm{H}_{2} \mathrm{O}+\mathrm{KI}+\mathrm{KCl}\right\}$ at $T=298.15 \mathrm{~K}$ and ambient pressure. (-) $\mathrm{S}_{\mathrm{KCl}} \mathrm{L}_{\mathrm{w}}-,(\diamond) \mathrm{S}_{\mathrm{KCl}} \mathrm{S}_{\mathrm{KI}} \mathrm{L}_{\mathrm{w}}-$, and $(-) \mathrm{S}_{\mathrm{KI}} \mathrm{L}_{\mathrm{w}}$-equilibrium, this work. (O) experimental data [60] (data point at $\mathrm{S}_{\mathrm{KCl}}-\mathrm{S}_{\mathrm{KI}}-\mathrm{L}_{\mathrm{w}}$ equilibrium is the averaged value over the data points given in [60]).

\subsection{Application of the eNRTL model to the description of gas hydrate equilibria}

Four different aqueous ternary or quaternary electrolyte systems of the type $\mathrm{H}_{2} \mathrm{O}+\mathrm{CA}+$ gas or $\mathrm{H}_{2} \mathrm{O}+\mathrm{C}_{1} \mathrm{~A}+\mathrm{C}_{2} \mathrm{~A}+$ gas have been modelled. The influence of the strong electrolytes $\mathrm{NaCl}$, $\mathrm{KCl}$ and $\mathrm{CaCl}_{2}$ on the $\mathrm{HL}_{\mathrm{w}} \mathrm{G}$-phase equilibrium obtained in mixtures containing the hydrate forming gases methane $\left(\mathrm{CH}_{4}\right)$ and carbon dioxide $\left(\mathrm{CO}_{2}\right)$, respectively, was investigated. Values of the eNRTL solvent-salt parameters $B_{\mathrm{CA}, \mathrm{w}, 0}, B_{\mathrm{CA}, \mathrm{w}, 1}$ and $B_{\mathrm{CA}, \mathrm{w}, 2}$ and $B_{\mathrm{w}, \mathrm{CA}, 0}$, $B_{\mathrm{w}, \mathrm{CA}, 1}$ and $B_{\mathrm{w}, \mathrm{CA}, 2}$ for $\mathrm{CA}=\mathrm{NaCl}, \mathrm{KCl}, \mathrm{CaCl}_{2}$ were retrieved from the Aspen Properties ${ }^{\circledR}$ data bank of the Aspen Engineering Suite and are listed in Table 5. Salt-salt-parameters were set to zero. The influence of the amount of gas dissolved in the liquid phase on the activity coefficient of the solvent species $\gamma_{x, \mathrm{w}}^{\mathrm{L}_{\mathrm{w}}}$ was neglected. With the eNRTL expression for $\gamma_{x, \mathrm{w}}^{\mathrm{L}_{\mathrm{w}}}$ (eq. (8) in combination with eq. (17) and eq. (40) for $j \equiv \mathrm{w}$ ), modelling calculations have been carried out on the three-phase $\mathrm{H}-\mathrm{L}_{\mathrm{w}}-\mathrm{G}$-boundary $p$-T-lines of ternary and quaternary mixtures at different values of the ionic strengths involving gas hydrate phases.

Table 5 Ion-pair-water eNRTL parameters $B_{\mathrm{CA}, \mathrm{w}, 0}, B_{\mathrm{CA}, \mathrm{w}, 1}$ and $B_{\mathrm{CA}, \mathrm{w}, 2}$, and water-ionpair eNRTL parameters $B_{\mathrm{w}, \mathrm{CA}, 0}, B_{\mathrm{w}, \mathrm{CA}, 1}$ and $B_{\mathrm{w}, \mathrm{CA}, 2}$ for $\mathrm{CA}=\mathrm{NaCl}, \mathrm{KCl}, \mathrm{CaCl}_{2}$ required for obtaining $\tau_{\mathrm{CA}, \mathrm{w}}(T)$ and $\tau_{\mathrm{w}, \mathrm{CA}}(T)$ according to eqs. (43) and (44).

\begin{tabular}{lccc}
\hline Parameter $^{\mathrm{a}}$ & $\mathrm{NaCl}$ & $\mathrm{KCl}$ & $\mathrm{CaCl}_{2}$ \\
\hline$B_{\mathrm{CA}, \mathrm{w}, 0}$ & -3.789168 & -4.060085 & -5.06 \\
$B_{\mathrm{CA}, \mathrm{w}, 1} / \mathrm{K}$ & -216.3646 & -30.93534 & 0.0 \\
$B_{\mathrm{CA}, \mathrm{w}, 2}$ & -1.100418 & 1.42956 & 0.0 \\
$B_{\mathrm{w}, \mathrm{CA}, 0}$ & 5.980196 & 6.849537 & 10.472 \\
$B_{\mathrm{w}, \mathrm{CA}, 1} / \mathrm{K}$ & 841.5181 & 402.9818 & 0.0
\end{tabular}




\begin{tabular}{llll}
$B_{\mathrm{w}, \mathrm{CA}, 2}$ & 7.4335 & 0.206522 & 0.0 \\
\cline { 2 - 2 } a Retrieved from the data bank provided by Aspen Properties ${ }^{\circledR}$.
\end{tabular}

The Langmuir constant $C_{j i}$ was expressed by means of eqs. (A.1)-(A.3) in terms of the microscopic quantities $\sigma_{j \mathrm{w}}, \varepsilon_{j \mathrm{w}}, a_{j}, z_{i}$ and $R_{i}$. The Kihara parameters $\sigma_{j \mathrm{w}}$ and $\varepsilon_{j \mathrm{w}}$ were taken from our previous study [34], whereas the numerical values for the hard core radius $a_{j}$ were taken from [35]. The complete set of Kihara parameters, including a comparison with values published in the literature for $\sigma_{j \mathrm{w}}$ and $\varepsilon_{j \mathrm{w}}$ [1,35], is compiled in Table 6. With regard to the radius $R_{i}$ of the cavity of type $i, R_{i}=395 \mathrm{pm}$ was used for the small $5^{12}$ - and $R_{i}=433 \mathrm{pm}$ for the large $5^{12} 6^{2}$-cavity of sI hydrates, respectively, whereas $R_{i}=391 \mathrm{pm}$ was used for the small $5^{12}$ - and $R_{i}=473 \mathrm{pm}$ for the large $5^{12} 6^{4}$-cavity of sII hydrates, respectively [35]. For the coordination number $z_{i}$, the value 20 and 24 was employed for the small and large cavity of structure I, respectively, whereas the value of 20 and 28 was used for $z_{i}$ of the small and the large cavity of structure II, respectively [35].

Table 6 Kihara parameters. $\sigma_{j \mathrm{w}}$ - and $\varepsilon_{j \mathrm{w}}$-values obtained from a previous regression [34] along with corresponding literature data; $a_{j}$-values taken from $[1,35]$

\begin{tabular}{llll}
\hline & $a_{j} / \mathrm{pm}$ & $\sigma_{j \mathrm{w}} / \mathrm{pm}$ & $\varepsilon_{j \mathrm{w}} /\left(k_{\mathrm{B}} \mathrm{K}\right)$ \\
\hline $\mathrm{CH}_{4}$ & $38.34^{\mathrm{a}}$ & $315.03^{\mathrm{b}}$ & $158.71^{\mathrm{b}}$ \\
& & $314.393^{\mathrm{c}}$ & $155.593^{\mathrm{c}}$ \\
& & $316.50^{\mathrm{a}}$ & $154.54^{\mathrm{a}}$ \\
$\mathrm{CO}_{2}$ & $68.05^{\mathrm{a}}$ & $298.30^{\mathrm{b}}$ & $171.41^{\mathrm{b}}$ \\
& & $297.638^{\mathrm{c}}$ & $175.405^{\mathrm{c}}$ \\
& & $298.18^{\mathrm{a}}$ & $168.77^{\mathrm{a}}$ \\
\hline
\end{tabular}

${ }^{a} 2^{\text {nd }}$ ed. of the monograph of Sloan [35].

${ }^{\mathrm{b}}$ Used in this study. Taken from our previous publication (data set of "Model 3") [34].

${ }^{c} 3^{\text {rd }}$ ed. of the monograph of Sloan and Koh [1].

\subsection{1 $H-\mathrm{L}_{w}-\mathrm{G}$-equilibrium in aqueous electrolyte systems containing methane}

Modelling calculations on the incipient hydrate forming in the electrolyte systems $\left\{\mathrm{H}_{2} \mathrm{O}+\mathrm{NaCl}+\mathrm{CH}_{4}\right\}, \quad\left\{\mathrm{H}_{2} \mathrm{O}+\mathrm{NaCl}+\mathrm{KCl}+\mathrm{CH}_{4}\right\}$ and $\left\{\mathrm{H}_{2} \mathrm{O}+\mathrm{NaCl}+\mathrm{CaCl}_{2}+\mathrm{CH}_{4}\right\}$ were carried out for mixtures of given initial salt concentration in the liquid phase. The modelled results are presented in Figure 4 in terms of $p-T-\mathrm{H}-\mathrm{L}_{\mathrm{w}}-\mathrm{G}$-phase boundary lines along with corresponding experimental data of Dholabhai et al. (1991) [61].

For the systems $\left\{\mathrm{H}_{2} \mathrm{O}+\mathrm{NaCl}+\mathrm{CH}_{4}\right\}$ and $\left\{\mathrm{H}_{2} \mathrm{O}+\mathrm{NaCl}+\mathrm{KCl}+\mathrm{CH}_{4}\right\}$ (Figure 4 a)), the model shows a good overall performance despite the relatively high pressure range $(2<p / \mathrm{MPa}<10)$ covered. The values for the Average Absolute Relative Deviation (AARD) between the experimental [61] and calculated pressures defined as

$$
\left\langle\frac{|\Delta p|}{p}\right\rangle=\frac{1}{N_{\text {exp data }}} \sum_{q=1}^{N_{\text {exp data }}} \frac{\left|p_{\text {exp }, q}-p_{\text {calc }, q}\right|}{p_{\text {exp }, q}}
$$

range from $2.8 \%$ for the mixture $\left\{\mathrm{H}_{2} \mathrm{O}+\mathrm{NaCl}+\mathrm{CH}_{4}\right\}$ with $\bar{x}_{\mathrm{NaCl}}=0.0094$ to approximately $7.0 \%$ for the two salt-system with $\bar{x}_{\mathrm{NaCl}}=0.0367$ and $\bar{x}_{\mathrm{KCl}}=0.0354$. The curves show the potential of the salts for acting as inhibitors with respect to the formation of gas hydrates since at $T=$ const the pressure rises with increasing salt concentration. 
While for the system $\left\{\mathrm{H}_{2} \mathrm{O}+\mathrm{NaCl}+\mathrm{CaCl}_{2}+\mathrm{CH}_{4}\right\}$ (Figure $4 \mathrm{~b}$ )), the temperature and pressure range $(265<T / \mathrm{K}<281,2<p / \mathrm{MPa}<10)$ as well as the AARD values relative to the data of Dholabhai et al. (1991) [61] are comparable with those of the previous mixtures (between $2 \%$ and $6 \%$ ), the overall electrolyte concentration is smaller. However, since the 21-electrolyte $\mathrm{CaCl}_{2}$ possesses a bivalent cation, the ionic strength range is not smaller. Not only does $\mathrm{CaCl}_{2}$ release three ions in solution, but the $\mathrm{Ca}^{2+}$-ion does also have a higher charge and charge density than the $\mathrm{K}^{+}$-ion, leading to an increased hydration of the $\mathrm{Ca}^{2+}$-ion [62]. Nevertheless, the performance of the eNRTL model for this mixture is still very good.
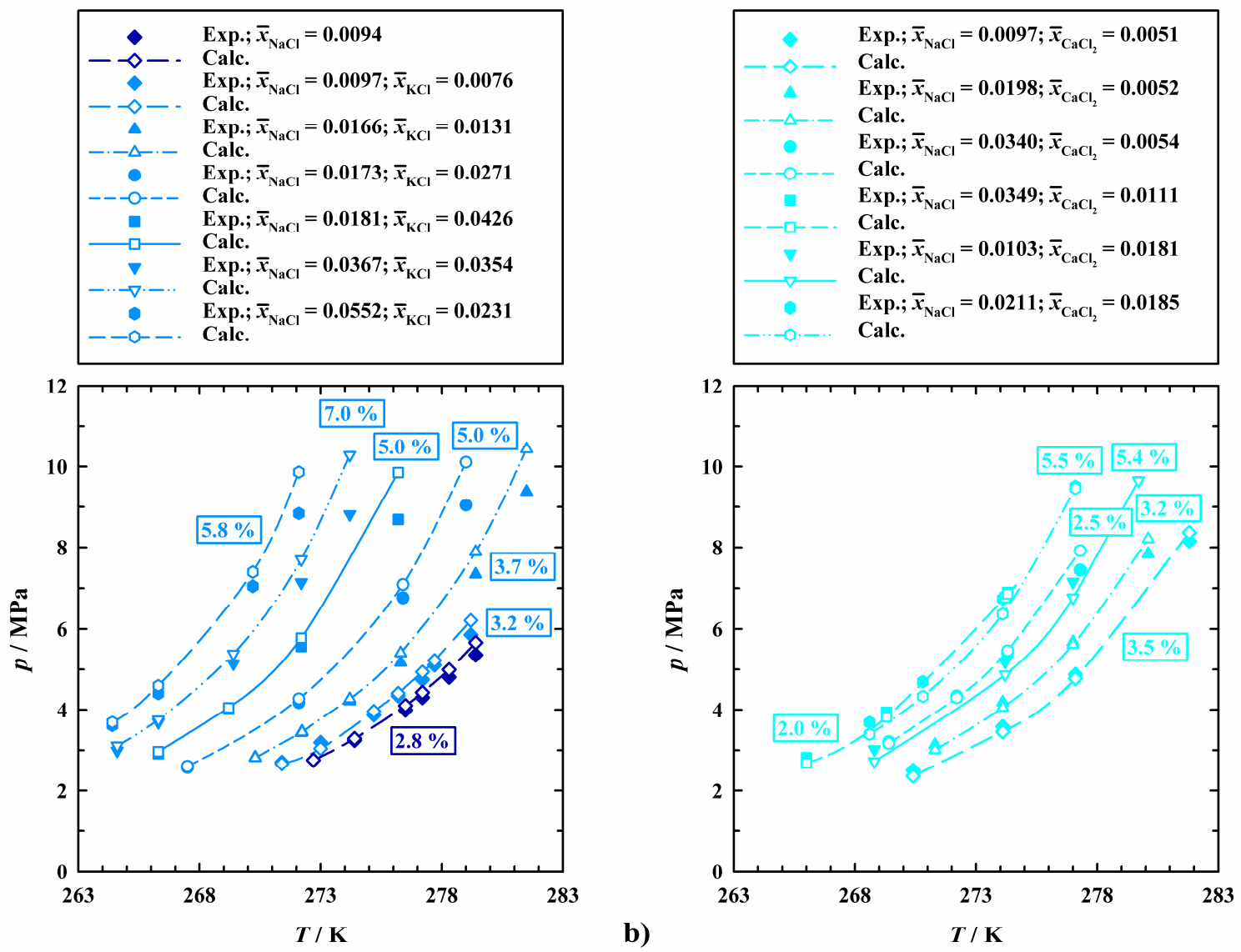

Figure $4 \mathrm{H}-\mathrm{L}_{\mathrm{w}}-\mathrm{G}-p-T$ equilibrium data in a) the systems $\left\{\mathrm{H}_{2} \mathrm{O}+\mathrm{NaCl}+\mathrm{CH}_{4}\right\}$ and $\left\{\mathrm{H}_{2} \mathrm{O}+\mathrm{NaCl}+\mathrm{KCl}+\mathrm{CH}_{4}\right\}$ and in b) the system $\left\{\mathrm{H}_{2} \mathrm{O}+\mathrm{NaCl}+\mathrm{CaCl}_{2}+\mathrm{CH}_{4}\right\}$ at given overall mole fractions of the electrolytes. Lines and hollow symbols: modelling, solid symbols: experimental data of Dholabhai et al. (1991) [61].

\subsection{2 $\mathrm{H}-\mathrm{L}_{\mathrm{w}}-\mathrm{G}$-equilibrium in aqueous electrolyte systems containing carbon dioxide}

Incipient hydrate forming conditions have additionally been modelled for aqueous systems containing the same electrolytes as the ones treated in section 3.2.1, but with carbon dioxide instead of methane as the hydrate forming component (Figure 5). 

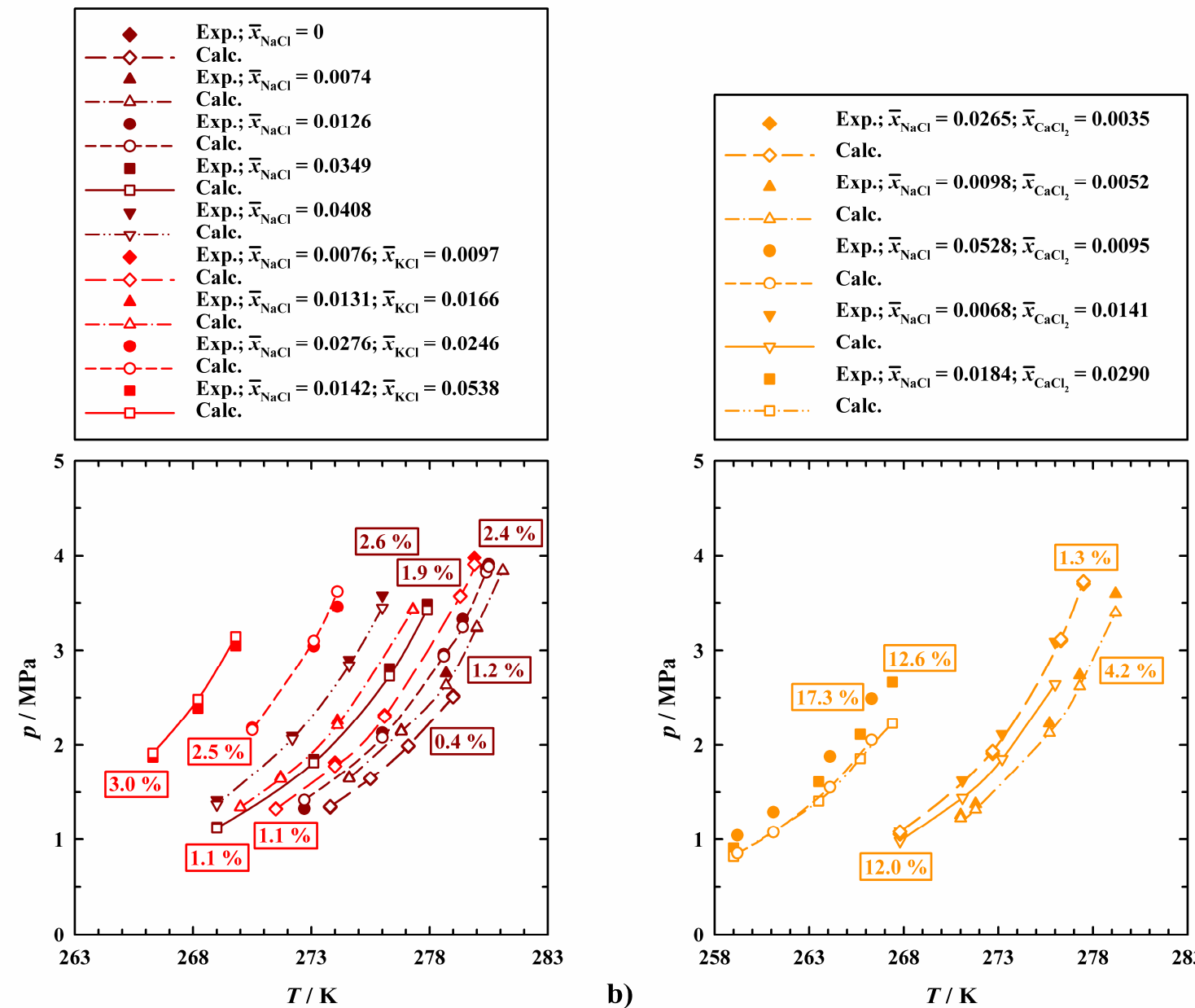

a)

$T / \mathbf{K}$

b)

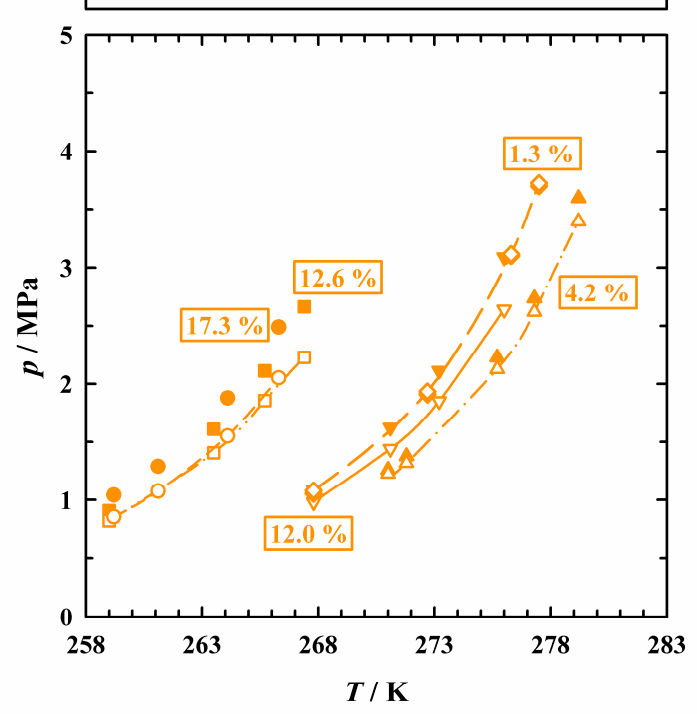

Figure $5 \mathrm{H}-\mathrm{L}_{\mathrm{w}}-\mathrm{G}-p$ - $T$-equilibrium in a) the systems $\left\{\mathrm{H}_{2} \mathrm{O}+\mathrm{CO}_{2}\right\},\left\{\mathrm{H}_{2} \mathrm{O}+\mathrm{NaCl}+\mathrm{CO}_{2}\right\}$ and $\left\{\mathrm{H}_{2} \mathrm{O}+\mathrm{NaCl}+\mathrm{KCl}+\mathrm{CO}_{2}\right\}$, respectively, and in b) the quarternary system $\left\{\mathrm{H}_{2} \mathrm{O}+\mathrm{NaCl}+\mathrm{CaCl}_{2}+\mathrm{CO}_{2}\right\}$ at given overall mole fractions of the electrolytes. Lines and hollow symbols: modelling, solid symbols: experimental data of Dholabhai et al. (1993) [63].

As can be seen in Figure 5 a), for the single salt system $\left\{\mathrm{H}_{2} \mathrm{O}+\mathrm{NaCl}+\mathrm{CO}_{2}\right\}$ the maximum overall mole fraction of $\mathrm{NaCl}$ is $\bar{x}_{\mathrm{NaCl}}=0.04$, whereas for the system $\left\{\mathrm{H}_{2} \mathrm{O}+\mathrm{NaCl}+\mathrm{KCl}+\mathrm{CO}_{2}\right\} \quad \bar{x}_{\mathrm{NaCl}, \text { max }}+\bar{x}_{\mathrm{KCl}, \text { max }} \approx 0.07$. Within the pressure range of $0<p / \mathrm{MPa}<4$ a very good performance of the eNRTL model is observed for this system with AARD values varying mostly between 1 and $2 \%$. Like in the mixtures with $\mathrm{CH}_{4}$ (Figure 4), the curves in Figure 5 a) show that the strong electrolytes $\mathrm{NaCl}$ and $\mathrm{KCl}$ act as hydrate inhibitors, causing the temperature (at a given pressure) to fall, or the pressure (at a given temperature) to rise for hydrate formation with increasing salt mole fraction.

Our study is completed by the results of the modelling of the incipient hydrate forming conditions in the quaternary mixture $\left\{\mathrm{H}_{2} \mathrm{O}+\mathrm{NaCl}+\mathrm{CaCl}_{2}+\mathrm{CO}_{2}\right\}$. The results (Figure $5 \mathrm{~b}$ )) reveal that on a similar pressure interval as in the previous example, higher deviations between calculated and experimental pressures are observed than for the other systems. Whereas the result for the two lowest concentrated mixtures is fairly good with AARD values with respect to the data of Dholabhai et al. (1993) [63] of $1.3 \%$ and $4.2 \%$ at $\bar{x}_{\mathrm{NaCl}}=0.0265$ and $\bar{x}_{\mathrm{CaCl}_{2}}=0.0035$, and $\bar{x}_{\mathrm{NaCl}}=0.0098$ and $\bar{x}_{\mathrm{CaCl}_{2}}=0.0052$, respectively, the deviations 
increase up to values between $12 \%$ and $18 \%$ for the higher concentrated solutions. This is most probably due to the influence of the significantly higher degree of hydration of the $\mathrm{Ca}^{2+}$-ion rather than due to neglecting the solubility of the $\mathrm{CO}_{2}$ in the liquid phase in calculating $\gamma_{x, \mathrm{w}}^{\mathrm{L}_{\mathrm{w}}}$. Moreover, since the salt-salt parameters between $\mathrm{NaCl}$ and $\mathrm{CaCl}_{2}$ were not known, the interaction between the ions of the two salts had to be neglected as well.

\section{Conclusion}

In this article, it is demonstrated by numerous examples that the eNRTL-model of Chen and co-workers [15,20-23] has been implemented successfully in a Java programme. The eNRTL model implementation in turn was incorporated in a previously developed in-house programme enabling to perform, among other features, predictive calculations on $\mathrm{H}-\mathrm{L}_{\mathrm{w}}-\mathrm{G}$ phase boundaries of systems involving gas hydrates.

The correctness of the code has been verified by calculations on osmotic coefficients and mean ionic activity coefficients of binary solutions of strong electrolytes and ternary mixtures of the type $\left\{\right.$ water + salt $_{1}+$ salt $\left._{2}\right\}$ where the constituting salts have one ion in common. The examples selected for this purpose were taken from the original articles on the eNRTL model by Chen and Evans [21] and Bollas et al. [23]. In case of the $\left\{\mathrm{H}_{2} \mathrm{O}+\mathrm{NaCl}+\mathrm{LiCl}\right\}$-mixture, the shape of the osmotic coefficient curves could not reproduced with the salt-salt-parameter values given in [21]. However, upon incrementing each of them by one, it turned out that the curves were reproduced at least qualitatively. Since the results of that calculation had also been checked independently by means of the computer algebra software "mathcad", it is suspected that the sequence of the salt-salt coefficients given in [21] was reported erroneously. The data of the remaining systems could be reproduced from the original work. The results reveal once more, that the eNRTL model provides an accurate description of liquid phase non-ideality of the electrolyte systems over the ranges of state conditions investigated. The model does not only correlate thermodynamic data, but possesses also predictive capability using model parameters determined exclusively from data of the constituting binaries and ternary salt-salt systems with a common ion [21].

The model was subsequently used in the purely predictive modelling of $\mathrm{H}-\mathrm{L}_{\mathrm{w}}-\mathrm{G}$-hydrate phase equilibria of mixtures with water, one or two of the salts $\mathrm{NaCl}, \mathrm{KCl}$ and $\mathrm{CaCl}_{2}$ and methane or carbon dioxide using a set of Kihara parameters obtained in an earlier study [34]. In calculating $\gamma_{x, \mathrm{w}}^{\mathrm{L}_{\mathrm{w}}}$, the presence of $\mathrm{CO}_{2}$ in the liquid phase was neglected. Salt-saltinteraction parameters were also neglected. Despite of these simplifications, the $p$ - $T$-values obtained reveal a good overall performance of the model leading to average absolute relative deviations ranging from $2 \%$ to $7 \%$. Only at higher ionic strengths and when the bivalent $\mathrm{Ca}^{2+}$-ion gets involved, the deviations increase remarkably to reach approximately $20 \%$. In a future work this deficiency may be overcome by implementing a model version that takes hydration into account [62]. Nevertheless, in view of the simplifications introduced, it can be stated that the results are quite satisfying from an engineering point of view.

\section{Acknowledgement}

This work has been carried out within the framework of the ANR (French Research Agency) project SECOHYA and the European iCap research project (EU FP7, GA No. 241393). We are grateful to Peter J. Herslund for inspiring discussions on several topics related to the thermodynamics of gas hydrates. 


\section{List of symbols}

Normal symbols

$a \quad$ a) Spherical hard core radius in Kihara potential $[a]=\mathrm{pm}$; b) coefficients in Henry's constant correlation with temperature, dimensionless

$A_{\phi} \quad$ Debye-Hückel constant, dimensionless

A Coefficient used in the temperature correlation for the eNRTL-parameters $\tau_{m m^{\prime}}$ and $\tau_{m^{\prime} m} .\left[A_{1}\right]=\mathrm{K},\left[A_{3}\right]=\mathrm{K}^{-1}, A_{0}$ and $A_{2}$, dimensionless

AARD Average absolute relative deviation

$\alpha \quad$ Nonrandomness factor, dimensionless

$b \quad$ Coefficient used in the correlation for $\Delta_{\beta}^{\mathrm{L}_{\mathrm{w}}} C_{p, \mathrm{~m}, \mathrm{w}}^{\circ}\left(T, p_{0}\right)$ with temperature, $[b]=\mathrm{J} \mathrm{K}^{-2} \mathrm{~mol}^{-1}$

$b_{j} \quad$ Molality of a chemical species $j,\left[b_{j}\right]=\mathrm{mol} \mathrm{kg}^{-1}$

$\bar{b}_{k} \quad$ Overall or apparent molality of component $k,\left[\bar{b}_{k}\right]=\mathrm{mol} \mathrm{kg}^{-1}$

$B \quad$ Coefficient used in temperature correlation of eNRTL-parameters $\tau_{\mathrm{CA}, m}, \tau_{m, \mathrm{CA}}$, $\tau_{\mathrm{AC}, \mathrm{AC}}, \tau_{\mathrm{AC}^{\prime}, \mathrm{AC}}, \tau_{\mathrm{CA}, \mathrm{CA}^{\prime}}, \tau_{\mathrm{CA}^{\prime}, \mathrm{CA}} \cdot\left[B_{1}\right]=\mathrm{K}, B_{0}$ and $B_{2}$, dimensionless

$c$

Constant used for calculating the effective mole fractions $X$ in eNRTL equations. $c_{j}$ to be set to zero for $j \in S_{m}$, and to $\left|z_{j}\right|$ for $j \in S_{\mathrm{C}} \cup S_{\mathrm{A}}$, respectively

$C \quad$ a) Langmuir constant, $[C]=\mathrm{Pa}^{-1}$; b) heat capacity, $[C]=\mathrm{J} \mathrm{K}^{-1}$

$\Delta \quad$ Finite difference between two values of a quantity

$\Delta_{\alpha}^{\beta} \quad$ Finite difference between two values of a quantity for a process from initial state $\alpha$ to final state $\beta$

$e \quad$ Elementary charge, $e=(1.602176565 \pm 0.000000035) \times 10^{-19} \mathrm{C}[41]$

eNRTL Electrolyte Non-Random-Two-Liquid model for the excess Gibbs energy

EOS Equation of state

$\varepsilon_{j \mathrm{w}} \quad$ Characteristic energy between guest $j$ and host water molecule $\mathrm{w},[\varepsilon]=\mathrm{J}$

$\varepsilon_{0} \quad$ Permittivity of free space, $\left[\varepsilon_{0}\right]=8.854187817 \times 10^{12} \mathrm{Fm}^{-1}[41]$

$\varepsilon_{\mathrm{r}} \quad$ Relative permittivity, dimensionless

$f \quad$ Fugacity, $[f]=\mathrm{Pa}$

$g$

$G$

Molar interaction energy in the framework of the eNRTL model, $[g]=\mathrm{J} \mathrm{mol}^{-1}$

a) Gibbs energy, $[G]=\mathrm{J}$; b) Boltzmann kind factor, dimensionless

$\gamma \quad$ Activity coefficient, dimensionless

I Ionic strength, dimensionless

$k_{\mathrm{B}} \quad$ Boltzmann constant, $k_{\mathrm{B}}=(1.3806488 \pm 0.0000013) \times 10^{-23} \mathrm{~J} \mathrm{~K}^{-1}[41]$

$k_{\mathrm{H}, j, \mathrm{w}} \quad$ Henry's constant of gas $j$ in water, $\left[k_{\mathrm{H}, j, \mathrm{w}}\right]=\mathrm{Pa}$

$m \quad$ Mass, $[m]=\mathrm{kg}$

$M \quad$ Molar mass, $[M]=\mathrm{g} \mathrm{mol}^{-1}$

$\mu \quad$ Chemical potential of a species or component, $[\mu]=\mathrm{J} \mathrm{mol}^{-1}$ 
$n \quad$ Amount of substance or mole number, $[n]=$ mol

$N \quad$ Number in general, dimensionless

NRTL Non-Random-Two-Liquid model for the excess Gibbs energy

$N_{\mathrm{Av}} \quad$ Avogadro constant, $N_{\mathrm{Av}}=(6.02214129 \pm 0.00000027) \times 10^{23} \mathrm{~mol}^{-1}$ [41]

$v \quad$ a) Stoichiometric coefficient, dimensionless; b) number of water molecules per number of guest molecules in a cage of type $i$ (hydration number), dimensionless

$p \quad$ Pressure, $[p]=\mathrm{Pa}$

$R \quad$ Molar gas constant, $R=(8.3144621 \pm 0.0000075) \mathrm{J} \mathrm{mol}^{-1} \mathrm{~K}^{-1}$ [41]

$\rho \quad$ a) Density, $[\rho]=\mathrm{kg} \mathrm{m}^{-3}$; b) Closest approach parameter, dimensionless

$T \quad$ Absolute temperature, $[T]=\mathrm{K}$

$\tau \quad$ Interaction energy eNRTL-parameter, dimensionless

$\theta_{j i} \quad$ Fraction of sites occupied by species $j$ in cavity of type $i$, dimensionless

$S \quad$ Given set (here of indices) in general

SAFT Statistical Fluid Associated Solution Theory

$\sigma_{j \mathrm{w}} \quad$ Core distance at which attraction and repulsion between guest species $j$ and host water molecule $\mathrm{w}$ in host-pair balance each other, $\left[\sigma_{j \mathrm{w}}\right]=\mathrm{pm}$

$V \quad$ Volume, $[V]=\mathrm{m}^{3}$

VRE Variable Range for Electrolytes; particular model variant of the SAFT-EOS

$\bar{w}_{k} \quad$ Overall or apparent weight fraction of component $k$, dimensionless

$x_{j} \quad$ Mole fraction of chemical species $j$, dimensionless

$\bar{x}_{k} \quad$ Overall or apparent mole fraction of component $k$, dimensionless

$X_{j} \quad$ Effective mole fractions of species $j$, dimensionless

$Y_{j} \quad$ Ionic charge fractions of ionic species $j=\mathrm{C}, \mathrm{A}$, dimensionless

$z_{j} \quad$ Charge number of species $j$, positive for cations, negative for anions, zero for neutral species, dimensionless

Subscripts
A, $A^{\prime}, A^{\prime \prime}$ Anionic species $A^{\left|z_{A}\right|-}$
$b \quad$ Indicating reference to molality as composition
$\mathrm{C}, \mathrm{C}^{\prime}, \mathrm{C}^{\prime \prime} \quad$ Cationic species $\mathrm{C}^{\mathrm{Z}^{+}}$
CA Binary salt $\mathrm{C}_{v_{\mathrm{C}}} \mathrm{A}_{v_{\mathrm{A}}}$, composed of $v_{\mathrm{C}}$ cations, $\mathrm{C}^{\mathrm{z}_{\mathrm{C}}{ }^{+}}$, and $v_{\mathrm{A}}$ anions, $\mathrm{A}^{\left|z_{\mathrm{A}}\right|-}$
cav Referring to type of cavity
exp data Referring to experimental data
fus Property referring to the process of fusion
g Referring to type of guest species
$i \quad$ Type of cavity
$j, l \quad$ Chemical species
$k \quad$ Indicating components (molecular and strong electrolyte components) 


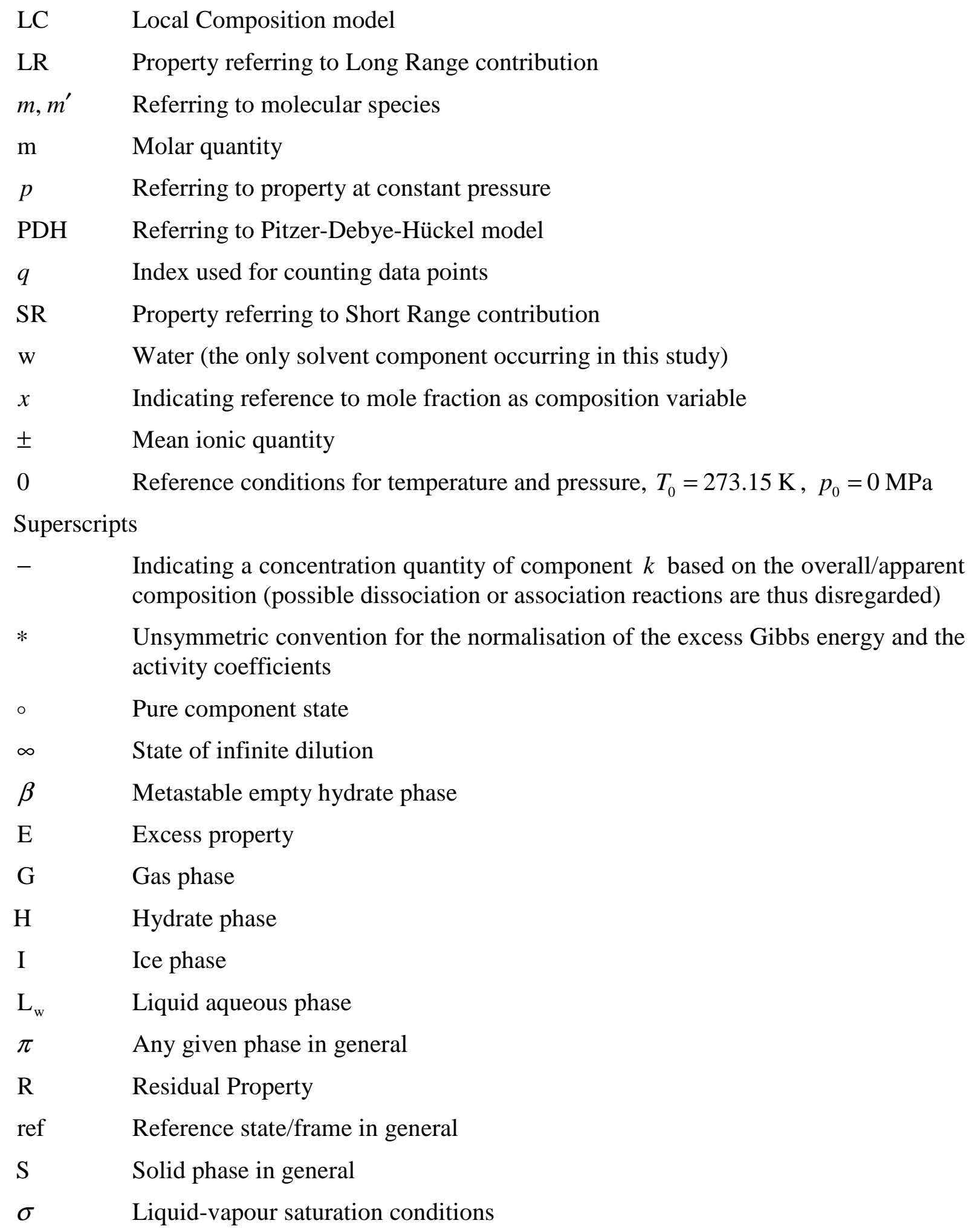

\section{A Appendix}

\section{A.1 The cell potential function and its relation to the Langmuir constant}

The Langmuir constant $C_{j i}$ reflects the intermolecular forces between the guest molecule $j$ and the water molecules constituting the cavity of type $i$ by which it is enclosed. Since these forces are in turn related to the host-guest interaction potential, $C_{j i}$ can be calculated from a suitable expression for the potential energy $\omega_{j i}$ of species $j$ in cavity $i$. In this study, the interaction potential energy was assumed to be describable by the cell potential $\omega_{j i}(r)$ 
presented by Parrish and Prausnitz [43] which assumes the cavities to be of spherically symmetrical geometry. In accordance with the suggestion of MacKoy and Sinanoğlu [45] this cell potential is based on the Kihara potential [64] as the underlying intermolecular pair potential energy model. In this model the effect of the finite size of the different interacting molecules is taken into account by ascribing a hard core to each molecule [45].

To arrive at the expression for $\omega_{j i}(r)$, the integral effect of the interactions between guest $j$ and each of the nearest neighbouring host molecules within the type $i$ cavity is obtained by means of the averaging procedure used in the cell theory of Lennard-Jones and Devonshire [65]. In applying the averaging method [65] to the assembly of the guest species and its nearest neighbouring spherically arranged water molecules, the guest molecule $j$ is regarded as a spherical hard core of radius $a_{j}[66]$, whereas the water molecules are approximated by point molecules. This leads to the following cell potential energy function [43]

$$
\omega_{j i}(r)=2 z_{i} \varepsilon_{j \mathrm{w}}\left(\frac{\sigma_{j \mathrm{w}}^{12}}{R_{i}^{11} r}\left(\delta_{j i}(12)+\frac{a_{j}}{R_{i}} \delta_{j i}(11)\right)-\frac{\sigma_{j \mathrm{w}}^{6}}{R_{i}^{5} r}\left(\delta_{j i}(4)+\frac{a_{j}}{R_{i}} \delta_{j i}(5)\right)\right)
$$

where

$$
\delta_{j i}(N)=\frac{1}{N}\left(\left(1-\frac{r}{R_{i}}-\frac{a_{j}}{R_{i}}\right)^{-N}-\left(1+\frac{r}{R_{i}}-\frac{a_{j}}{R_{i}}\right)^{-N}\right)
$$

In eq. (A.1) and (A.2), $r$ is the distance between the centre of the cavity and the centre of the guest molecule, whereas $\sigma_{j \mathrm{w}}$ stands for the core distance at which attraction and repulsion balance each other. $\varepsilon_{j \mathrm{w}}$ denotes the characteristic maximum attractive potential energy. Along with $a_{j}, \sigma_{j \mathrm{w}}$ and $\varepsilon_{j \mathrm{w}}$ are referred to as the "Kihara parameters" which depend on the properties of guest species only. $z_{i}$ and $R_{i}$ are the coordination number and the radius of the spherically assumed cavity $i$. They have been uniquely determined for each cavity from $\mathrm{x}$-ray diffraction experiments and are regarded as independent of the guest molecule [1].

It should be pointed out here that throughout the literature two different coordinate systems are used (as e.g. in $[43,45,64,67]$ ) for expressing the distance quantities and parameters appearing in the Kihara potential energy expression. Often, like in eqs. (A.1) and (A.2), different standards are even used in the same equation [68]: whereas $\sigma_{j \mathrm{w}}$ measures the shortest distance between the edge of the core and the water point molecule, $r$ refers to the distance measured relative to the centre of the guest molecule. The various standards used for the distance quantities and the possible confusion arising from the inconsistent usage of these different standards have been reviewed by Bakker et al. (1996) [68] and Bakker (1998) [69].

The relation between the Langmuir constant $C_{j i}$ and the potential energy $\omega_{j i}(r)$ of the guest molecule $j$ in the spherically symmetrical cavity $i$ is given by

$$
C_{j i}=\frac{4 \pi}{k_{\mathrm{B}} T} \int_{0}^{R_{i}-a_{j}} \exp \left(-\frac{\omega_{j i}(r)}{k_{\mathrm{B}} T}\right) r^{2} d r
$$

where $T$ denotes the thermodynamic temperature and $k_{\mathrm{B}}$ the Boltzmann constant [41], respectively. Although $\omega_{j i}(r)$ is not defined at $r=0$, it can be shown that this discontinuity can be removed since the right-sided limes for $r \rightarrow 0+$ exists. Evaluation of the latter leads to 


$$
\lim _{r \rightarrow 0+} \omega_{j i}(r)=4 z_{i} \varepsilon_{j}\left(\frac{\sigma_{j}}{R_{i}-a_{j}}\right)^{6}\left(\left(\frac{\sigma_{j}}{R_{i}-a_{j}}\right)^{6}-1\right)
$$

The lower limit of integration in the expression of eq. (A.3) can thus be set to zero. However, $\omega_{j i}(r)$ possesses another discontinuity at $r=R_{i}-a_{j}$ which in contrast to the former is a singularity with a change in sign that can not be removed. When approaching $R_{i}-a_{j}$ from the left side, $\omega_{j i}(r)$ tends to $+\infty$, when $R_{i}-a_{j}$ is approached from the right sight, $\omega_{j i}(r)$ tends to $-\infty$. Therefore, since $\exp \left(-\omega_{j i}(r) / k_{\mathrm{B}} T\right)$ diverges when $R_{i}-a_{j}$ is approached from the right side, the upper integration limit in eq. (A.3) has to be set to $R_{i}-a_{j}$. The region between $R_{i}-a_{j}$ and $R_{i}$ is thus to be excluded from the integration interval.

\section{A.2 The description of the chemical potential of water in the liquid phase}

The difference between the chemical potential of water in the liquid and in the $\beta$-phase, $\Delta_{\beta}^{\mathrm{L}_{\mathrm{w}}} \mu_{\mathrm{w}}\left(T, p, \vec{x}^{\mathrm{L}_{\mathrm{w}}}\right)$, is calculated from the following classical thermodynamic relation

$$
\begin{aligned}
\frac{\Delta_{\beta}^{\mathrm{L}_{\mathrm{w}}} \mu_{\mathrm{w}}\left(T, p, \vec{x}^{\mathrm{L}_{\mathrm{w}}}\right)}{R T}= & \frac{\Delta_{\beta}^{\mathrm{L}_{\mathrm{w}}} \mu_{\mathrm{w}}^{\circ}\left(T_{0}, p_{0}\right)}{R T_{0}}-\int_{T_{0}}^{T} \frac{\Delta_{\beta}^{\mathrm{L}_{\mathrm{w}}} H_{\mathrm{m}, \mathrm{w}}^{\circ}\left(T, p_{0}\right)}{R T^{2}} d T+\int_{p_{0}}^{p} \frac{\Delta_{\beta}^{\mathrm{L}_{\mathrm{w}}} V_{\mathrm{m}, \mathrm{w}}^{\circ}(T, p)}{R T} d p \\
& +\ln a_{\mathrm{w}}^{\mathrm{L}_{\mathrm{w}}}\left(T, p, \vec{x}^{\mathrm{L}_{\mathrm{w}}}\right)
\end{aligned}
$$

where $\vec{x}^{\mathrm{L}_{\mathrm{w}}}$ and $a_{\mathrm{w}}^{\mathrm{L}_{\mathrm{w}}} \equiv a_{x, \mathrm{w}}^{\mathrm{L}_{\mathrm{w}}}$ denote the vector of independent mole fractions and the activity of water in the liquid phase, respectively. The activity of water is defined by means of its corresponding activity coefficient $\gamma_{x, \mathrm{w}}^{\mathrm{L}_{\mathrm{w}}}$ as

$$
a_{\mathrm{w}}^{\mathrm{L}_{\mathrm{w}}}=x_{\mathrm{w}}^{\mathrm{L}_{\mathrm{w}}} \gamma_{x, \mathrm{w}}^{\mathrm{L}_{\mathrm{w}}}
$$

$T_{0}=273.15 \mathrm{~K}$ and $p_{0}=0 \mathrm{MPa}$ in eq. (A.5) are reference values for temperature and pressure [34]. $\Delta_{\beta}^{\mathrm{L}_{\mathrm{w}}} \mu_{\mathrm{w}}^{\circ}\left(T_{0}, p_{0}\right)$ is the chemical potential difference at standard conditions. Assuming a linear empirical relationship for the molar isobaric heat capacity difference according to

$$
\Delta_{\beta}^{\mathrm{L}_{\mathrm{w}}} C_{\mathrm{m}, \mathrm{w}}^{\circ}\left(T, p_{0}\right)=\Delta_{\beta}^{\mathrm{L}_{\mathrm{w}}} C_{\mathrm{m}, \mathrm{w}}^{\circ}\left(T_{0}, p_{0}\right)+b\left(T-T_{0}\right),
$$

and regarding the corresponding molar volume difference $\Delta_{\beta}^{\mathrm{L}_{\mathrm{w}}} V_{\mathrm{m}, \mathrm{w}}^{\circ}(T, p)$ as constant by using its value at reference conditions, $\Delta_{\beta}^{\mathrm{L}_{\mathrm{w}}} V_{\mathrm{m}, \mathrm{w}}^{\circ}\left(T_{0}, p_{0}\right)$, the integration of eq. (A.5) leads to eq. (4) when eqs. (A.6) and (A.7) are additionally taken into account. Thereby, use had to be made of the thermodynamic relationship $\Delta_{\beta}^{\mathrm{L}_{\mathrm{w}}} C_{\mathrm{m}, \mathrm{w}}^{\circ}\left(T, p_{0}\right)=\left(\partial \Delta_{\beta}^{\mathrm{L}_{\mathrm{w}}} H_{\mathrm{m}, \mathrm{w}}^{\circ}\left(T, p_{0}\right) / \partial T\right)_{p, \vec{x}}$.

\section{A.3 On activity coefficients and the osmotic coefficient}

The activity coefficient $\gamma_{x, j}$ describing the deviation of a given phase from an appropriately defined ideal mixture (mostly applied to quantify liquid phase non-idealities) can be derived from an expression for the excess molar Gibbs energy $G_{\mathrm{m}}^{\mathrm{E}}$ according to

$$
\ln \gamma_{x, j}=\frac{1}{R T}\left(\frac{\partial\left(n G_{\mathrm{m}}^{\mathrm{E}}\right)}{\partial n_{j}}\right)_{T, p, n_{l \neq j}}
$$

where $n$ is the total amount of substance on the basis of species and $n_{j}$ is the amount of substance of species $j$. With the symmetrically referenced activity coefficient $\gamma_{x, j}$, the unsymmetrically referenced activity coefficient $\gamma_{x, j}^{*}$ can be derived by 


$$
\gamma_{x, j}^{*}=\frac{\gamma_{x, j}}{\gamma_{x, j}^{\infty}} \quad\left(\text { for all } j \in\left\{S_{m} \cup S_{\mathrm{C}} \cup S_{\mathrm{A}}\right\} \backslash\{\mathrm{w}\}\right)
$$

where $\gamma_{x, j}^{\infty}$ stands for the activity coefficient at infinite dilution which is defined by

$$
\gamma_{x, j}^{\infty}=\lim _{x_{\mathrm{w}} \rightarrow 1} \gamma_{x, j}
$$

Care has to be taken when deriving activity coefficients of ions at infinite dilution in multicomponent electrolyte systems in regard of whether or not this limiting value does exist in a strict mathematical sense (see remarks in appendix A.4).

The activity coefficient refers to the mole fraction (index $x$ ) as composition variable. Conversion to the value referring to molality (index $b$ ) is performed by

$$
\gamma_{b, j}^{*}=\gamma_{x, j}^{*} x_{\mathrm{w}} \quad\left(\text { for all } j \in\left\{S_{m} \cup S_{\mathrm{C}} \cup S_{\mathrm{A}}\right\} \backslash\{\mathrm{w}\}\right)
$$

The mean ionic activity coefficient $\gamma_{x, \mathrm{CA}, \pm}$ is, in contrast to the activity coefficient of the individual ions, an experimentally accessible quantity. It is defined in terms of the activity coefficients of the cation and the anion constituting the corresponding ion pair through

$$
\ln \gamma_{x, \mathrm{CA}, \pm}=\frac{v_{\mathrm{C}, \mathrm{CA}} \ln \gamma_{x, \mathrm{C}}+v_{\mathrm{A}, \mathrm{CA}} \ln \gamma_{x, \mathrm{~A}}}{v_{\mathrm{C}, \mathrm{CA}}+v_{\mathrm{A}, \mathrm{CA}}}=\frac{z_{\mathrm{C}} \ln \gamma_{x, \mathrm{~A}}+\left|z_{\mathrm{A}}\right| \ln \gamma_{x, \mathrm{C}}}{z_{\mathrm{C}}+\left|z_{\mathrm{A}}\right|}
$$

where $v_{\mathrm{C}, \mathrm{CA}}$ and $v_{\mathrm{A}, \mathrm{CA}}$ is the cationic and anionic stoichiometric coefficient of the cationanion combination, respectively, and $z_{\mathrm{C}}$ and $z_{\mathrm{A}}$ is the charge number of the cation and the anion, respectively.

The (molal) osmotic coefficient $\phi$ is defined in terms of the activity coefficient of the solvent $\gamma_{x, \mathrm{w}}$ as [9]

$$
\phi=-\frac{\ln x_{\mathrm{w}}+\ln \gamma_{x, \mathrm{w}}}{M_{\mathrm{w}} \sum_{j \in\left\{S_{m} \cup S_{\mathrm{C}} \cup S_{\mathrm{A}}\right\} \backslash\{\mathrm{w}\}} b_{j}}
$$

where $b_{j}$ designates the molality of species $j$.

\section{A.4 The short range eNRTL-contribution to the activity coefficient for the ionic species}

To derive the expressions for the activity coefficients of the ionic species, the calculation of the first partial derivative of the $G_{\mathrm{SR}}^{\mathrm{E}}$-function with respect to $n_{j}$, the mole number of species $j$, is required. Since the ionic charge fractions $Y_{\mathrm{C}}$ and $Y_{\mathrm{A}}$ appear in the expression for $G_{\mathrm{SR}}^{\mathrm{E}}$ (explicitly and implicitly via the mixing rules for the concentration dependent model parameters), this step involves the calculation of $\left(\partial Y_{\mathrm{C}} / \partial n_{j^{\prime}}\right)_{T, p, n_{l \neq j^{\prime \prime}}}$ and $\left(\partial Y_{\mathrm{A}} / \partial n_{j^{\prime}}\right)_{T, p, n_{l \neq j^{\prime}}}$. Calculating $\left(\partial Y_{j} / \partial n_{j^{\prime}}\right)_{T, p, n_{l \neq j}}$ for $j=\mathrm{C}$ (for all $\mathrm{C} \in S_{\mathrm{C}}$ ), implying $j^{\prime \prime}=\mathrm{C}^{\prime \prime}$ (for all $\mathrm{C}^{\prime \prime} \in S_{\mathrm{C}}$ ), or $j=\mathrm{A}$ (for all $\mathrm{A} \in S_{\mathrm{A}}$ ), implying $j^{\prime \prime}=\mathrm{A}^{\prime \prime}$ (for all $\mathrm{A}^{\prime \prime} \in S_{\mathrm{A}}$ ), leads to

$$
\left(\frac{\partial Y_{j}}{\partial n_{j^{\prime}}}\right)_{T, p, n_{l \neq j^{\prime}}}=\left\{\begin{array}{l}
z_{j} Y_{j}\left(1-Y_{j}\right) /\left(n X_{j}\right) \text { for } j^{\prime}=j \\
-z_{j^{\prime \prime}} Y_{j^{\prime \prime}} Y_{j} /\left(n X_{j^{\prime \prime}}\right) \text { for } j^{\prime}=j^{\prime \prime}(\neq j), \\
0 \text { for } j^{\prime} \neq j, j^{\prime \prime}
\end{array}\right.
$$

where it is understood that the indices $j$ and $j^{\prime \prime}$ are taken from the same set of indices of ionic species, i.e., either cationic or anionic species, respectively, but that $j \neq j^{\prime \prime} . j^{\prime} \neq j, j^{\prime \prime}$ 
means that $j^{\prime}$ originates from a set of a different type of species. In other words, the differentiation leads to the result that $\left(\partial Y_{\mathrm{C}} / \partial n_{j^{\prime}}\right)_{T, p, n_{l \neq j}}$ vanishes only for all $j^{\prime} \in S_{m} \cup S_{\mathrm{A}}$, but not for $j^{\prime} \in S_{\mathrm{C}}$ (the inverse holds for the derivative $\left(\partial Y_{\mathrm{A}} / \partial n_{j^{\prime}}\right)_{T, p, n_{\neq j^{\prime}}}$, i.e., it vanishes for all $j^{\prime} \in S_{m} \cup S_{\mathrm{C}}$, but not for $\left.j^{\prime} \in S_{\mathrm{A}}\right)$. While the derivative vanishes in any case if it the differentiation is executed with respect to $n_{m}\left(m \in S_{m}\right)$, it remains finite if the differentiation of $Y_{j}$ is performed with respect to the mole number of an ion with a charge number of the same sign. Hence, taking the derivatives $\left(\partial Y_{\mathrm{C}} / \partial n_{j^{\prime}}\right)_{T, p, n_{\ddagger \neq j^{\prime}}}$ and $\left(\partial Y_{\mathrm{A}} / \partial n_{j^{\prime}}\right)_{T, p, n_{\ddagger \neq j^{\prime}}}$ correctly into account leads to expressions for $\ln \gamma_{x, \mathrm{C}, \mathrm{SR}}$ and $\ln \gamma_{x, \mathrm{~A}, \mathrm{SR}}$ which are remarkably more complicated than the corresponding expression for $\ln \gamma_{x, m, \mathrm{SR}}$. In the original publication on the multicomponent version of the eNRTL model, Chen and Evans [21] have set $\left(\partial Y_{\mathrm{C}} / \partial n_{j^{\prime}}\right)_{T, p, n_{l \neq j^{\prime}}}=\left(\partial Y_{\mathrm{A}} / \partial n_{j^{\prime}}\right)_{T, p, n_{l \neq j}}=0$, apparently in order to simplify the calculations and resulting functions for $\ln \gamma_{x, \mathrm{C}, \mathrm{SR}}$ and $\ln \gamma_{x, \mathrm{~A}, \mathrm{SR}}$. Only in 2008, Bollas et al. [23] presented an updated version of the model, in which the simplifying assumption of vanishing derivatives $\left(\partial Y_{\mathrm{C}} / \partial n_{j^{\prime}}\right)_{T, p, n_{\neq \neq j^{\prime}}}$ and $\left(\partial Y_{\mathrm{A}} / \partial n_{j^{\prime}}\right)_{T, p, n_{\neq \neq j^{\prime}}}$ made in deriving $\gamma_{x, \mathrm{C}, \mathrm{SR}}$ and $\gamma_{x, \mathrm{~A}, \mathrm{SR}}$ had been removed. The quite lengthy most general expression for $\ln \gamma_{x, \mathrm{C}, \mathrm{SR}}$, derived within the framework of the model version of 2008, is given below. It was was corrected for a typing error found in the original publication [23] and reads

$$
\begin{aligned}
& \frac{\ln \gamma_{x, \mathrm{C}, \mathrm{SR}}}{z_{\mathrm{C}}}=\sum_{\mathrm{A} \in S_{\mathrm{A}}} Y_{\mathrm{A}} \frac{\sum_{j \in S_{m} \cup S_{\mathrm{A}}} X_{j} G_{j \mathrm{C}, \mathrm{AC}} \tau_{j \mathrm{C}, \mathrm{AC}}}{\sum_{j^{\prime} \in S_{m} \cup S_{\mathrm{A}}} X_{j^{\prime}} G_{j^{\prime} \mathrm{C}, \mathrm{AC}}} \\
& +\sum_{m \in S_{m}} \frac{X_{m}}{\sum_{k \in S_{m} \cup S_{\mathrm{C}} \cup S_{\mathrm{A}}} X_{k} G_{k m}}\left[\begin{array}{c}
G_{\mathrm{C} m}\left(\sum_{\mathrm{C} m}-\frac{\sum_{j \in S_{m} \cup S_{\mathrm{C}} \cup S_{\mathrm{A}}} X_{j} G_{j m} \tau_{j m}}{\sum_{j^{\prime} \in S_{m} \cup S_{\mathrm{C}} \cup S_{\mathrm{A}}} X_{j^{\prime}} G_{j^{\prime} m}}\right) \\
\sum_{\mathrm{A} \in S_{\mathrm{A}}} \frac{X_{\mathrm{A}}}{\sum_{\mathrm{C}^{\prime} \in S_{\mathrm{C}}} X_{\mathrm{C}^{\prime}}} \frac{\left(\alpha_{\mathrm{A} m} G_{\mathrm{CA}, m}-\alpha_{\mathrm{CA}, m} G_{\mathrm{A} m}\right) \tau_{\mathrm{A} m}-\left(G_{\mathrm{CA}, m}-G_{\mathrm{A} m}\right)}{\alpha_{\mathrm{A} m}} \\
-\frac{\sum_{j \in S_{m} \cup S_{\mathrm{C}} \cup S_{\mathrm{A}}} X_{j} G_{j m} \tau_{j m}}{\sum_{j^{\prime} \in S_{m} \cup S_{\mathrm{C}} \cup S_{\mathrm{A}}} X_{j^{\prime}} G_{j^{\prime} m}} \sum_{\mathrm{A} \in S_{\mathrm{A}}} \frac{X_{\mathrm{A}}}{\sum_{\mathrm{C}^{\prime} \in S_{\mathrm{C}}} X_{\mathrm{C}^{\prime}}}\left(G_{\mathrm{CA}, m}-G_{\mathrm{A} m}\right)
\end{array}\right]
\end{aligned}
$$

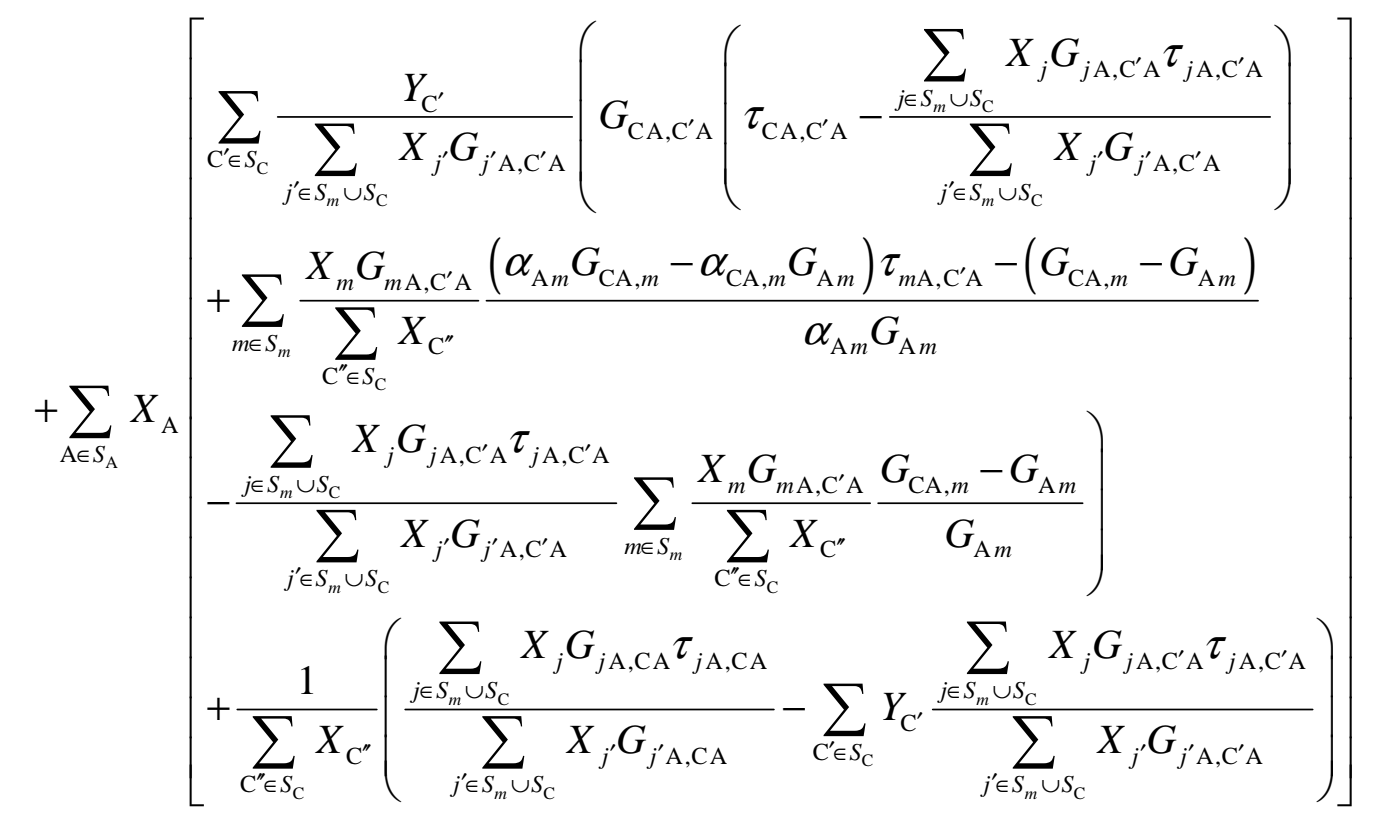


Similarly, by applying eq. (A.8) to eq. (25) for $j=\mathrm{A}$, the corresponding relation for $\ln \gamma_{x, \mathrm{~A}, \mathrm{SR}}$ is derived [23].

$$
\begin{aligned}
& \frac{\ln \gamma_{x, \mathrm{~A}, \mathrm{SR}}}{\left|z_{\mathrm{A}}\right|}=\sum_{\mathrm{C} \in S_{\mathrm{C}}} Y_{\mathrm{C}} \frac{\sum_{j \in S_{m} \cup S_{\mathrm{C}}} X_{j} G_{j \mathrm{~A}, \mathrm{CA}} \tau_{j \mathrm{~A}, \mathrm{CA}}}{\sum_{j^{\prime} \in S_{m} \cup S_{\mathrm{C}}} X_{j^{\prime}} G_{j^{\prime} \mathrm{A}, \mathrm{CA}}} \\
& +\sum_{m \in S_{m}} \frac{X_{m}}{\sum_{j^{\prime} \in S_{m} \cup S_{\mathrm{C}} \cup S_{\mathrm{A}}} X_{j^{\prime}} G_{j^{\prime} m}}\left[\begin{array}{c}
G_{\mathrm{A} m}\left(\sum_{\mathrm{A} m}-\frac{\sum_{j \in S_{m} \cup S_{\mathrm{C}} \cup S_{\mathrm{A}}} X_{j} G_{j m} \tau_{j m}}{\sum_{j^{\prime} \in S_{m} \cup S_{\mathrm{C}} \cup S_{\mathrm{A}}} X_{j^{\prime}} G_{j^{\prime} m}}\right. \\
+\sum_{\mathrm{C} \in S_{\mathrm{C}}} \frac{X_{\mathrm{C}} \sum_{\mathrm{A}^{\prime} \in S_{\mathrm{A}}} X_{\mathrm{A}^{\prime}}}{\left(\alpha_{\mathrm{C} m} G_{\mathrm{CA}, m}-\alpha_{\mathrm{CA}, m} G_{\mathrm{C} m}\right) \tau_{\mathrm{C} m}-\left(G_{\mathrm{CA}, m}-G_{\mathrm{C} m}\right)} \\
\sum_{\mathrm{C} m} X_{j} G_{j m} \tau_{j m} \\
-\frac{\sum_{j \in S_{m} \cup S_{\mathrm{C}} \cup S_{\mathrm{A}}} X_{j^{\prime} \in S_{m} \cup S_{\mathrm{C}} \cup S_{\mathrm{A}}}}{X_{j^{\prime}} G_{j^{\prime} m}} \sum_{\mathrm{C} \in S_{\mathrm{C}}} \frac{X_{\mathrm{C}}}{\sum_{\mathrm{A}^{\prime} \in S_{\mathrm{A}}^{\prime}} X_{\mathrm{A}^{\prime}}}\left(G_{\mathrm{CA}, m}-G_{\mathrm{C} m}\right)
\end{array}\right]
\end{aligned}
$$

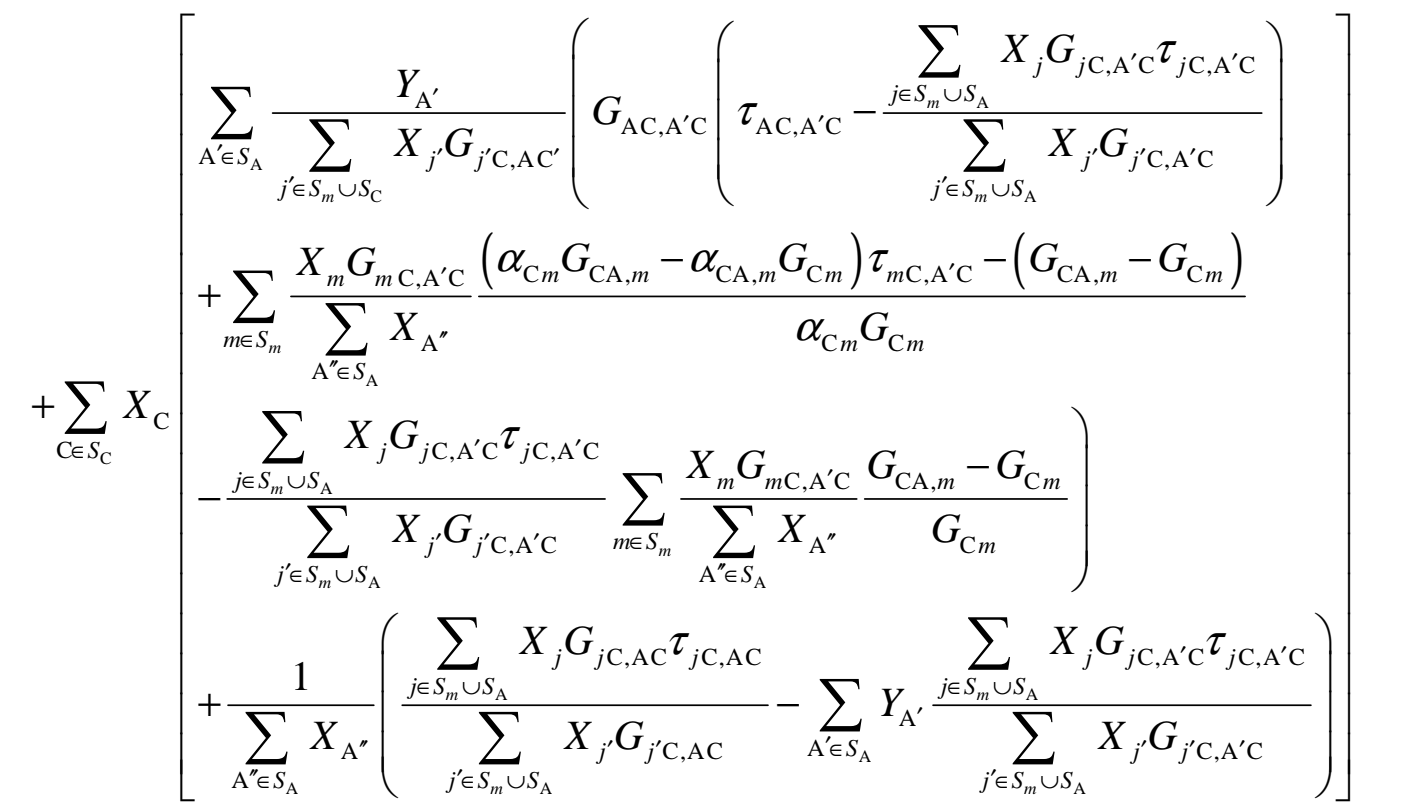

From eqs. (A.15) and (A.16), the corresponding activity coefficients at infinite dilution, $\gamma_{x, \mathrm{C}, \mathrm{SR}}^{\infty}$ and $\gamma_{x, \mathrm{~A}, \mathrm{SR}}^{\infty}$, can be derived by applying eq. (A.10). The latter in turn enable the calculation of the unsymmetrically referenced activity coefficients $\gamma_{x, \mathrm{C}, \mathrm{SR}}^{*}$ and $\gamma_{x, \mathrm{~A}, \mathrm{SR}}^{*}$ using eq. (A.9). Upon deriving $\ln \gamma_{x, \mathrm{C}, \mathrm{SR}}^{\infty}$ and $\ln \gamma_{x, \mathrm{~A}, \mathrm{SR}}^{\infty}$ it was found that the corresponding expressions given in the original article of Bollas et al. [23] for the most general case of different nonrandomness parameters are erroneous. Moreover, an additional remark not made in [23] should be made here with regard to the calculation of the limiting value according to eq. (A.10). In fact, for the case of multielectrolyte solutions, i.e. if the number of different ionic species exceeds 2 , the limiting value for $x_{\mathrm{w}} \rightarrow 1$ of at least some of the quantities depending on the ionic charge fractions $Y_{j}$ can not be calculated in the strict mathematical sense. More precisely, the limiting value for identically vanishing mole fractions of all species other than the solvent species is diverging and hence can not be calculated for all those $Y_{j}$ depending quantities whenever $Y_{j} \neq 1 . Y_{j} \neq 1$ in turn is necessarily observed when more than 
one ion occurs in the respective expression for $Y_{\mathrm{C}}$ or $Y_{\mathrm{A}}$. However, if it is assumed that the relative composition of all solute species remains constant during the limiting process of approaching the state of infinite dilution, the respective quantities causing problems could be evaluated. In order to indicate that these quantities refer to limiting values obtained in this "approximate way", they are endowed with the superscript " $\infty$ " as well. The complication outlined above does not appear for a solution containing besides the solvent and any number of molecular solutes only one single electrolyte, that generates only two ions when being dissolved, since $Y_{j}$ is unity for both $j=\mathrm{C}$ and $j=\mathrm{A}$, respectively.

A further remark should be added in this context. The fact that the limiting value of $Y_{j}$ for $x_{\mathrm{w}} \rightarrow 1$, and thus $\gamma_{x, \mathrm{C}, \mathrm{SR}}^{\infty}$ and/or $\gamma_{x, \mathrm{~A}, \mathrm{SR}}^{\infty}$, may not exist does not have the consequence that the corresponding limiting values of $\gamma_{x, \mathrm{C}, \mathrm{SR}}^{*}$ and $\gamma_{x, \mathrm{~A}, \mathrm{SR}}^{*}$ do not exist either. Due to a compensation of terms after normalisation of the expressions for $\gamma_{x, \mathrm{C}, \mathrm{SR}}$ and $\gamma_{x, \mathrm{~A}, \mathrm{SR}}$, the limiting values $\gamma_{x, \mathrm{C}, \mathrm{SR}}^{*, \infty}$ and $\gamma_{x, \mathrm{~A}, \mathrm{SR}}^{*, \infty}$ do exist. In particular, as expected and in accordance with the Henry's law reference frame $\gamma_{x, \mathrm{C}, \mathrm{SR}}^{*, \infty}=\gamma_{x, \mathrm{~A}, \mathrm{SR}}^{*, \infty}=1$ for all $\mathrm{C} \in S_{\mathrm{C}}$ and $\mathrm{A} \in S_{\mathrm{A}}$.

With the conventions outlined above, the expression for $\ln \gamma_{x, \mathrm{C}, \mathrm{SR}}^{\infty}$, corrected for the error found in [23], reads

$$
\begin{aligned}
\frac{\ln \gamma_{x, \mathrm{C}, \mathrm{SR}}^{\infty}=}{z_{\mathrm{C}}}= & \frac{1}{z_{\mathrm{C}}} \lim _{x_{\mathrm{w}} \rightarrow 1}\left(\ln \gamma_{x, \mathrm{C}, \mathrm{SR}}\right)=\sum_{\mathrm{A} \in S_{\mathrm{A}}} Y_{\mathrm{A}}^{\infty} \tau_{\mathrm{wC}, \mathrm{AC}}^{\infty}+G_{\mathrm{Cw}}^{\infty} \tau_{\mathrm{Cw}}^{\infty} \\
& +\sum_{\mathrm{A} \in S_{\mathrm{A}}} \frac{X_{\mathrm{A}}^{\infty} \sum_{\mathrm{C}^{\prime} \in S_{\mathrm{C}}} X_{\mathrm{C}^{\prime}}^{\infty} \frac{\left(\alpha_{\mathrm{Aw}}^{\infty} G_{\mathrm{CA}, \mathrm{w}}-\alpha_{\mathrm{CA}, \mathrm{w}} G_{\mathrm{Aw}}^{\infty}\right) \tau_{\mathrm{Aw}}^{\infty}-\left(G_{\mathrm{CA}, \mathrm{w}}-G_{\mathrm{Aw}}^{\infty}\right)}{\alpha_{\mathrm{Aw}}^{\infty}}}{} \\
& +\sum_{\mathrm{A} \in S_{\mathrm{A}}} X_{\mathrm{A}}^{\infty}\left(\sum_{\mathrm{C}^{\prime} \in S_{\mathrm{C}}} \frac{\sum_{\mathrm{C}^{\prime \prime} \in S_{\mathrm{C}}}^{\infty} X_{\mathrm{C}^{\prime}}^{\infty}}{\sum_{\mathrm{C}^{\prime \prime} \in S_{\mathrm{C}}} X_{\mathrm{C}^{\prime \prime}}^{\infty}}\left(\frac{\left(\alpha_{\mathrm{Aw}}^{\infty}-\alpha_{\mathrm{CA}, \mathrm{w}}\right) G_{\mathrm{Aw}}^{\infty} \tau_{\mathrm{wA}, \mathrm{C}^{\prime} \mathrm{A}}^{\infty}-\left(G_{\mathrm{CA}, \mathrm{w}}-G_{\mathrm{Aw}}^{\infty}\right)}{\alpha_{\mathrm{Aw}}^{\infty} G_{\mathrm{Aw}}^{\infty}}\right)\right.
\end{aligned}
$$

whereas the correct expression for $\ln \gamma_{x, \mathrm{~A}, \mathrm{SR}}^{\infty}$ reads

$$
\begin{aligned}
\frac{\ln \gamma_{x, \mathrm{~A}, \mathrm{SR}}^{\infty}=}{\left|z_{\mathrm{A}}\right|} & \frac{1}{\left|z_{\mathrm{A}}\right|} \lim _{\mathrm{x}_{\mathrm{w}} \rightarrow 1}\left(\ln \gamma_{x, \mathrm{~A}, \mathrm{SR}}\right)=\sum_{\mathrm{C} \in S_{\mathrm{C}}} Y_{\mathrm{C}}^{\infty} \tau_{\mathrm{wA}, \mathrm{CA}}^{\infty}+G_{\mathrm{Aw}}^{\infty} \tau_{\mathrm{Aw}}^{\infty} \\
& +\sum_{\mathrm{C} \in S_{\mathrm{C}}} \frac{X_{\mathrm{C}}^{\infty} \in S_{\mathrm{A}}}{X_{\mathrm{A}^{\prime}}^{\infty}} \frac{\left(\alpha_{\mathrm{Cw}}^{\infty} G_{\mathrm{CA}, \mathrm{w}}-\alpha_{\mathrm{CA}, \mathrm{w}} G_{\mathrm{Cw}}^{\infty}\right) \tau_{\mathrm{CW}}^{\infty}-\left(G_{\mathrm{CA}, \mathrm{w}}-G_{\mathrm{CW}}^{\infty}\right)}{\alpha_{\mathrm{Cw}}^{\infty}} \\
& +\sum_{\mathrm{C} \in S_{\mathrm{C}}} X_{\mathrm{C}}^{\infty}\left(\sum_{\mathrm{A}^{\prime} \in S_{\mathrm{A}}} \frac{\sum_{\mathrm{A}^{\prime} \in S_{\mathrm{A}}} X_{\mathrm{A}^{\prime}}^{\infty}}{\sum_{\mathrm{A}^{\prime \prime} \in S_{\mathrm{A}}} X_{\mathrm{A}^{\prime \prime}}^{\infty}}\left(\frac{\left(\alpha_{\mathrm{CW}}^{\infty}-\alpha_{\mathrm{CA}, \mathrm{w}}\right) G_{\mathrm{Cw}}^{\infty} \tau_{\mathrm{wA}, \mathrm{C}^{\prime} \mathrm{A}}^{\infty}-\left(G_{\mathrm{CA}, \mathrm{w}}-G_{\mathrm{Cw}}^{\infty}\right)}{\alpha_{\mathrm{Cw}}^{\infty} G_{\mathrm{Cw}}^{\infty}}\right)\right)
\end{aligned}
$$




\section{A.5 On the number of (isothermal) eNRTL parameters}

The following coefficients are to be considered by the model: For a set $S_{m}=\left\{m_{1}, \ldots, m_{N_{m}}\right\}$ of $N_{m}=\left|S_{m}\right|$ different molecular components, a set $S_{\mathrm{C}}=\left\{\mathrm{C}_{1}, \ldots, \mathrm{C}_{N_{\mathrm{C}}}\right\}$ of $N_{\mathrm{C}}=\left|S_{\mathrm{C}}\right|$ different cations and a set $S_{\mathrm{A}}=\left\{\mathrm{A}_{1}, \ldots, \mathrm{A}_{N_{\mathrm{A}}}\right\}$ of $N_{\mathrm{A}}=\left|S_{\mathrm{A}}\right|$ different anions, the following types of isothermal eNRTL coefficients have to be considered and the corresponding numerical values to be provided: a) $\alpha_{m m^{\prime}}, \tau_{m m^{\prime}}, \tau_{m^{\prime} m}$, with $m<m^{\prime}$ for all $m, m^{\prime} \in S_{m}$, b) $\alpha_{m, \mathrm{CA}}, \tau_{m, \mathrm{CA}}, \tau_{\mathrm{CA}, m}$, for all $m \in S_{m}, \mathrm{C} \in S_{\mathrm{C}}$ and $\left.\mathrm{A} \in S_{\mathrm{A}}, \mathrm{c}\right) \alpha_{\mathrm{CA}, \mathrm{C}^{\prime} \mathrm{A}}, \tau_{\mathrm{CA}, \mathrm{C}^{\prime} \mathrm{A}}, \tau_{\mathrm{C}^{\prime} \mathrm{A}, \mathrm{CA}}$, for all $\mathrm{C}, \mathrm{C}^{\prime} \in S_{\mathrm{C}}$ with $\mathrm{C}<\mathrm{C}^{\prime}$ and $\mathrm{A} \in S_{\mathrm{A}}$ and d) $\alpha_{\mathrm{AC}, \mathrm{A}^{\prime} \mathrm{C}}, \tau_{\mathrm{AC}, \mathrm{A}^{\prime} \mathrm{C}}, \tau_{\mathrm{A}^{\prime} \mathrm{C}, \mathrm{AC}}$ for all $\mathrm{A}, \mathrm{A}^{\prime} \in S_{\mathrm{A}}$ with $\mathrm{A}<\mathrm{A}^{\prime}$ and $\mathrm{C} \in S_{\mathrm{C}}$. Combinatorial considerations lead to the total number of isothermal coefficients $N_{\text {coeff }}$ necessary to describe the multicomponent electrolyte system

$$
\begin{aligned}
N_{\text {coeff }}=\mid\left\{\alpha_{m m^{\prime}},\right. & \left.\tau_{m m^{\prime}}, \tau_{m^{\prime} m}\right\}|+|\left\{\alpha_{m, \mathrm{CA}}, \tau_{m, \mathrm{CA}}, \tau_{\mathrm{CA}, m}\right\}|+|\left\{\alpha_{\mathrm{CA}, \mathrm{C}^{\prime} \mathrm{A}}, \tau_{\mathrm{CA}, \mathrm{C}^{\prime} \mathrm{A}}, \tau_{\mathrm{C}^{\prime} \mathrm{A}, \mathrm{CA}}\right\} \mid \\
& +\left|\left\{\alpha_{\mathrm{AC}, \mathrm{A}^{\prime} \mathrm{C}}, \tau_{\mathrm{AC}, \mathrm{A}^{\prime} \mathrm{C}}, \tau_{\mathrm{A}^{\prime} \mathrm{C}, \mathrm{AC}}\right\}\right| \\
& =\frac{3}{2}\left(N_{m}\left(N_{m}-1\right)+N_{\mathrm{C}} N_{\mathrm{A}}\left(2 N_{m}+N_{\mathrm{C}}+N_{\mathrm{A}}-2\right)\right)
\end{aligned}
$$

If it is assumed in accordance with a very common approximation in the eNRTL-model that for the salt-salt interaction parameters the following relation is obeyed

$$
\begin{aligned}
& \tau_{\mathrm{CA}, \mathrm{C}^{\prime} \mathrm{A}}=-\tau_{\mathrm{C}^{\prime} \mathrm{A}, \mathrm{CA}} \\
& \tau_{\mathrm{AC}, \mathrm{A}^{\prime} \mathrm{C}}=-\tau_{\mathrm{A}^{\prime} \mathrm{C}, \mathrm{AC}}
\end{aligned}
$$

and that for the non-randomness factors $\alpha_{m m^{\prime}}$ (for the case of $N_{m}>1$ )

$$
\underset{m \in S_{m}}{\forall} \underset{\substack{m^{\prime} \in S_{m} \\ m^{\prime}>m}}{\forall}\left(\alpha_{m m^{\prime}}=\alpha_{0}\right)
$$

and the non-randomness factors $\alpha_{m, \mathrm{CA}}, \alpha_{\mathrm{CA}, \mathrm{C}^{\prime} \mathrm{A}}$ and $\alpha_{\mathrm{AC}, \mathrm{A}^{\prime} \mathrm{C}}$ the relations $\alpha_{m, \mathrm{CA}}=\alpha_{1}$ (for all $m \in S_{m}, \mathrm{C} \in S_{\mathrm{C}}$ and $\mathrm{A} \in S_{\mathrm{A}}$ ), $\alpha_{\mathrm{CA}, \mathrm{C}^{\prime} \mathrm{A}}=\alpha_{1}$ (for all $\mathrm{C}, \mathrm{C}^{\prime} \in S_{\mathrm{C}}$ with $\mathrm{C}<\mathrm{C}^{\prime}$ and $\mathrm{A} \in S_{\mathrm{A}}$ ) and $\alpha_{\mathrm{AC}, \mathrm{A}^{\prime} \mathrm{C}}=\alpha_{1}$ (for all $\mathrm{A}, \mathrm{A}^{\prime} \in S_{\mathrm{A}}$ with $\mathrm{A}<\mathrm{A}^{\prime}$ and $\mathrm{C} \in S_{\mathrm{C}}$ ) do hold, the number of isothermal parameters $N_{\text {coeff }}$ required to describe the system is given by

$$
N_{\text {coeff }}=N_{m}\left(N_{m}-1\right)+N_{\mathrm{C}} N_{\mathrm{A}}\left(2 N_{m}+\frac{1}{2} N_{\mathrm{C}}+\frac{1}{2} N_{\mathrm{A}}-1\right)+2-\delta_{1 N_{m}},
$$

where $\delta_{1 N_{m}}$ is Dirac's delta function, defined by

$$
\delta_{1 N_{m}}=\left\{\begin{array}{l}
0 \text { for } N_{m} \neq 1 \\
1 \text { for } N_{m}=1
\end{array}\right.
$$

If it is, however, assumed that $\tau_{\mathrm{CA}, \mathrm{C}^{\prime} \mathrm{A}}=\tau_{\mathrm{C}^{\prime} \mathrm{A}, \mathrm{CA}}=\tau_{\mathrm{AC}, \mathrm{A}^{\prime} \mathrm{C}}=\tau_{\mathrm{A}^{\prime} \mathrm{C}, \mathrm{AC}}=0$ and $\alpha_{m m^{\prime}}=\alpha_{0}$ (for all $m \in S_{m}$ and $m^{\prime} \in S_{m}$ with $m^{\prime}>m$ ) does hold along with $\alpha_{m, \mathrm{CA}}=\alpha_{1}$ (for all $m \in S_{m}, \mathrm{C} \in S_{\mathrm{C}}$ and $\mathrm{A} \in S_{\mathrm{A}}$ ) and the assumption that $\alpha_{\mathrm{CA}, \mathrm{C}^{\prime} \mathrm{A}}$ (for all $\mathrm{C}, \mathrm{C}^{\prime} \in S_{\mathrm{C}}$ with $\mathrm{C}<\mathrm{C}^{\prime}$ and $\mathrm{A} \in S_{\mathrm{A}}$ ) and $\alpha_{\mathrm{AC}, \mathrm{A}^{\prime} \mathrm{C}}$ (for all $\mathrm{A}, \mathrm{A}^{\prime} \in S_{\mathrm{A}}$ with $\mathrm{A}<\mathrm{A}^{\prime}$ and $\mathrm{C} \in S_{\mathrm{C}}$ ) take any but finite values (since they are not needed), the number of isothermal parameters $N_{\text {coeff }}$ needed to characterise the system is to be calculated from

$$
N_{\text {coeff }}=N_{m}\left(N_{m}+2 N_{\mathrm{C}} N_{\mathrm{A}}-1\right)+2-\delta_{1 N_{m}}
$$




\section{References}

[1] Sloan, E. D.; Koh, C. A.; "Clathrate Hydrates of Natural Gases"; CRC Press, Taylor \& Francis Group, Boca Raton, London, New York, $3^{\text {rd }}$ ed. (2008).

[2] Ribeiro Jr., C. P.; Lage, P. L. C.; "Modelling of hydrate formation kinetics: State-ofthe-art and future directions"; Chem. Eng. Sci. 63 (2008) 2007-2034.

[3] Englezos, P.; "Chlathrate Hydrates“; Ind. Eng. Chem. Res. 32 (1993) 1251-1274.

[4] Sloan, E. D.; "Fundamental principles and applications of natural gas hydrates"; Nature 46 (2003) 353-359.

[5] Eslamimanesh, A.; Mohammadi, A. H.; Richon, D.; Naidoo, P. Ramjugernath, D.; "Application of gas hydrate formation in separation processes: A review of experimental studies"; J. Chem. Thermodynamics 46 (2012) 62-71.

[6] Barker, J. W.; Gomez, R. K.; "Formation of hydrates during deepwater drilling operations"; J. Petrol. Technol. 41 (1989) 297-301.

[7] Hsieh, M.-K.; Yeh, Y.-T.; Chen, Y.-P.; Chen, P.-C.; Lin, S.-T.; Chen, L.-J.; "Predictive Method fort he Change in Equilibrium Conditions of Gas Hydrates with Addition of Inhibitors and Electrolytes"; Ind. Eng. Chem. Res. 51 (2012) 2456-2469.

[8] Clarke, M. A.; Bishnoi, P. R.; "Development of a new equation of state for mixed salt and mixed solvent systems, and application to vapour-liquid and solid (hydrate)vapour-liquid equilibrium calculations"; Fluid Phase Equilib. 220 (2004) 21-35.

[9] Luckas, M.; Krissmann, J.; "Thermodynamik der Elektrolytlösungen - Eine einheitliche Darstellung der Berechnung komplexer Gleichgewichte“; SpringerVerlag, Berlin, Heidelberg, New York (2001).

[10] Fürst, W.; Renon, H.; "Representation of excess properties of electrolyte solutions using a new equation of state"; AIChE J. 39 (1993) 335-343.

[11] Zuo, J. Y.; Zhang, D.; Fürst, W.; „Extension of the electrolyte EOS of Fürst and Renon to mixed solvent electrolyte systems“; Fluid Phase Equilib. 175 (2000) 285-310

[12] Trebble, M. A.; Bishnoi, P. R.; "Development of a new four-parameter cubic equation of state"; Fluid Phase Equilib. 35 (1987) 1-18.

[13] Trebble, M. A.; Bishnoi, P. R.; "Extension of the Trebble-Bishnoi equation of state to fluid mixtures"; Fluid-Phase Equilib. 40 (1988) 1-21.

[14] Galindo, A.; Gil-Villegas, A.; Jackson, G.; Burgess, A. N.; "SAFT-VRE: Phase Behavior of Electrolyte Solutions with the Statistical Associating Fluid Theory for Potentials of Variable Range"; J. Phys. Chem. B 103 (1999) 10272-10281.

[15] Chen, C.-C.; Song, Y.; "Generalized Electrolyte-NRTL Model for Mixed-Solvent Electrolyte Systems"; AIChE J. 50 (2004) 1928-1941.

[16] Bromley, L. A.; "Thermodynamic Properties of Strong Electrolytes in Aqueous Solution"; AIChE J. 19 (1973) 313-320. 
[17] Pitzer, K. S.; “Thermodynamics of Electrolytes. I. Theoretical Basis and General Equations"; J. Phys. Chem. 77 (1973) 268-277.

[18] Pitzer, K. S.; "Electrolytes: From Dilute Solutions to Fused Salts"; J. Am. Chem. Soc. 102 (1980) 2902-2906.

[19] Cruz, J. L.; Renon, H.; “A New Thermodynamic Representation of Binary Electrolyte Solutions Nonideality in the Whole Range of Concentrations"; AIChE J. 24 (1978) 817-830.

[20] Chen, C.-C.; Britt, H. I.; Boston, J. F.; Evans, L.B.; "Local Composition Model for Excess Gibbs Energy of Electrolyte Systems”; AIChE J. 28 (1982) 588-596.

[21] Chen, C.-C., Evans, L. B.; "A Local Composition Model for the Excess Gibbs Energy of Aqueous Electrolyte Systems"; AIChE J. 32 (1986) 444-454.

[22] Chen, C.-C.; Bokis, C. P.; Mathias, P. M.; “A Segment-Based Excess Gibbs Energy Model for Aqueous Organic Electrolyte Systems"; AIChE J., 47 (2001) 2593-2602.

[23] Bollas, G. M., Chen, C. C., Barton, P. I.; "Refined Electrolyte-NRTL Model: Activity Coefficient Expressions for Application to Multi-Electrolyte Systems"; AIChE J. 54 (2008) 1608-1624.

[24] Li, J; Polka, H. M.; Gmehling, J.; “ $A g^{\mathrm{E}}$ model for single and mixed solvent electrolyte systems 1. Model and results for strong electrolytes." Fluid Phase Equilibria, 94 (1998) 89-114

[25] Papaiconomou, N.; Simonin, J.-P.; Bernard, O.; Kunz, W.; "MSA-NRTL Model for the Description of the Thermodynamic Properties of Electrolyte Solutions"; Phys. Chem. Chem. Phys. 4 (2002) 4435-4443.

[26] van der Waals, J. H.; Platteeuw, J. C.; "Clathrate solutions"; Adv. Chem. Phys. 2 (1959) 1-57.

[27] Englezos, P.; Bishnoi, P. R. Bishnoi; "Prediction of Gas Hydrate Formation Conditions in Aqueous Electrolyte Solutions"; AIChE J. 34 (1988) 1718-1721.

[28] Meissner, H. P.; Kusik, C. L.; "Activity Coefficients of Strong Electrolytes in Multicomponent Aqueous Electrolyte Solutions“; AIChE J. 18 (1972) 294-.

[29] Stryjek, R.; Vera, J. H.; "PRSV: An Improved Peng-Robinson Equation of State for Pure Compounds and Mixtures”; Can. J. Chem. Eng. 64 (1986) 323-333.

[30] Michelsen, M. L.; "A Modified Huron-Vidal Mixing Rule for Cubic Equations of State"; Fluid Phase Equilib. 60 (1990) 213-219.

[31] Yan, W. D.; Topphoff, M.; Rose, C.; Gmehling, J.; "Prediction of Vapour-Liquid Equilibria in Mixed-Solvent Electrolyte Systems Using the Group Contribution Concept"; Fluid Phase Equilib. 227 (2005) 157-164.

[32] Hsieh, C. M.; Sandler, S. I.; Lin, S. T.; "Improvements of COSMOO-SAC for VapourLiquid and Liquid-Liquid Equilibrium Predictions"; Fluid Phase Equilib. 297 (2010) 90-97. 
[33] Hsieh, M. T.; Lin, S. T.; "A Predictive Model for the Excess Gibbs Free Energy of Fully Dissociated Electrolyte Solutions”; AIChE J. 57 (2011) 1061-1074.

[34] Herri J.-M.; Bouchemoua, A.; Kwaterski, M.; Fezoua, A.; Ouabbas, Y.; Cameirao, A.; "Gas Hydrate Equilibria for $\mathrm{CO}_{2}-\mathrm{N}_{2}$ and $\mathrm{CO}_{2}-\mathrm{CH}_{4}$ gas mixtures - Experimental studies and Thermodynamic Modelling”, Fluid Phase Equilib. 301 (2011) 171-190.

[35] Sloan, E.D.; "Clathrate hydrates of natural gases"; $2^{\text {nd }}$ ed., Marcel Decker, New York, Basel (1997).

[36] Matthias Kwaterski; Jean-Michel Herri; “Thermodynamic Modelling of Gas SemiClathrate Hydrates using the electrolyte NRTL Model", under preparartion

[37] Belvèze, L. S., Brennecke, J. F., Stadtherr, M. A.; „Modeling of Activity Coefficients of Aqueous Solutions of Quaternary Ammonium Salts with the Electrolyte-NRTL Equation"; Ind. Eng. Chem. Res. 43 (2004) 815-825.

[38] Lindenbaum, S.; Boyd, G. E.; "Osmotic and Activity Coefficients for the Symmetrical Tetraalkyl Ammonium Halides in Aqueous Solution at $25^{\circ} \mathrm{C}^{\prime}$. J. Phys. Chem. 68 (1964) 911-917.

[39] Ballard, A. L.; Sloan Jr., E. D.; "The next generation of hydrate prediction I. Hydrate standard states and incorporation of spectroscopy"; Fluid Phase Equilib. 194-197 (2002) 371-383.

[40] "A Report of IUPAC Commission 1.2 on Thermodynamics Notation for states and processes, significance of the word 'standard' in chemical thermodynamics, and remarks on commonly tabulated forms of thermodynamic functions"; J. Chem. Thermodyn. 14 (1982) 805-815.

[41] Mohr, P. J.; Taylor, B. N.; Newell, D. B.; "CODATA Recommended Values of the Fundamental Physical Constants: 2010”; J. Phys. Chem. Ref. Data, 41 (2012) 1-84.

[42] Soave, G.; "Equilibrium constants from a modified Redlich-Kwong equation of state"; Chem. Eng. Sci. 27 (1972) 1197-1203.

[43] Parrish, W.R.; Prausnitz, J.M.; "Dissociation pressure of gas hydrates formed by gas mixtures"; Ind. Eng. Chem. Process Des. Develop. 11 (1972) 26-35.

[44] Kihara, T.; "The second virial coefficient of non-spherical molecules"; J. Phys. Soc. Japan 6 (1951) 289-296.

[45] McKoy, V.; Sinanoğlu, O. J.; "Theory of dissociation pressures of some gas hydrates"; J Chem. Phys 38 (1963) 2946-2956.

[46] Holder, G. D.; Corbin, G.; Papadopoulos, K. D.; "Thermodynamic and Molecular Properties of Gas Hydrates from Mixtures Containing Methane, Argon and Krypton"; Ind. Eng. Chem. Fundam. 19 (1980) 282-286.

[47] Dharmawandhana, P. B.; "The measurement of the thermodynamic parameters of the hydrate structure and application of them in the prediction of natural gas hydrates", PhD Thesis, Colorado School of Mines, Golden, CO, USA (1980). 
[48] John, V. T.; Papadopoulos, K. D.; Holder, G. D.; “A Generalized Model for Predicting Equilibrium Conditions for Gas Hydrates"; AlChE J. 31 (1985) 252-259.

[49] Handa, Y. P.; Tse, J. S.; "Thermodynamic properties of empty lattices of structure I and structure II clathrate hydrates", J. Phys. Chem. 90 (1986) 5917-5921.

[50] Von Stackelberg, M.; Müller, H. R.; "On the structure of gas hydrates"; J. Chem. Phys. 19 (1951) 1319-1320.

[51] Holder, G.D.; Zetts, S.P.; Pradhan, N.; "Phase behavior in systems containing clathrate hydrates, a review"; Rev. Chem. Eng. 5 (1988) 1-70.

[52] McMillan W. G., Mayer J. E.; "The statistical thermodynamics of multicomponent systems"; J. Chem. Phys. 13 (1945) 276-305.

[53] Aspen Technology, Inc.; "Aspen Physical Property System-Physical Property Models”-Manual; Vers. Nr. V7.1; 01/2009; 200 Wheeler Road Burlington, MA, USA.

[54] Renon, H.; Prausnitz, J. M.; "Local Compositions in Thermodynamic Excess Functions for Liquid Mixtures"; AIChE J. 14 (1968) 135-144.

[55] Austgen, D. M.; Rochelle, G. T.; Peng, X.; Chen, C.-C.; "Model of Vapor-Liquid Equilibria for Aqueous Acid Gas-Alkanolamine Systems Using the Electrolyte-NRTL Equation"; Ind. Eng. Chem. Res. 28 (1989) 1060-1073.

[56] Danesh, A.; "PVT and Phase Behaviour of Petroleum Reservoir Fluids"; Elsevier (1998).

[57] Mock B.; Evans, L. B.; Chen, C. C.; "Thermodynamic representation of phaseequilibria of mixed-solvent electrolyte systems"; AIChE. J. 32 (1986) 1655-1664.

[58] Robinson, R. A.; Stokes, R. H.; "Electrolyte Solutions, $2^{\text {nd }}$ rev. ed., Dover publications; Inc., Mineola, New York (2002). Reprint of the rev. ed. 1970.

[59] Downloaded from "http://www.southalabama.edu/physics/software/plotdigitizer.htm", Department of Physics, University of South Alabama, Mobile, AL 36688, USA

[60] Linke, W. F.; "Solubilities. Inorganic and Metal-Organic Compounds"; 4th ed., Am. Chem. Soc. Washington, DC, II (1965).

[61] Dholabhai, P.D.; Englezos, P.; Kalogerakis, N.; Bishnoi, P.R.; "Equilibrium conditions for methane hydrate formation in aqueous mixed electrolyte solutions"; Can. J. Chem. Eng. 69 (1991) 800-805.

[62] Chen C.-C.; Mathias, P. M.; and Orbey, H.; "Use of hydration and dissociation chemistries with the electrolyte-NRTL model"; AIChE J. 45 (1999) 1576-1586.

[63] Dholabhai, P.D.; Kalogerakis, N.; Bishnoi, P.R.; "Equilibrium conditions for carbon dioxide hydrate formation in aqueous electrolyte solutions". J. Chem. Eng. Data 38 (1993) 650-654.

[64] Kihara, T.; "The second virial coefficient of non-spherical molecules"; J. Phys. Soc. Japan 6 (1951) 289-296. 
[65] Lennard-Jones, J.E.; Devonshire, A. F.; "Critical Phenomena in Gases. I"; Proc. R. Soc. Lond. A 163 (1937) 53-70.

[66] Mooijer-van den Heuvel, M. M.; "Phase Behaviour and Structural Aspects of Ternary Clathrate Hydrate Systems"; PhD thesis, Technical University of Delft, The Netherlands (2004).

[67] Tee, L. S.; Gotoh, S.; Stewart, W. E.; "Molecular Parameters for Normal Fluids - The Kihara Potential with a spherical core"; Ind. Eng. Chem. Fundam. 5 (1966) 363-367.

[68] Bakker, R. J.; Dubessy, J.; Cathelineau, M.; "Improvements in clathrate modelling: I. The $\mathrm{H}_{2} \mathrm{O}-\mathrm{CO}_{2}$ system with various salts”; Cosmochim. Geochim. Acta 60 (1960) 1657-1681.

[69] Bakker, R. J.; "Improvements in clathrate modelling II: the $\mathrm{H}_{2} \mathrm{O}-\mathrm{CO}_{2}-\mathrm{CH}_{4}-\mathrm{N}_{2}-\mathrm{C}_{2} \mathrm{H}_{6}$ fluid system"; in: Henriet, J.-P.; Mienert, J. (eds.); "Gas Hydrates: Relevance to World Margin Stability and Climate Change"; Geological Society, London, Special Publications 137 (1998) 75-105. 